\title{
Diagnostic value of the erythrocyte sedimentation rate in general practice
}

Citation for published version (APA):

Dinant, G. J. (1991). Diagnostic value of the erythrocyte sedimentation rate in general practice. [Doctoral Thesis, Maastricht University]. Rijksuniversiteit Limburg. https://doi.org/10.26481/dis.19910404gd

Document status and date:

Published: 01/01/1991

DOI:

10.26481/dis.19910404gd

Document Version:

Publisher's PDF, also known as Version of record

\section{Please check the document version of this publication:}

- A submitted manuscript is the version of the article upon submission and before peer-review. There can be important differences between the submitted version and the official published version of record.

People interested in the research are advised to contact the author for the final version of the publication, or visit the DOI to the publisher's website.

- The final author version and the galley proof are versions of the publication after peer review.

- The final published version features the final layout of the paper including the volume, issue and page numbers.

Link to publication

\footnotetext{
General rights rights.

- You may freely distribute the URL identifying the publication in the public portal. please follow below link for the End User Agreement:

www.umlib.nl/taverne-license

Take down policy

If you believe that this document breaches copyright please contact us at:

repository@maastrichtuniversity.nl

providing details and we will investigate your claim.
}

Copyright and moral rights for the publications made accessible in the public portal are retained by the authors and/or other copyright owners and it is a condition of accessing publications that users recognise and abide by the legal requirements associated with these

- Users may download and print one copy of any publication from the public portal for the purpose of private study or research.

- You may not further distribute the material or use it for any profit-making activity or commercial gain

If the publication is distributed under the terms of Article $25 \mathrm{fa}$ of the Dutch Copyright Act, indicated by the "Taverne" license above, 
DLAGNOSTIC VALUE OF THE ERYTHROCYTE SEDIMENTATION RATE IN GENERAL PRACTICE 



\section{PROEFSCHRIFT}

ter verkrijging van de graad van doctor aan de Rijksuniversiteit Limburg te Maastricht, op gezag van de Rector Magnificus,

Prof. mr. M.J. Cohen,

volgens het besiuit van het College van Dekanen, in het openbaar te verdedigen op

donderdag, 4 april 1991 om 14.00 uur

door

Geert-Jan Dinant

geboren te Eindhoven 
Promotor: Prof. Dr. J.A. Knottnerus

Co-promotor". Dr. J.W.J. van Wersch

Beoordelingscommissie:

Prof. Dr. P.G. Knipschild (voorzitter)

Prof. Dr. P.J. Brombacher

Prof. Dr. J.M.J.P. van der Linden

Dr. P. Pop

Prof. Dr. C. van Weel

De uitgave van dit proefschrift werd mede mogelijk gemaakt door een financiële bijdrage van:

- de firma E. Merck Nederland B.V. te Amsterdam

- Stichting Dr. Ir. van de Laar te Heerlen

- de firma Coulter Electronics Nederland te Mijdrecht 
General practitioners (GP) are used to meeting uncertainties of a diagnostic and therapeutic nature. Medical textbooks and clinical reports may help them deal with these uncertainties, but often they do not. The lack of studies performed in a general practice setting is at least partly the cause of this situation, which leaves experience as the most important guide for GPs. Rapid developments in clinical practice are in contrast with this situation and sometimes make patients prefer the more costly cure and care which they can receive in the outpatient clinic.

It was reflections like these which gave rise to the one year Research Training for General Practitioners in Maastricht, the Netherlands. As I passed through this course, the interest which I already had in research got a more solid basis. In addition, it made me aware of the scientifically unstable basis of decision making in the GP's patient care. In fact, a kind of paradox gradually dawned on me; studying the diagnostic value of the erythrocyte sedimentation rate (ESR), resulted in my applying this blood test more frequently in daily general practice.

During the study, time management sometimes turned out to be a problem. Despite being $50 \%$ researcher and $50 \%$ practitioner, each domain required a $100 \%$ devotion if I was to become less unexperienced and to remain updated. My success in facing this duality was only partial, and I realize that the struggle will not stop after this thesis has been written. Nevertheless, the research efforts certainly made patient care more meaningful to me. I now realize the lack of scientific research training during medical school, where one is taught truths and skills which were rarely discussed as to their merits in real practice.

I enjoyed doing the study presented here, in which I was patiently and carefully coached by my supervisors. Their boundless enthousiasm and many stimulating ideas got me going and supplied me with the energy I needed. To the GPs and their assistants, the rheumatologists, laboratory workers and research assistants who co-operated in the study, I am greatly endebted. Their compliance was indispensible to the study and they made 
me realize that research will never be a solitary activity. To me, research turned out to be a time consuming, yet fascinating activity. I hope that by reading this book GPs will find themselves challenged to enter the field. I dedicate this study to those who do so. 


\section{Contents}

1 Introduction

1.1 General introduction 1

1.2 Blood tests in general practice 5

2 Reliability of the erythrocyte sedimentation rate in general practice

2.1 Reliability of the erythrocyte sedimentation rate before and after intervention

2.2 Blood sample transportation and the erythrocyte sedimentation rate

2.3 Reliability of the erythrocyte sedimentation rate in general practice; results from a workshop

3 Discriminating ability of the erythrocyte sedimentation rate in general practice

3.1 Desktop laboratory in general practice; the discriminating ability of the erythrocyte sedimentation rate

3.2 Diagnostic impact of the erythrocyte sedimentation rate in general practice; a before-after analysis

4 Alternatives to the erythrocyte sedimentation rate

4.1 Erythrocyte sedimentation rate versus plasma viscosity in diagnosing rheumatoid arthritis and ankylosing spondylitis

4.2 The leucocyte count in general practice; its discriminating ability as compared to the erythrocyte sedimentation rate

5 General discussion

5.1 Introduction

5.2 Reliability of the erythrocyte sedimentation rate $\quad 126$

5.3 Discriminating ability of the erythrocyte sedimentation rate 
5.4 Discriminating ability of plasma viscosity and leucocyte count

5.5 Future developments and conclusion

6 Summary

Samenvatting

Dankwoord

Curriculum vitae

Appendices

I Questionnaire, measurements and observations on the reliability of the erythrocyte sedimentation rate

II Questionnaire on the diagnostic value of the erythrocyte sedimentation rate

III Follow-up procedure concerning the discriminating ability of the erythrocyte sedimentation rate

IV Questionnaire on the discriminating ability of the erythrocyte sedimentation rate 


\subsection{General introduction}

The determination of the erythrocyte sedimentation rate (ESR) is frequently performed or requested by the general practitioner (GP), but it has been poorly investigated as to its diagnostic value in this setting $(1,2)$. Finding no critical scientific analyses of the test in general practice, we decided to start our programme of studies on this subject.

The purpose of this thesis is to present a series of coherent, studies on the diagnostic value of ESR in general practice, by which we mean its reliability and discriminating ability. We tried to answer the following questions:

1. a. How reliable is ESR, in terms of intra- and inter-practice variablity, when performed in the usual way in general practice and compared with the results from a reference laboratory?

b. How can we explain the variability?

2. To what extent does the answer to the first question change after an intervention concerning technical aspects of the test performance?

3. Which are the indications for determining ESR in general practice?

4. What is the diagnostic impact of ESR before and after its performance?

5. What is the ability of ESR to discriminate "pathology" from "no pathology" in the so-called "indicated population" in general practice?

6. What is the answer to the question 5 with respect to alternative tests, viz. the determination of plasma viscosity (PV) and the leucocyte count, in comparison to ESR?

The results of the investigations by which we tried to answer these questions have been published before, or have been submitted for publication. The reports are found in the Chapters 2,3 and 4 . The results in Chapters 1.2 and 2.3 were originally published in Dutch and translated before insertion into 
this thesis. The Summary (Chapter 6) is presented in both languages (Samenvatting), whereas the acknowledgements are only given in Dutch (Dankwoord), because all investigations took place in the Netherlands.

After the general introduction the scope of our study is described in Chapter 1.2. The concepts of reliability (reproducibility) and discriminating ability (sensitivity, specificity and positive and negative predictive values) are introduced, and their significance for frequently used blood tests in general practice (haemoglobin, ESR and leucocyte count and differentiation) is discussed.

Chapter 2.1 reports on the reliability of ESR before and after intervention (questions 1 and 2). We used centrally prepared blood samples, obtained from the local hospital laboratory, and distributed them among the participating general practice centers. Observations and measurements on the performance of ESR were made and a questionnaire was presented to each GP's assistant(s) (Appendix I). Since we thought that vibrations and the transportation of blood samples might be possible causes of the variability, we investigated these aspects separately by performing additional experiments (Chapters 2.1 and 2.2).

The results of the studies in Chapters 2.1 and 2.2 were used in a workshop on the diagnostic value of blood tests in general practice, which provided us with information on the knowledge of GPs about relliability aspects of ESR (Chapter 2.3).

Chapter 3 concentrates on the discriminating ability of ESR (question 5). After a prospective follow-up of 362 patients who were seen by their GP because of a new complaint for which the GP wanted to know ESR (the "indicated population"; ques" tion 3), we were able to measure the indices concerned (Chapter 3.1). For that purpose we compared a group of patients with inflammatory diseases or malignancies ("pathology") with a group of patients who had minor complaints or ailments ("no pathology"). The final diagnoses were established after a followup period of three months (Appendix III). The study was preceeded by a session in which we questionned 20 GPs about the subject (Appendix II):

In the same study we recorded the diagnoses postulated by the GPs before as well as after the performance of ESR (Ap- 
pendix IV). A before-after analysis then allowed us to establish the diagnostic impact of ESR (Chapter 3.2; question 4).

In order to compare its discriminating ability with that of ESR, we also determined the leucocyte count among a subsample of the patients described in Chapters 3.1 and 3.2 (Chapter 4.2 ; question 6). Two different leucocyte counters were used for this purpose.

Since we considered PV to be a possible alternative to ESR, we studied its discriminating ability as well. We compared a group of patients suffering from rheumatoid arthritis or ankylosing spondylitis on the one hand, and patients presenting new complaints of the locomotor system which were ultimately diagnosed to be of non inflammatory origin on the other (Chapter 4.1; question 6). This study was carried out at the outpatient rheumatology clinic, the patients who presented new complaints being referred there by their GP.

The general discussion in Chapter 5 reviews our findings and discusses several methods in more detail. In addition, the implications of the study results are summarized and we try to cast some light on future developments with respect to laboratory testing in primary health care.

The investigations started in November 1986. Data collection ended in April 1989. Many persons participated in the study and many patients were willing to co-operate. Their ESR will never be more than a diagnostic instrument for the doctor; feeling healthy or ill cannot be measured by performing ESR. This should be kept in mind when reading this thesis.

\section{References}

1. Knottnerus JA, Kerkhof PD, Schouten LJ. De hoge bezinking. Een literatuuroverzicht, aangevuld met enkele onderzocksgegevens. Huisarts en Wetenschap 1984; $27: 123-9$.

2. Ryan DH, Arvan DA. Erythrocyte sedimentation rate. In: Griner PF, Panzer RJ, Greenland P. Clinical Diagnosis and the Laboratory. Chicago: Year Book Medical Publishers, 1986: 476-90. 



\title{
1.2 Blood tests in general practice
}

\author{
G.J. Dinant
}

The article was previously published as: Dinant GJ, 'Bloedonderzoek in de huisartspraktijk'. In: Het medisch jaar 1989, 39. 46. Utrecht/Antwerpen: Bohn, Scheltema \& Holkema, 1989. 
The diagnostic value of a laboratory test is determined by its reproducibility and discriminating ability. The relevance of research into these aspects is discussed, paying special attention to the present situation with regard to blood tests with a general "screening" character which are frequently used by general practitioners in their own surgery laboratory. The value of haemoglobin determination in fatigue complaints proved to be low. Reproducibility studies of the determination of erythrocyte sedimentation rate, as routinely carried out in general practice, showed a clinically relevant spread. This test is currently being investigated for its ability to discriminate between "pathology" and "no pathology". Conclusions about leucocyte count and leucocyte differentiation are largely based on research performed in specialised health care. 


\section{Introduction}

One of the tools a general practitioner can use to diagnose and monitor a disorder is the examination of the blood. His diagnostic methods in this respect fall into two categories; on the one hand he uses tests with the exclusive purpose to rule out or confirm a specific diagnosis, such as a blood glucose test. On the other hand he uses tests of a more generalized "screening" nature i.e. tests used to discriminate between "pathology" (defined as inflammatory diseases and malignancies) and "no pathology". The global and partly intuitive distinction "pathology"-"no pathology" is important, for instance, in deciding whether a particular patient should be referred to specialised health care.

The "screening"-type blood tests include in particular the following tests: haemoglobin $(\mathrm{Hb})$, erythrocyte sedimentation rate (ESR), leucocyte count (including leucocyte differentiation) and liverfunction tests. Some of these tests can be performed in the general practitioner's own surgery (Hb, ESR). Other tests will sometimes (leucocyte count) or always (liverfunction tests) have to be done by an outside laboratory, although new desktop laboratory devices (which can perform several haematological and blood chemistry tests in the general practitioner's own surgery) may change this. The present review will concentrate on blood tests which are currently performed in the general practitioner's own surgery, viz. $\mathrm{Hb}$, ESR and leucocyte count. It is estimated that over half of the $\mathrm{Hb}$ and ESR tests are done in the general practice surgery. Studies have shown that new complaints lead general practitioners to perform an average of four $\mathrm{Hb}$ tests and an average of two to three ESR tests each week in their surgery $(1,2)$.

\section{Diagnostic value}

A relevant question for the general practitioner is whether the relatively limited number of screening tests available to him ultimately enables him to distinguish between disorders which have to be approached as "pathology" and those which are to be regarded as "no pathology". Characterizing a disorder erro" neously as "pathology" may give rise to unnecessary additional 
examinations for the patient, while a false characterization of "no pathology" may imply that essential further examinations may be withheld from him. In other words: both general practitioner and patient may benefit from blood tests with an optimal discriminating ability.

Discriminating ability is usually described using the concepts of sensitivity, specificity and predictive wahe. Sensitivity and specificity are usually regarded as test characteristics, while the predictive value is also determined by the prevalence of a disorder in the population studied. It is a well-known fact that populations studied in primary and specialised health care have different compositions, since the specialist sees only a selection of the complaints presented to the general practitioner. Accordingly, the prevalence of "pathology" in primary health care is generally lower than that in specialised health care (3). Hence, studies of the discriminating ability of a test in general practice should preferably use a population of those patients who present at the general practitioner's surgery and for whom the doctor, after history taking and physical examination, would consider supplementary blood tests to be indicated.

In addition to the discriminating ability, reproducibility is an important factor in the diagnostic value of a test. Reproducibility expresses the degree of similarity between the results of a number of tests, performed simultaneously in different practices on the same blood sample (inter-practice variability), and the degree of similarity between the results of repeated tests performed in the same practice on the same blood sample (intrapractice variability). The term "reliability" is often used as a synonym of reproducibility. Reproducibility has hardly been studied in the context of general practice. However, as good reproducibility is a precondition for good discriminating ability, this aspect certainly deserves more attention.

It is not only the patient and the general practitioner who can benefit from research into the diagnostic value of tests; a more general interest is at stake. If the value of a particular test is more precisely known, it may be requested on better grounds and superfluous tests can be omitted. It is obvious that such studies should be performed before general practitioners are offered additional laboratory facilities such as test strips or instruments for determining liver function, kidney function, electrolytes, cholesterol and triglycerides. Otherwise, such extra 
facilities might lead to an overuse of diagnostic tools (since the general practitioner can then easily perform these tests in his own surgery), and may imply that the general practitioner will more often find (false) positive values inducing further exploration. Thus, while the original goal was fewer blood tests and fewer referrals, the opposite effect may actually be achieved.

As was mentioned above, the diagnostic value of blood tests with a "screening" character, carried out in the general practitioner's own surgery, has hardly been investigated. The following sections discuss in some more detail the recent developments in this area, each section dealing with a particular test.

\section{Haemoglobin}

A number of observational studies of the significance of the $\mathbf{H b}$ test in patients with fatigue, performed in primary health care, have yielded some interesting conclusions. No relevant differences in $\mathrm{Hb}$ values and serum ferritin were found between a group of patients whose main complaint was fatigue and a control group of persons who had undergone a general medical examination without any specific complaints (4). It was also found that a general practitioner's suspicion of anaemia which is based solely on complaints of fatigue is rarely confirmed (5). In $55 \%$ of patients who had visited a general practitioner with complaints of unexplained fatigue, no diagnosis was made, or any problem found, within a period of one year after the first consultation (6). The diagnostic problems in the complaint of fatigue do not concern only the limited value of the Hb test in "anemic complaints", this type of complaint itself is also hard to interpret. It will depend on the general practitioner's working hypothesis whether this problem will subsequently lead to more blood tests, in his own surgery or elsewhere. In this respect it is important to note that when patients complain of fatigue, general practitioners more often think of psychosocial causes, while internists more often consider (serious) somatic pathology (7).

Markus (8) reported on a study of the reproducibility of the Hb test in general practice, which compared Sicca and Spencer $\mathrm{Hb}$-photometers. Hb values, measured by nine general practitioners' assistants, ranged from 6.6 to $9.4 \mathrm{mMol} / \mathrm{l}$, with a mean of $8.0 \mathrm{mMol} / 1$. The authors concluded, among other things, that 
an improved reproducibllity could probably be obtained with (more expensive) spectrophotometers. Van der Ros (9) repeated this study several years later. He found both the Sicca and the Spencer meters to be highly accurate.

\section{Erythrocyte sedimentation rate}

It is well known that ESR tests are frequently requested and performed in the general practitioner's own laboratory. This test has often been investigated in the past. As early as 1898, Müller's (10) thesis described a study of the mechanism of the ESR test. In 1933, Specken (11) published his dissertation, in which the clinical value of ESR tests for gynaecology was assessed. Specken had studied factors which could influence the ESR (temperature, $\mathrm{Hb}$, sodium citrate concentrations, etc.). A thesis by Vaandrager (12) reported on the influence of prior physical activity on ESR.

ESR is also one of the oldest laboratory tests. Specken describes how it was primitively determined even by the ancient Greek scientists (Aristotle, Hippocrates), who allowed blood to clot, and tried to distinguish the four main bodily humours in the clot as it was forming. They assumed that the lower, black layer consisted of melancholy and the upper, red layer of blood in the strict sense of the word. On top of that came the yellow bile which had been driven out of the blood clot, while the clot itself was held together by the phlegm. It was claimed that this latter substance was not to be found as a separate layer in healthy blood, but would collect as a grayish white layer on top of the blood clot in diseased blood, which was assumed to have an increased phlegm concentration.

Although the ESR test has been used frequently and for a long time, and has also often been the subject of research, no unequivocal assessment can as yet be made of its diagnostic value in general practice. Several investigators have advocated different reference values for the distinct age groups (13-16), and the influences of gender, anaemia and pregnancy on the ESR can as yet not be accurately quantified. Another problem is the lack of data from studies in a population of patients who are indicated for ESR determination. This aspect is being investigated at our department. 
With respect to the technique of performing ESR tests, uniform guidelines do exist (17). These show that the test must be carefully performed and that there is interference by external factors such as temperature, turbulence, etcetera.

We investigated reproducibility of the ESR test in 1987 (see also chapter 2.1). A clinically relevant variability was found in the ESR values measured in the general practitioner's office, which was perhaps partly attributable to suboptimal performance of the test. Both inter-practice and intra-practice variability were considerable. These findings prompted us to start a subsequent study under more standardized conditions, which meant that the technical demands for the performance of the test were controlled as strictly as possible. This study is reported on in chapter 2.1 .

\section{Leucocyte count and differentiation}

In 1985, the Scientific Council of the National Organization for Quality Assurance for Hospitals in the Netherlands (CBO, 18) published a report on a literature study and a consensus meeting on the subject "Can there be a "routine" indication for the leucocyte count?' The report concluded that the leucocyte count has a poor sensitivity and specificity with respect to certain disorders, and that the test can only be usefully applied as a screening test if there is a clear suspicion of a haematological malignancy (increased number of granulocytes), mononucleosis infectiosa (elevated and aberrant lymphocytes) or bacterial meningitis (excess of neutrophilic granulocytes). The research on which these conclusions were based was carried out exclusively in the (inpatient or outpatient) clinic. The report further describes the low reproducibility of the microscopical (or "manual") counting method. For certain indications, this method is still being used even in hospital laboratories, since automated counting methods cannot distinguish between all types of cells. This means that a critical attitude is justified not only towards leucocyte count tests performed by the general practitioner himself, but also towards the results of tests performed at hospital laboratories. If elevated values are found which may have clinical consequences, it might be useful to repeat the test. 
As far as the above indications are concerned, the general practitioner will normally see patients with a possible haematological malignancy far less frequently than patients with mononucleosis infectiosa, and in diagnosing the latter disease he will tend to rely mostly on the results of the Paul-Bunnel test. If a patient is suspected of having bacterial meningitis, there is no reason to wait for the results of laboratory tests; the patient must immediately be referred.

The above lead to the conclusion that the leucocyte differentiation has no place in general practice. It must be kept in mind, however, that such a conclusion would only be based on research not performed in primary health care populations. It is insufficiently known which indications lead the general practitioner to request a leucocyte count, and to what extent the results of such a test enable him to differentiate between "pathology" and "no pathology".

\section{Epilogue/conclusion}

Physicians are used to dealing with uncertainties, especially in the field of diagnostics. It is particularly the general practitioners who try to estimate the chance that a complaint may signal serious pathology. This process of estimating probabilities is generally intuitive rather than conscious. One of its manifestations is doing a quick ESR and/or $\mathrm{Hb}$. In addition, blood tests may occasionally be used in order to gain time for reflection, or because the patient specifically asks for them. However, the diagnostic hypothesis which crosses the mind of the general practitioner is rarely expressed, and this is even more true for the subsequent question: 'To what extent does this ESR or $\mathrm{Hb}$ test enable me, as a general practitioner, to confirm or rule out this particular disease?' Asking such questions is important if one is to learn to use these (sometimes expensive) diagnostic tools critically. The answer can only be given after studies in general practice. Investigations along these lines will offer good perspectives for a profession which is increasingly prepared to review its own medical practice critically, and which will in future also be confronted with more sophisticated laboratory tests, such as those involving monoclonal antibodies, which are already being used in pregnancy tests. 


\section{References}

1. Voorn TB ea. Anemie. Uit de serie huisartsgeneeskundige conferenties. Huisants en Wetenschap 1982; 25: 143-7 [summary in English].

2. Dinant GJ, Knottnerus JA, Wersch JWJ van, Dolkain JPH. De bezinkingssnelheid der erythrocyten; een onderzoek naar de reproduceerbairheid van deze bepaling in de huisartspraktijk. Ned Tyjdsch Geneeskd 1988; 132: 680-4 [abstract in English].

3. Knottnerus JA, Knipschild $P G$, Sturmans F. Symptoms and selectionbias: the influence of selection towards specialists care on the relationship between symptoms and diagnoses. Theoretical Medicine 1989; 10:67-81.

4. Knottmerus JA, Knipschild PG, Wersch JWJ van, Sijstermans AHJ. De betekenis van de ferritinebepaling in serum van gezonden en wan patiënten met onverklaarde moeheid in de huisartspraktijk. Ned Tijdsch Geneeskd 1986; 130: 2085-8 [summary in English].

5. Knottnerus JA, Knipschild PG, Wersch JWJ wan, Sijstermans AHJ. Unexplained farigue and hemoglobin level, a primary case study. Can Fam Physician 1986; 32: 1601-4.

6. Knottnerus JA, Starmans R, Vissers A. Diagnostische conclusies van de huisarts naar aanleiding van onverklaarde moeheid. Huisarts en Wetenschap 1987; 30: 9-12 [synopsis in English].

7. Boenink A, Vos $\mathbf{P}$ de, Knottnerus JA. Moeheid: verschillen in benadering tussen huisartsen en internisten. Med Contact 1986; 41: 119-22.

8. Markus HJM, Hoogen HJM van den, Huygen FJA. 'De betrouwbaarheid van hemoglobinebepalingen in de huisartspraktijk. Huisarts en Wetenschap 1981; 23: 47-51 [summary in English].

9. Ros $\mathrm{N}$ van der, Nauta JJP. De nauwkeurigheid wan kleine Hb-meters. Huisarts en Wetenschap 1988; 31: 285-8 [summary in English].

10. Müller O. Beobachtungen über spontane Biutsechmentienung. [Thesis] 1898.

11. Specken JLH. De klinische waarde van de uitzakkingsreactie der erythrocyten in de gyneacologie. [Thesis], HJ Paris: Amsterdam, 1933.

12. Vaandrager $\mathrm{K}$. De betekenis van de bloedbezinkingssnelheid in de praktijk. [Thesis]. Groningen: Schut \& van der Molen, 1946 [summary in English].

13. Knottnerus JA, Kerkhof PD, Schouten LJ. De hoge bezinking. Huisarts en Wetenschap 1984; 27 : 123-9.

14. Crawford J, Eye-Boland MK, Cohen HJ. Clinical utility of erythrocyte sedimentation rate and plasma protein analysis in the elderly. Am J Med 1987; 82: $239-46$

15. Nâyhä $\mathrm{S}$. Normal variation in erythrocyte sedimentation rate in males over 50 years old. Scand J Prim Health Care 1987; 5: 5-8.

16. Schapera $R$. The significance of erythrocyte sedimentation rates in aged persons. SA Med J 1982; 62: 394-6.

17. International Committee for Standardization in Haematology. Recommendation for measurement of erythrocyte sedimentation rate of human blood. Am J Clin Pathol 1977; 68: 505-7.

18. Centraal begeleidingsorgaan voor de intercollegiale toetsing, wetenschappelijke raad. 'Routine'-laboratoriumonderzoke is er plaats voor een 'routine'indicatie van de leucocytendifferentiatie? Utrecht: Vaessen-Baggen, 1985. 



\subsection{Reliability of the erythrocyte sedimentation rate before and after intervention}

G.J. Dinant, J.A. Knotrnerus, P.G.J. Van Aubet, J.W.J. VAN WERSCH

The essentials of this study have been published as:

1. Dinant GJ, Knottnerus JA, Wersch JWJ Van, Dolhain JPH. 'De bezinkingssnelheid der erythrocyten; een onderzoek naar de reproduceerbaarheid van deze bepaling in de huisartspraktijk' Ned Tijdschr Geneeskd 1988; 132: 680-4. [Abstract in English]

2. Dinant GJ, Knottnerus JA, Aubel PGJ Van, Wersch JWJ Van. 'Reliability of the erythrocyte sedementation rate in general practice'. Scand J Prim Health Care 1989; 7: 231-5.

3. Dinant GJ, Wersch JWJ Van, Knottmerus JA. De kwaliteit van de BSE in de huisartspraktijk'. Huisarts en Wetenschap 1989; 32: 412-7, 438, 546. [Abstract in English]

4. Dinant GJ, Knottnerus JA, Wersch JWJ Van. 'De kwaliteit van de bloedbezinkingsbepaling in de huisartspraktijk' [abstract]. Tijdschr Soc Gezondheidszorg 1988; 66: middenkatern 17.

5. Dinant GJ, Knottmerus JA, Wersch JWJ Van. "The erythrocyte sedimentation rate and its quality in general practice" [abstract]. Fam Physician 1989; 17: 19. 
Becalse of the need for an accurate determination of the erythrocyte sedimentation rate (ESR), and because of the fact that many general practitioners frequently determine ESR in their own surgery "we investigated the reliability of the blood test in this setting. For this purpose, blood samples, obtained from the local hospital laboratory, were distributed, and the participating general practice centres were requested to determine ESR in each sample. A clinically relevant intra- and interpractice variability was found in the ESR values measured. The experiment was then repeated one year later under more standardized conditions, which resulted in a significant decrease in the intra- and inter-practice variability $(p=.04$ and .003 , respectively). Vibrations within the hospital building could not account for the systematically higher ESR values measured in the hospital laboratory.

We conclude that a considerable amelioration of in the quality of ESR performance in general practice can be achieved by means of relatively simple interventions.

Key words: erythrocyte sedimentation rate, reliability, intervention study, general practice 


\section{Introduction}

The determination of the erythrocyte sedimentation rate (ESR) is a frequently used blood test in establishing diagnoses both in general practice (1) and in the hospital (2). We investigated the reliability of ESR, since this is an important aspect of its diagnostic value which has hardly been studied so far. One commonly used and recommended way to perform the test is Westergren's method (3). International standards for this methim od (see Table 1) must be met accurately (3). The use of correct techniques (4) and careful handling (5) should be regarded as important in performing any laboratory test. A study of the error rate in physicians' office laboratories recently emphasized this (6), and it is important to note the less comprehensive quality control in general practice laboratories in which the determination of ESR is frequently performed (7).

Table 1. Important technical aspects of the determination of the erythrocyte sedimentation rate (ESR), following the Westergren method (Am J Clin Pathol 1977; 68: 505-7).

Anticoagulant

1. trisodiumcitate dihydrate solution; $3.1 \%$

2. if turbid it must be discarded

Anticoagulant-blood mixture
3. $0.4 \mathrm{ml}$ anticoagulant and $1.6 \mathrm{ml}$ venous blood

4. after venapunction determination of $E S R$ within 2 hours, or 6 hours if kept at $4^{\circ}$ Celsius (C)

Sedimentation tubes

5. made of glass or some plastic materials (disposable tubes)

6. overall length $300 \pm 1.5 \mathrm{~mm}$

7. scale extending over the lower $200 \pm 0.35 \mathrm{~mm}$

8. external diameter $5.5 \pm 0.5 \mathrm{~mm}$

9. tube bore $2.55 \pm 0.15 \mathrm{~mm}$

10. tubes must be clean and dry

11. cleaning in acetone water system

Determination

12. under room temperature $\left(18^{\circ}-25^{\circ} \mathrm{C}\right)$

13. tube placed vibration-free and in strictly vertical position $\left( \pm 1^{\circ}\right)$

1.4. tube is not exposed to direct sunlight or heatung apparatus

15. tube is free of vibrations and draughts

16. reading after 60 minutes 
A large inter-practice variability in measured ESR values was found among primary health care centres in Oslo (8). ESR, often regarded as a non-specific indicator for pathology in general practice, may point in the wrong direction if it is not reliably performed. This may result in missing occult but possibly important pathology, or in initiating unnecessary investigations.

Our study focussed on the intra- and inter-practice variability, and compared ESR measured in general practice with ESR measured in a reference laboratory. Furthermore, we investigated the effect of intervention in decreasing the analytical variability, and finally we considered the possible causes of the systematic deviation found at the reference laboratory. Reliability is defined as the degree of correspondence among several ESR measurements in the same blood sample at the same time in one or several general practice centres (intra- and interpractice variability, respectively).

\section{Methods}

Five general practice centres (GPCs) and the local hospital laboratory ("the laboratory") participated. Two experiments were carried out successively.

\section{EXPERIMENT I}

Centrally prepared blood samples, obtained from the laboratory (see Figure 1), were distributed by car on 17 different days during April and May 1987. ESR was determined in each sample presented, both in the GPCs and at the laboratory (see Figure 2). The test was performed in the usual manner without specific instructions being given. Each GPC used its own determination equipment. By using several blood sample pairs, each pair consisting of two samples of blood coming from one person, both intra- and inter-practice variability could be assessed. 3 or 5 blood samples were presented per delivery, which included one and two pairs, respectively. These pairs could not be recognized (see Table 2). ESR was performed simultaneously in these 3 or 5 samples. 
Figure 1 :

Blood samples obtained from the laboratory, just before distribution.

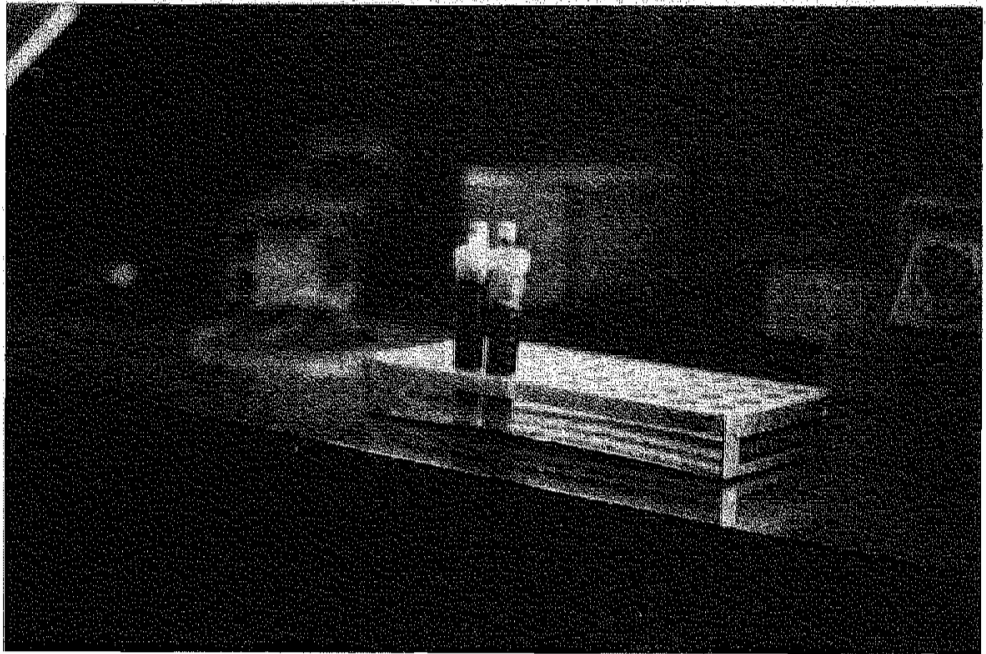

Figure 2

Determination of ESR at the hospital laboratory, using the Sterillon holding device and Omnilabo disposable tubes (on the left side of the picture).

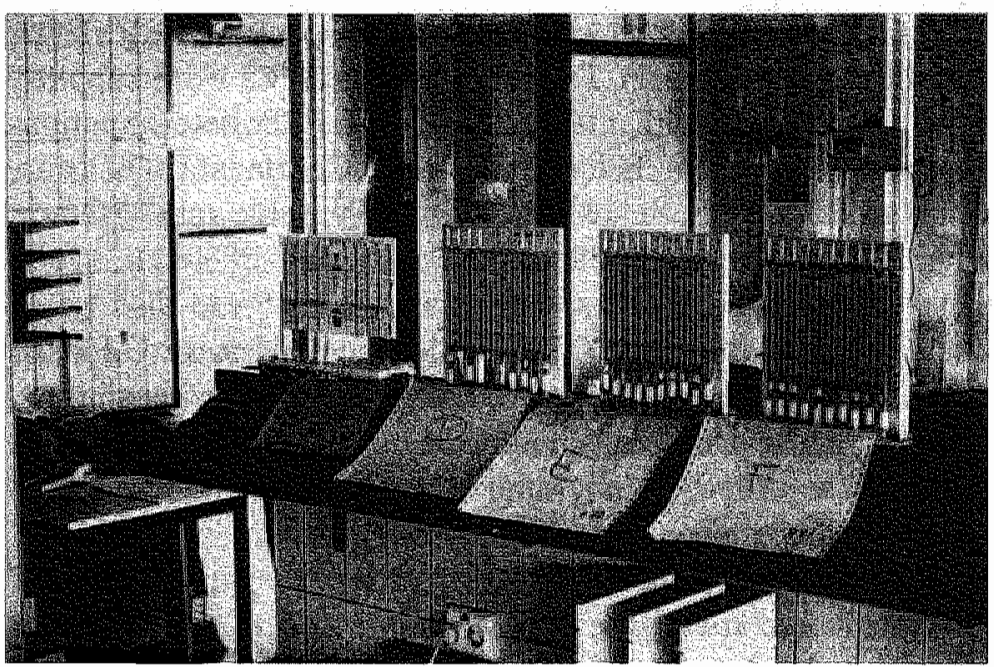


Table 2. Scheme for the blood sample distribution in determinimg the intrapractice wariability 1987, showing the number of samples, each consisting of about $2.5 \mathrm{ml}$ of blood, presented to each general practice centre (GPC) at four different days. Total amounts of blood obtained from each blood donor (patients and bealthy volunteers) are also indicated.

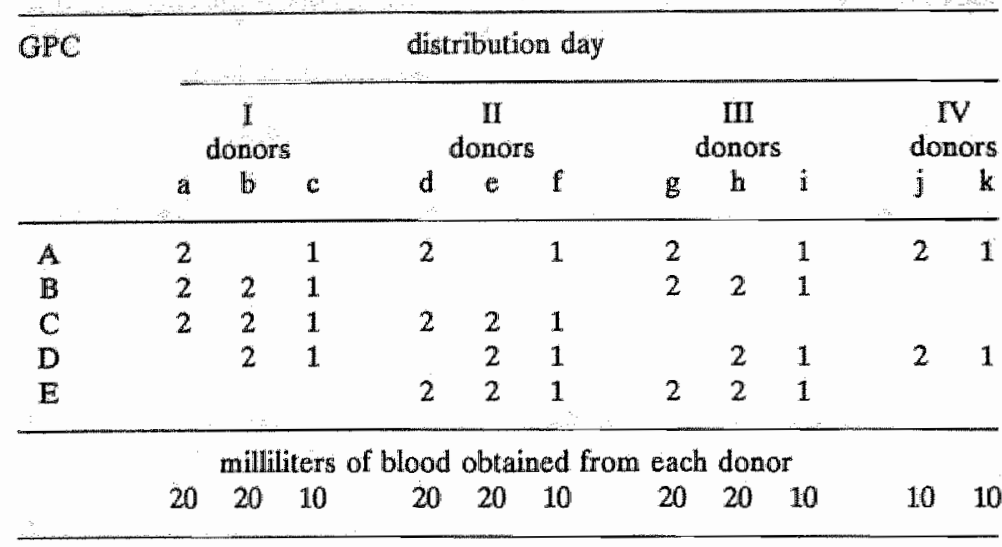

EXPERIMENT II

The second experiment was undertaken one year later, during April and May 1988. It was preceded by detailed instructions to each GPC about all important technical aspects of ESR determinations (see Table 1). Furthermore, all GPCs were supplied by the laboratory with the same type of ESR determinationequipment (Sterilin holding devices, Continental Pharma, Zutphen, The Netherlands), including disposable tubes (Omnilabo, Breda, The Netherlands, serial number 203001). Again, centrally prepared blood samples (and pairs) were distributed on 17 different days, and the ESR determinations were carried out without any delay. Series of 5 samples were used each time, because the devices could now hold up to 10 tubes at a time. The fifth, so-called dummy sample was used in the inter-practice reliability study.

PROCBDURES AND ADDTTIONAL EXPLORATTION

After verbal informed consent 68 blood samples were obtained from blood donors, laboratory personnel, and patients who were admitted to the local hospital. The patients were mostly known to have an elevated ESR and normal hemoglobin concentra- 
tions. The $10-30 \mathrm{ml}$ samples were collected by the laboratory personnel, in the usual way.

To prevent clotting, the blood was collected in Tri-potassium ethylenediaminetetra-acetate (EDTA-K3) tubes. After sample collection, distribution took place within four hours, during which the samples were stored in a refrigerator. The GPCs were visited in a different sequence each time. The performance of ESR determinations was closely observed several times in each GPC. During the first experiment several questions concerning the test performance were asked, and some measurements were performed on the devices used (see Appendix 1). The observations during the second experiment were followed by verbal instructions, if necessary. During the experiments, the GPCs were not informed about the values measured by the others, including the laboratory.

\section{ADDTIONAL INVESTIGATION}

Since the ESR values found in the experiment suggested a systematic difference between the GPCs and the laboratory, we investigated the possible influence of vibrations in the hospital building on the ESR values measured in the laboratory. In 19 blood sample pairs ESR was measured simultaneously in the laboratory on the third floor and in the blood collection centre on the ground floor of the hospital building.

\section{STATISTICAL ANALYSIS}

While blood samples with higher mean ESR values will partially account for increased ranges in the ESR values measured in the GPCs, the coefficient of variation (CV) can be regarded as an acceptable standard in the analysis of these ranges. After we had calculated all CVs for the intra- and inter-practice reliability, we compared the differences in $\mathrm{CVs}$ between the first and the second experiment by means of Wilcoxon's distribution free tests for dependent and independent samples (Signed Rank and Rank Sum Test respectively). Pearson's product moment cor* relation coefficient and the regression coefficient with its $95 \%$ confidence interval were used in the analysis of the validity of the ESR values measured in the GPCs compared with those measured in the laboratory. 


\section{Results}

Results of experiments I and II have been combined, focussing on the intra- and inter-practice variability and the effect of intervention.

\section{INTER-PRACTICE VARIABILTY}

The results are shown in Figures 3 and 4 . The figures show the range of ESR values measured in the GPCs, in relation to the values measured in the laboratory. The laboratory values are depicted on the horizontal axis, and for practical purposes the distance between two values is kept equal. As a result of holidays and accidental sample mismanagement, there were nine (5 in 1987, 4 in 1988) cases in which ESR could be measured in only four GPCs. From the data in Figures 3 and 4, the correlation coefficients between the laboratory results and the GPC results were calculated as $.83(p<0.001)$ and $.97(p<0.001)$, while the regression coefficients were .76 (intercept -1.13 ) and .79 (intercept -1.04 ) respectively. The $95 \%$ confidence intervals of the regression coefficients were $.63-.89$ and $.73-.85$.

Figure 5 shows the calculated CVs in relation to the laboratory values in 1987 and 1988 . The laboratory accidentally performed ESR measurements incorrectly in five cases in 1988. Accordingly, these values are not included in Figures 3 and 4, nor have they been used in the calculations above. However, in these five cases all GPCs performed ESR measurements properly, so CVs could still be assessed and used in the overall calculations. The values for these five cases are listed in Table 3.

Testing the difference in variability between 1987 and 1988 with the Rank Sum Test resulted in a .003 level of significance.

\section{INTRAPRACTICE VARLABIITYY}

The results can be seen from Tables 4 and 5. In 1988 each GPC received two sample pairs more than in 1987. Differences between the numbers of sample pairs per GPC are due to holidays and accidental sample mismanagement. $\mathrm{A}$ mean $\mathrm{CV}$ was calculated for each GPC for 1987 and 1988. The intrapractice difference between the mean CVs of 1987 and 1988 (see Table 6) was analysed using the Signed Rank Test, which resulted in a .04 level of significance. 
Figure 3

Correllation between erythrocyte sedimentation rates (ESR) measuired in the hospital laboratory (horizontal axis) and in general practice centres (vertical axis) in 1987 (before intervention). The inter-practice variability can be read from the vertical axis. $\mathrm{ESR}$ in $\mathrm{mm} / 1 \mathrm{hr}$, according to Westergren.

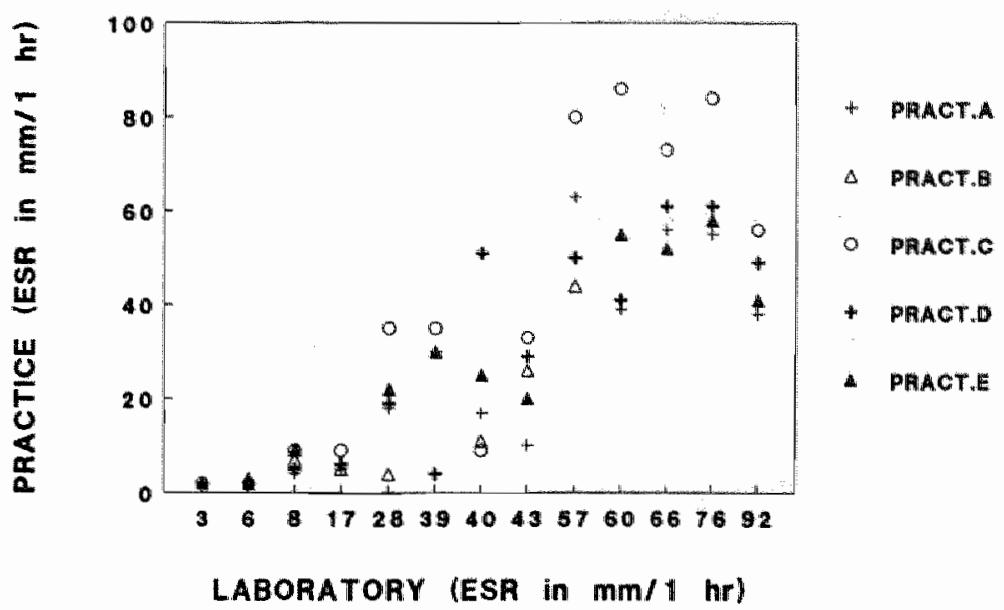

Figure 4

Correlation between the erythrocyte sedimentation rates (ESR) neasured in the hospital laboratory (horizontal axis) and in general practice centres (vertical axis) in 1988 (after intervention). The inter-practice variability can be read from the vertical axis. $\mathrm{ESR}$ in $\mathrm{mm} / 1 \mathrm{hr}$, according to Westergren.

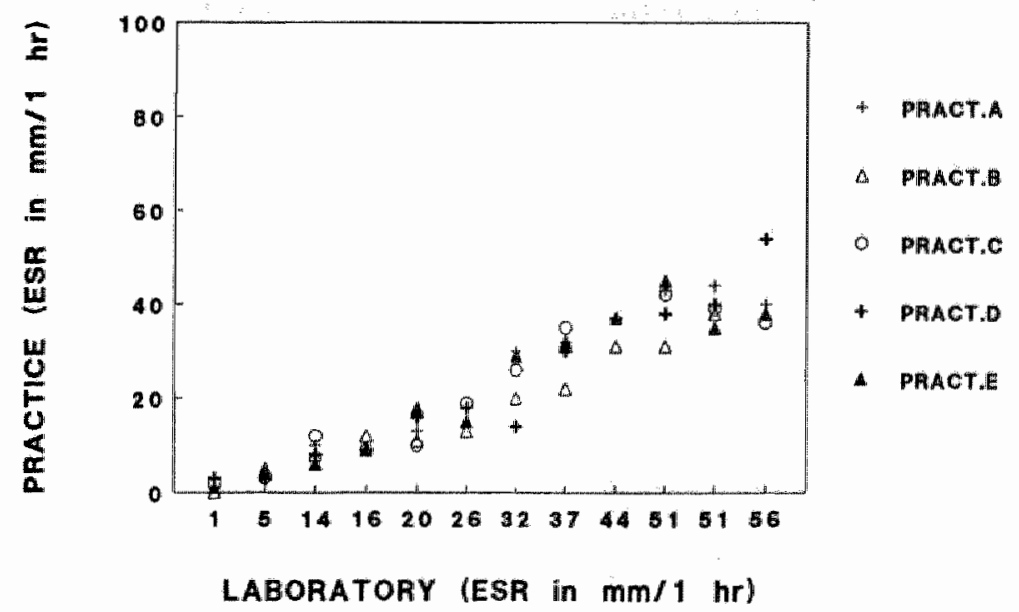


Figure 5

Coefficients of wariation (\%) for the initer-practice variability (vertical axis), as calculated from the erythrocyte sedimentation rates (ESR) measured in the general practice centres, and correlated to ESR values measured in the hospital laboratory (horizonital axis) in each blood sample in 1987 and 1988. ESR in mim/ $/ 1 \mathrm{hr}_{s}$ according to Westergren.

만 $\quad 1987$
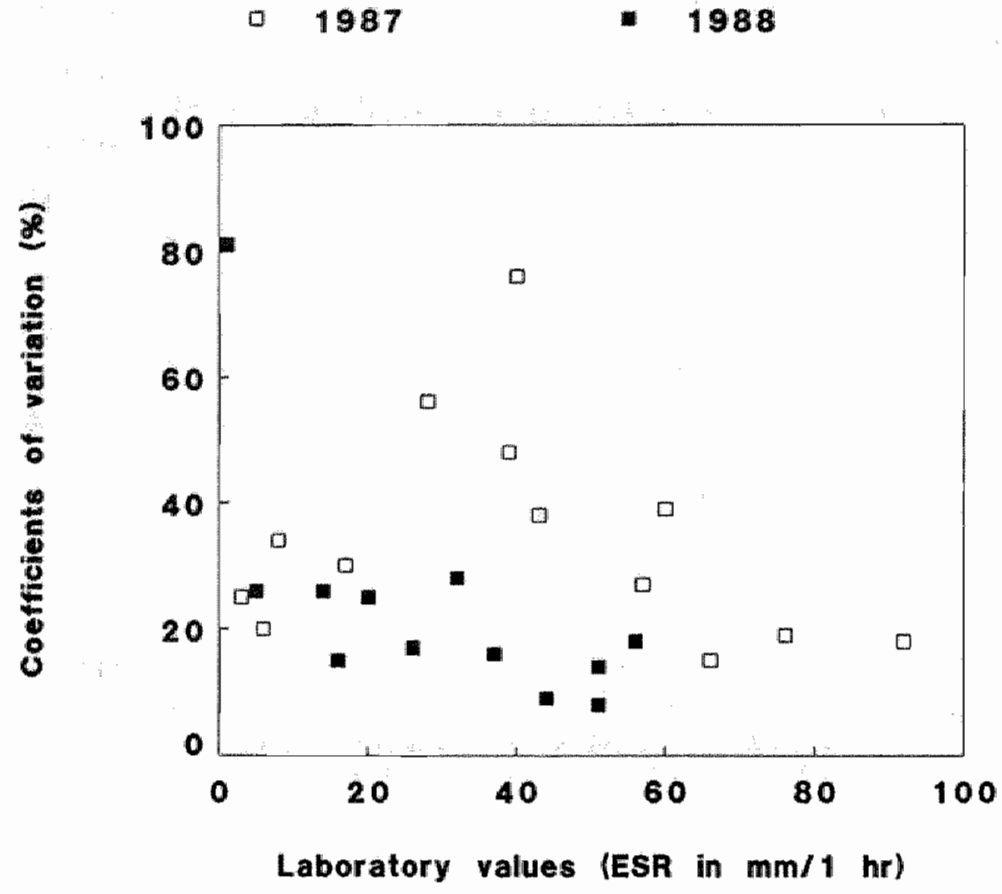

Table 3. The inter-practice variability (1988) for those erythrocyte sedimentation rates (ESR) lacking corresponding reference values. ESR's measured in each general practice centre (GPC) and the calculated coefficients of variation ( $\mathrm{CV}$ ) are listed.

\begin{tabular}{|c|c|c|c|c|c|}
\hline \multirow[t]{2}{*}{$\mathrm{GPC}$} & \multicolumn{5}{|c|}{$\begin{array}{c}\text { ESR in } \mathrm{mm} / 1 \mathrm{hr} \text {, according to Westergren } \\
\text { sample }\end{array}$} \\
\hline & 1 & 2 & 3 & 4 & 5 \\
\hline A & 10 & 28 & 48 & 49 & 59 \\
\hline B & 10 & 24 & 47 & 50 & 68 \\
\hline $\mathrm{C}$ & 9 & 28 & 52 & 50 & 63 \\
\hline $\mathrm{D}$ & 9 & 27 & 54 & 50 & 66 \\
\hline $\mathrm{E}$ & 13 & 25 & 51 & 50 & 59 \\
\hline $\mathrm{cV}(\%)$ & 16 & 7 & 7 & 1 & 6 \\
\hline
\end{tabular}


Table 4. Intra-practice variability of blood sample pairs in 1987. The erythrocyte sedimentation rates (ESR), as measured within each paix are listed according to the sequence in which the pairs were offered to each generall practice centre (GPC). Mean, difference and coefficient of variation (CV) were calculated for each pair. The blood donor codes correspond with those in Table 2.

\begin{tabular}{|c|c|c|c|c|c|c|}
\hline \multirow[t]{2}{*}{ GPC } & \multirow[t]{2}{*}{ donor } & \multicolumn{4}{|c|}{ ESR in mm/ $1 \mathrm{hr}$, according to Westergren } & \multirow[b]{2}{*}{$\mathrm{CV}(\%)$} \\
\hline & & $\begin{array}{l}\text { measure- } \\
\text { ment } 1\end{array}$ & $\begin{array}{l}\text { measure }- \\
\text { ment } 2\end{array}$ & mean & $\begin{array}{l}\text { diffe- } \\
\text { rence }\end{array}$ & \\
\hline \multirow[t]{3}{*}{$A$} & $a$ & 4 & 33 & 19 & 29 & 111 \\
\hline & d & 6 & 6 & 6 & 0 & 0 \\
\hline & $\mathrm{g}$ & 28 & 34 & 31 & 6 & 14 \\
\hline \multirow[t]{4}{*}{ B } & a & 16 & 11 & 14 & 5 & 26 \\
\hline & $\mathrm{b}$ & 79 & 116 & 98 & 37 & 27 \\
\hline & $\mathrm{g}$ & 38 & 26 & 32 & 12 & 27 \\
\hline & $\mathrm{h}$ & 2 & 2 & 2 & 0 & 0 \\
\hline \multirow[t]{4}{*}{$\mathrm{C}$} & a & 40 & 54 & 47 & 14 & 21 \\
\hline & b & 122 & 115 & 119 & 7 & 4 \\
\hline & $d$ & 6 & 7 & 7 & 1 & 11 \\
\hline & $\mathrm{e}$ & 2 & 2 & 2 & 0 & 0 \\
\hline \multirow[t]{4}{*}{ D } & b & 110 & 115 & 113 & 5 & 3 \\
\hline & e & 4 & 3 & 4 & 1 & 20 \\
\hline & $\mathrm{h}$ & 2 & 3 & 3 & $\mathbb{1}$ & 28 \\
\hline & j & 106 & 85 & 96 & 21. & 16 \\
\hline \multirow[t]{4}{*}{$\mathrm{E}$} & d & 7 & 10 & 9 & 3 & 25 \\
\hline & $\mathrm{e}$ & 3 & 4 & 4 & 1 & 20 \\
\hline & $\mathrm{g}$ & 18 & 8 & 13 & 10 & 54 \\
\hline & h & 18 & 3 & 11 & 15 & 101 \\
\hline
\end{tabular}

OBSERVATIONS, MEASUREMENTS AND ADDTTIONAL INVESTIGATION

In 1987 only GPC C used disposable sedimentation tubes (see Figure 6), whereas the remaining GPCs did not always use properly cleaned non-disposable tubes (cleaning with water only). In three GPCs $(\mathrm{A}, \mathrm{B}, \mathrm{E})$ (see Figure 7) a urine-sample centrifuge was situated not far from the sedimentation tube holding device. In 1988 this has been changed, so that centrifuge vibrations could not influence ESR measurements anymore. In both years, all determinations were carried out by trained personnel, in accordance with Westergren's method. Three GPCs were in the habit of sucking the anticoagulant-blood mixture into the sedimentation tube by mouth. This method may be regarded as obsolete nowadays. Apart from the factors mentioned above, the recommendations for correct performance (Table 1) were 
followed. The GPCs did not usually verify their determinations (App. I).

The results of the additional study (see Figure 8) showed no systematic difference between ESR values measured on the ground floor and these measured on the third floor of the hospital building. The correlation coefficient was calculated as $.99(\mathrm{p}<0.001)$ and the regression coefficient as $1.08(95 \%$ confidence interval $.98-1.17$, intercept -.06$)$.

\section{Discussion}

The finding of a considerable variability in daily practice is in agreement with the Norwegian study on this topic (8). However, we have shown that this can be substantially reduced by improving test management.

As can be seen from Figure 3, the range of ESR values measured before the intervention increases with higher laboratory values. This finding is of clinical importance with regard to laboratory values between approximately 20 and $60 \mathrm{~mm}$. For example, in the blood sample with an ESR of $40 \mathrm{~mm}$ as measured in the laboratory, the ESRs measured in the GPCs varied from 9 to $51 \mathrm{~mm}$. Whereas in general an ESR of $9 \mathrm{~mm}$ may be considered normal, $51 \mathrm{~mm}$ will be regarded as high, and quite different clinical policies might result in the two cases. Similar conclusions can be drawn from the ESR values in Table 4, concerning the intra-practice variability. For example, in one blood sample pair with a mean ESR of $19 \mathrm{~mm}$ GPC A measured ESR values of 4 and $33 \mathrm{~mm}$ (mean $19 \mathrm{~mm}$ ). Again, $4 \mathrm{~mm}$ may be regarded as normal and $33 \mathrm{~mm}$ as high (depending on the patient's age). These results may even be relatively optimistic, because the knowledge that one is cooperating in a scientific experiment might already have resulted in a more accurate execution of ESR measurements.

After the intervention, Figure 4 and Table 5 show a significant decrease in the variability, which is now no longer clinically important. Hence, the intervention on technical aspects of the ESR measurements can be regarded as successful. One may question which aspect in particular may account for this success. The observations during the first experiment suggested that the use of improperly cleaned sedimentation tubes could largely be 
held responsible for the initial variability. This conclusion was supported by the almost systematically higher ESR values measured by GPC C, the only GPC that used disposable tubes at the time. The plastic material of which such tubes are constructed may have partially accounted for this, since plastic is possibly smoother than glass. However, after the second experiment the use of disposable glass tubes resulted in a decrease in the mean CV in GPC C as well (Table 6).

Table 5. Intra-practice variability of blood sample pairs in 1988. Erythrocyte sedimentation rates (ESR), as measured within each pair, are listed according to the sequence in which pairs were offered to each general practice centre (GPC). Mean, difference and coefficient of wariation (CV) were calculated for each pair. In 1987 and 1988 two different blood donor groups were involved.

\begin{tabular}{|c|c|c|c|c|c|c|}
\hline \multirow[t]{2}{*}{ GPC } & \multirow[t]{2}{*}{ donor } & \multicolumn{4}{|c|}{ ESR in $\mathrm{mm} / 1 \mathrm{hr}$, according to Westergren } & \multirow[b]{2}{*}{$\mathrm{CV}(\%)$} \\
\hline & & $\begin{array}{c}\text { measure- } \\
\text { ment } 1\end{array}$ & $\begin{array}{l}\text { measure- } \\
\text { ment } 2\end{array}$ & mean & $\begin{array}{l}\text { diffe- } \\
\text { rence }\end{array}$ & \\
\hline \multirow[t]{6}{*}{ A } & $a$ & 106 & 106 & 106 & 0 & 0 \\
\hline & $b$ & $\mathbb{1 1}$ & 13 & 12 & 2 & 12 \\
\hline & $c$ & 8 & 9 & 9 & 1 & 8 \\
\hline & $d$ & 37 & 38 & 38 & 1 & 2 \\
\hline & $e$ & 41 & 40 & 41 & 1 & 2 \\
\hline & f & 59 & 61 & 60 & 2 & 2 \\
\hline \multirow[t]{3}{*}{$\mathrm{B}$} & a & 107 & 103 & 105 & 4 & 3 \\
\hline & $\mathrm{b}$ & 11 & 13 & 12 & 2 & 12 \\
\hline & $\mathrm{c}$ & 5 & 5 & 5 & 0 & 0 \\
\hline \multirow[t]{5}{*}{ C } & $a$ & 118 & 111 & 115 & 7 & 4 \\
\hline & $\mathrm{b}$ & 11 & 10 & 11 & 1 & 7 \\
\hline & $\mathrm{c}$ & 4 & 4 & 4 & 0 & 0 \\
\hline & $d$ & 36 & 38 & 37 & 2 & 4 \\
\hline & $\mathrm{e}$ & 46 & 46 & 46 & 0 & 0 \\
\hline \multirow[t]{6}{*}{$\mathrm{D}$} & $\mathrm{a}$ & 119 & 133 & 126 & 14 & 8 \\
\hline & $b$ & 12 & 14 & $\mathbb{1 1 3}$ & 2 & 11 \\
\hline & $c$ & 3 & 7 & 5 & 4 & 57 \\
\hline & $d$ & 31 & 33 & 32 & 2 & 4 \\
\hline & e & 46 & 45 & 46 & 1 & 2 \\
\hline & $\mathrm{f}$ & 74 & 69 & 72 & 5 & 5 \\
\hline \multirow[t]{6}{*}{$\mathbf{E}$} & $\mathrm{a}$ & 109 & 95 & 102 & 14 & 10 \\
\hline & $b$ & 11 & 12 & 12 & 1 & 6 \\
\hline & $c$ & 6 & 8 & 7 & 2 & 20 \\
\hline & $d$ & 33 & 37 & 35 & 4 & 8 \\
\hline & $\mathrm{e}$ & 33 & 36 & 35 & 3 & 6 \\
\hline & $\mathrm{f}$ & 50 & 54 & 52 & 4 & 5 \\
\hline
\end{tabular}


Table 6. Mean coeffeients of variation $(\%)$ within each general practice centre (GPC)used in studying intra-practice variability in 1987 and 1988.

\begin{tabular}{lrr}
\hline GPC & 1987 & 1988 \\
\hline$A$ & 42 & 4 \\
$B$ & 20 & 5 \\
C & 9 & 3 \\
$D$ & 17 & 14 \\
$\mathbb{E}$ & 50 & 9 \\
\hline
\end{tabular}

Wilcoxon's Signed Rank Test for the difference between 1987 and 1988: $-=.04$

The position of the holding device, not far from a potentially vibrating urine sample centrifuge, may have contributed to the variability in the first experiment as well. But the centrifuge will rarely have functioned simultaneously with an ESR determination. A third aspect of the decrease in variability may have been the absence of a time delay in the execution of ESR measurements during the second experiment. However, only a limited delay (always less than 150 minutes) occurred during the first experiment, and that only in a very few cases.

We conclude that the use of properly cleaned sedimentation rate tubes is an aspect of major importance in the correct execution of ESR determination. Whereas in the first experiment the intra- and inter-practice variability (Figure 3 and Table 4) decreased at very high laboratory values (above 110 and $60 \mathrm{~mm}$ respectively), a similar conclusion could not be made after the second experiment (Figure 4 and Table 5), partly because the laboratory values used in determining the inter-practice variability went up to $92 \mathrm{~mm}$ in 1987, whereas in 1988 the highest value was $56 \mathrm{~mm}$. This difference in experimental design was deliberate, as it could be concluded from the first experiment that the highest CVs were found with ESRs between 20 and $60 \mathrm{~mm}$, this being the clinically more interesting range in general practice. Laboratory values over 60 mm corresponded with relatively low CVs in 1987. Perhaps the latter finding can be explained from the fact that the sedimentation process is complete after one hour in case of a high ESR, while at low ESR levels it is still in progress at that time. 
Figure 6

Laboratory equipments in GPC-C. The holding device is on a shell, which is attached to the wall. Thus, ESR measurement is not influenced by vibrations. Moreover, it can be read at "eye-level".

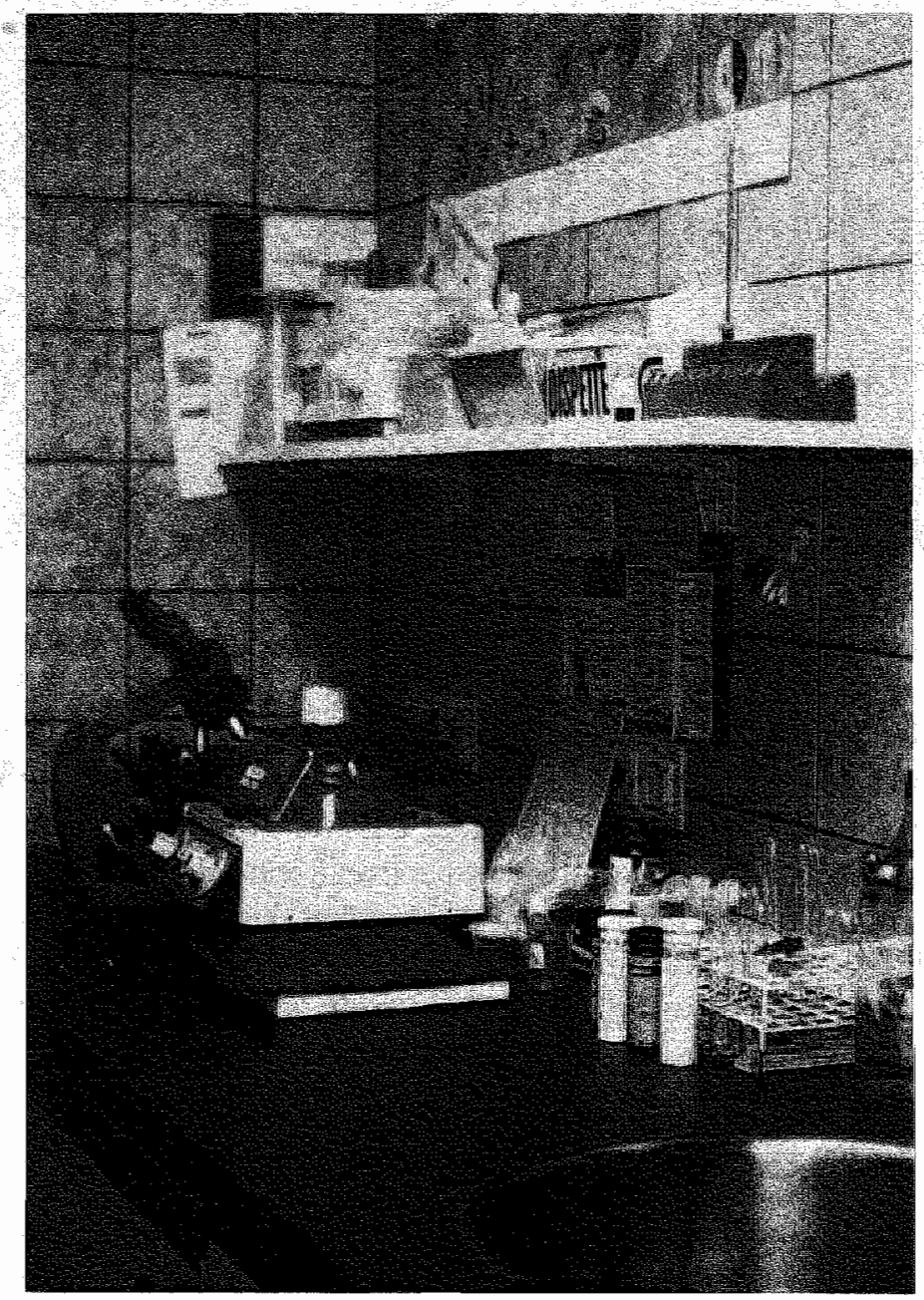

Whereas the regression coefficients differed only slightly in the first and second experiments, general practitioners seem to underestimate higher ESR: with increasing ESR values measured in the laboratory, the GPCs determined relatively lower ESRs. 
Figure 7. Laboratory equipments in GPC-A. The urine sample centrifuge is situated mear the holding device.

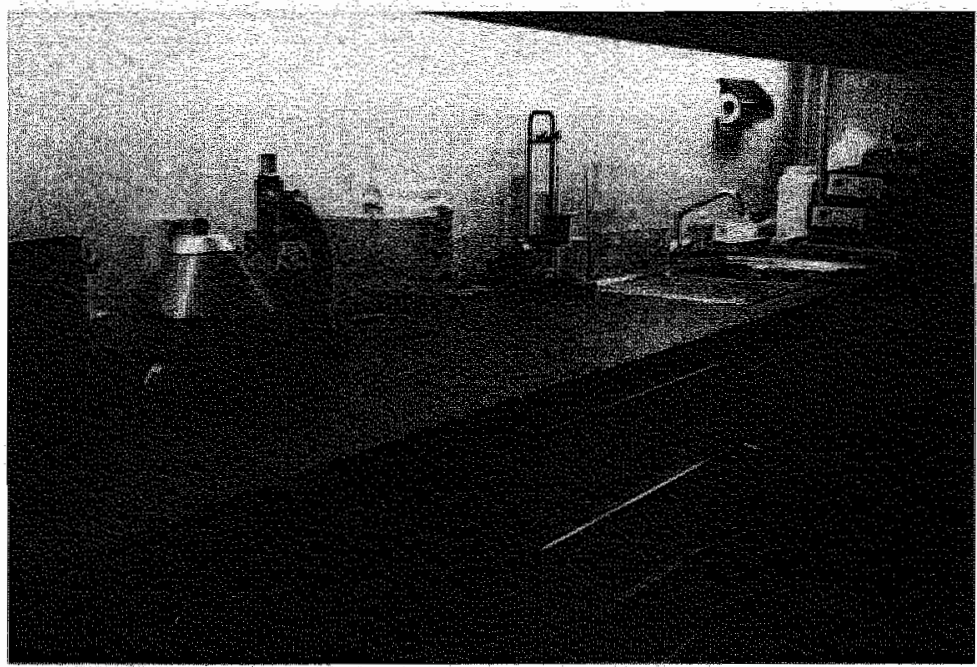

The correlation coefficient clearly increased in the second experiment. This means that the intervention not only reduced the variability, but improved the conformity between measured ESR values and laboratory values as well. Figures 3 and 4 show laboratory values which are systematically higher than measured ESRs. After the second experiment this was even more explicit. We thought that a more or less persistent vibration within the laboratory on the third floor of the hospital building might have influenced ESR measurements, which prompted us to undertake an additional investigation. The results of this experiment (Figure 8), however, imply that correction for any such vibration effects would not diminish the differences in ESR values between the laboratory and the GPCs. It might be supposed that the blood sample transportation by car might have influenced the ESR values measured. But, after investigating this aspect separately (9), we were able to reject this hypothesis. Since we considered it inappropriate to investigate the intra-laboratory variability any further, we conclude that we have found no satisfactory explanation for the higher ESR values measured in the hospital laboratory.

The performance of laboratory investigations in the general practice surgery may be considered an important aspect of everyday practice. The present study has demonstrated that verifying one's determinations once or twice a year is very useful. 


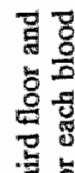

혼

䋍

5

둥

플

용

을

를

与.

을

$\alpha \frac{0}{0}$

II II

485

농

붕

면도 옹

\&

3

훙

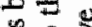

4. 8

동

5

눙

․․뭉

正

(I)

둔

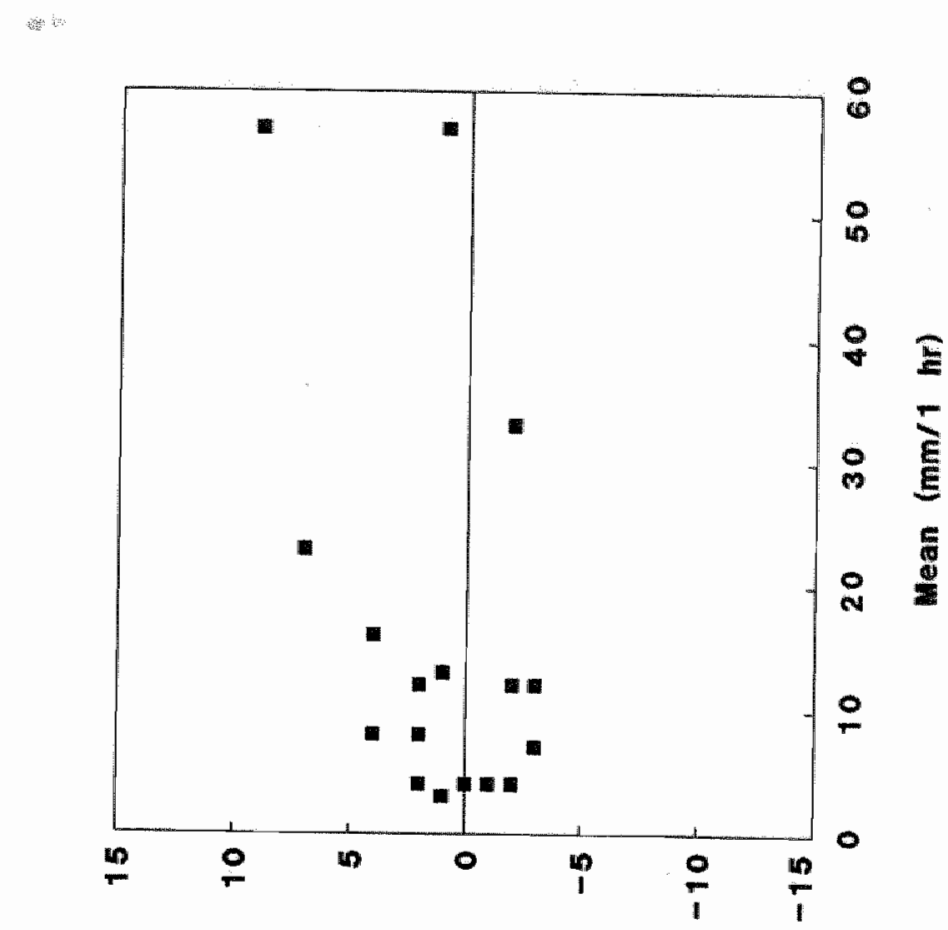

$-7$

홍

on

ㅂ.

늑 5

해용

4.

욜

5 L

5 s

눙 흘

눙 ⿶

몸몰

온

$5 \&$ 용

$\infty$

है

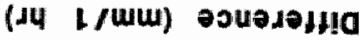

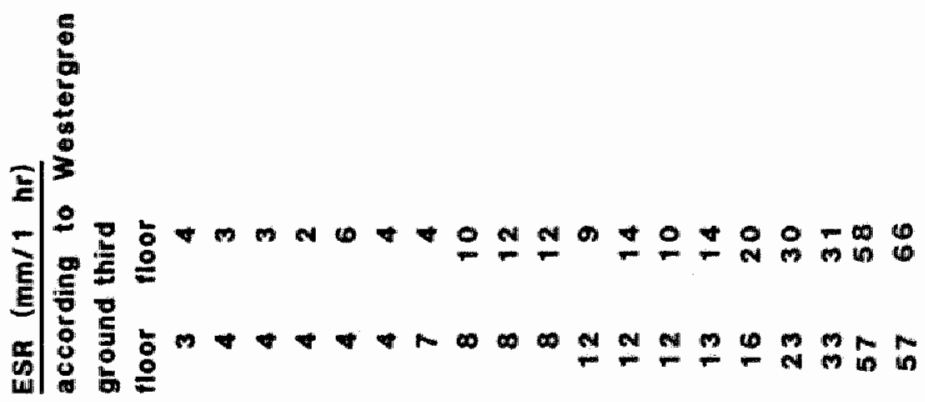




\section{References}

1. Kelly $M H$, Barber $\mathfrak{J H}$. Use of laboratory services and communication of results to patients in an urban practice: an audit. $I R$ Coll Gen Pract 1988; 38: 646.

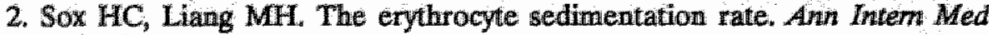
$1986,104: 51523$.

3. International Committee for Standardization in Haematology: Recommendation for measurement of erythrocyte sedimentation of human blood. Am J Cin Pathol 1977; 68: 505-7.

4. Tryding N. Impact of new technology in clinical chemistry. Upsalla J Med Sci 1086. $91 ; 121 ; 3$

5. Komaroff All The variability and inaccuracy of medical data. Proc of the IEEE 1979, 67: 1196-1207.

6. Lundberg GD. Longitudinal study of error prevalence in Pennsylvania physjcians office laboratories. JAMA 1988, 260: 230-5.

7. Neville RG. Introduction to new diagnostic aids in general practice. Update $1988,37,2311-4$

8. Landas $\mathrm{S}$, Juell A. The quality of laboratory analyses in the primary health care Scand I Prim Health Care 1986; 4, 169-73

9. Dinani GJ, Knottnerus JA, Wersch JWJ wan. Blood sample transportation and the erythrocyte sedimentation rate. I $R$ Coll Gen Pract 1989; 39: 302. 


\subsection{Blood sample transportation and the erythro- cyte sedimentation rate}

G.J. Dinant, J.A. KNOTtNerus, J.W.J. VAN Wersch

The essentials of the study have been published as:

1. Dinant GJ, Knottnerus JA, Wersch JWJ Van. 'Blood sample transportation and the erytrocyte sedimentation rate' [letter]. J R Coll Gen Pract 1989; 79: 302.

2. Dinant GJ, Wersch JWJ Van, Knottnerus JA. 'De kwaliteit van de BSE in de huisartspraktijk'. Huisarts en Wetenschap 1989; 32: 412-7, 438, 546. [Abstract in English]

3. Dinant GJ "Knottnerus JA, Wersch JWJ Van. 'De kwaliteit van de bloedbezinkingsbepaling in de huisartspraktijk' [abstract]. Tijdschr Soc Gezondheidszorg 1988; 66: middenkatern 17.

4. Dinant GJ, Knottnerus JA, Wersch JWJ Van. "The erythrocyte sedimentation rate and its quality in general practice' [abstract]. Fam Physician 1989; 17: 19. 
On the basis of previous studies concerning the quality of erythrocyte sedimentation rate (ESR) tests in general practice, it was hypothesized that transportation of the blood samples by car could have contributed to the clinically relevant inter- and intra-practice variability found in these studies. Therefore, an experiment was performed in the local hospital laboratory, involving the determination of the ESR in 18 centrally prepared blood samples, before and after their transport by car. Differences resulting from transport were not found (correlation coefficient $=98$, regression coefficient $=1.07$ ). Further investigations into the origins of the inter- and intra-practice variability are be performed (see chapter 2.1).

Keywords: erythrocyte sedimentation rate, general practice, blood sample transport, reliability. 
Determination of the erythrocyte sedimentation rate (ESR) is a frequently used blood test (1), which must be accurately performed, in accordance with international standards (2). For these reasons the reliability of the blood test is an important aspect of its diagnostic value in general practice (GP). Following the example of Norwegian investigators (3), we recently studied this aspect in the Netherlands (4). In both studies, centrally prepared blood samples were distributed, and ESR was determined for each sample in the participating GP centers. In our study we found a clinically relevant inter- and intra-practice variability. Despite the more standardized conditions in the Norwegian study, it showed an important inter-practice variability as well. The blood samples were transported by car, and, as we suggested in retrospect, this might have influenced the results of the studies to some extent. One group of Scandinavian investigators studied the stability of some serum and blood constituents during postal transport (5). No significant influence was found. However, ESR was not included in this study. We found no further literature on this subject, and therefore decided to investigate it ourselves. Apart from this, investigating the influence of transport can be considered relevant, since blood samples are frequently transported from district health centers to tocal hospital laboratories to be analyzed. Also, the study fits in well with attempts at developing a good collaboration between general practitioners and clinical chemists (6).

\section{Methods}

Five GP centers and the local hospital laboratory (hereafter "the laboratory"), participated in the study. Blood samples of $10-30 \mathrm{ml}$ were obtained from patients admitted to the local hospital, as well as from blood donors and laboratory personnel, after verbal informed consent. The subjects underwent a venapunction for this purpose. The samples were collected by laboratory personnel, in the usual way, and the blood was collected in ethylenediaminetetraacetate (EDTA-K3) tubes, to prevent clotting. After a brief storage ( $<120$ minutes) in the laboratory refrigerator, the samples were divided into pairs, and placed in 
small disposable plastic tubes. One of each pair was kept in the laboratory, and the remaining tubes were placed in the boot of a car, in the dark, in a fixed position. The car and its driver did not change during the study. All GP centers were visited within a time span of about 30 to 60 minutes. The car then returned to the laboratory. For each of these two tubes, the ESR of the blood sample was determined simultaneously in the laboratory. The test was carried out by the normal laboratory staff, following the Westergren method, taking the results in mm after one hour. From the beginning of April until the beginning of May, 1988, 17 blood sample pairs were collected and analyzed in this way. Dividing and distributing the samples was carried out by the first author. In analyzing the data, graphs were constructed in accordance with the recommendations about showing variables without an independent ("gold") standard (7). In addition to the product moment correlation coefficient ( $R$ ), the linear regression equation (BMDP-6D; 8) was also calculated.

\section{Results}

Figure 1 represents the measured ESR values. For reasons of clarity the individual values are also listed on the right side of the Figure. $R$ was calculated as $.98(\mathrm{p}<.001)$ and the regression coefficient as 1.07 (95\% confidence interval .96-1.19, intercept -3.0 ). The same ESR values are shown in a different way in Figure 2. This figure shows more distinctly how many times, to what extent, and in which direction ESR changed during the transport.

\section{Discussion}

While in three cases no differences could be established between the ESR values measured in the laboratory before and after the transport by car, there were two cases in which the differences amounted to 13 and 18 millimeters respectively. As could be expected, the blood sample pairs which showed no differences were those with a low mean ESR ( 1 to 15 ), whereas the highest differences were found for two pairs with a (very) high mean ESR (44 and 121 respectively). 


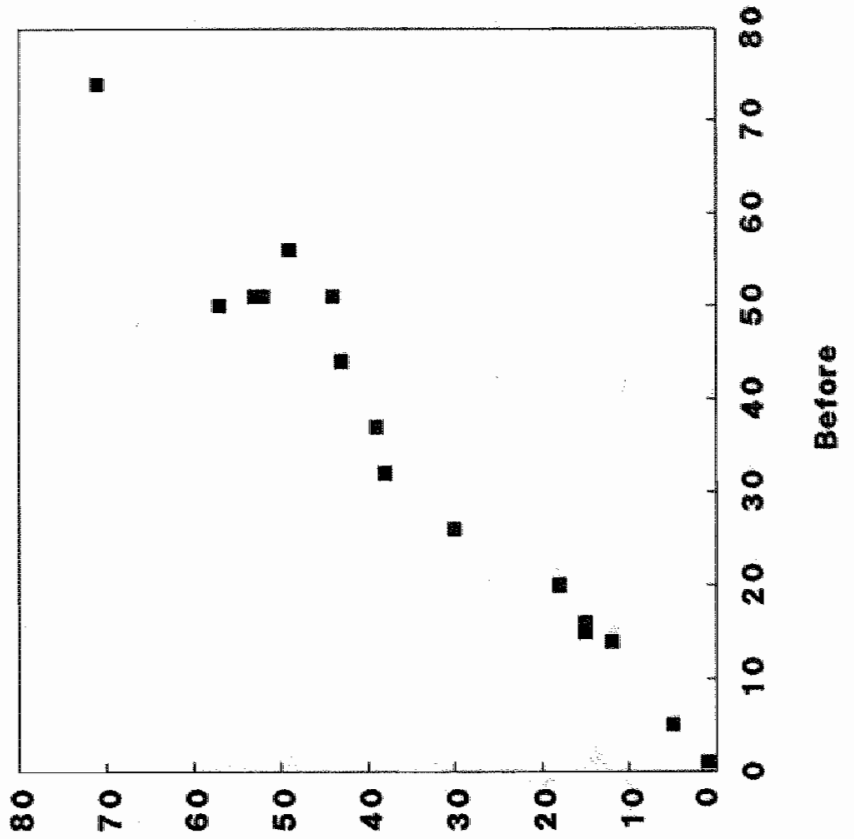

함 
Figure 2

Differences between pairs of ESR determinations; before and after transportation (vertical axis), in relation to the mean of these determinations (horizontal axis) for each blood sample pair. A higher $\mathbb{E S R}$ after transportation is regarded as a positive change, a lower ESR as a negative one.

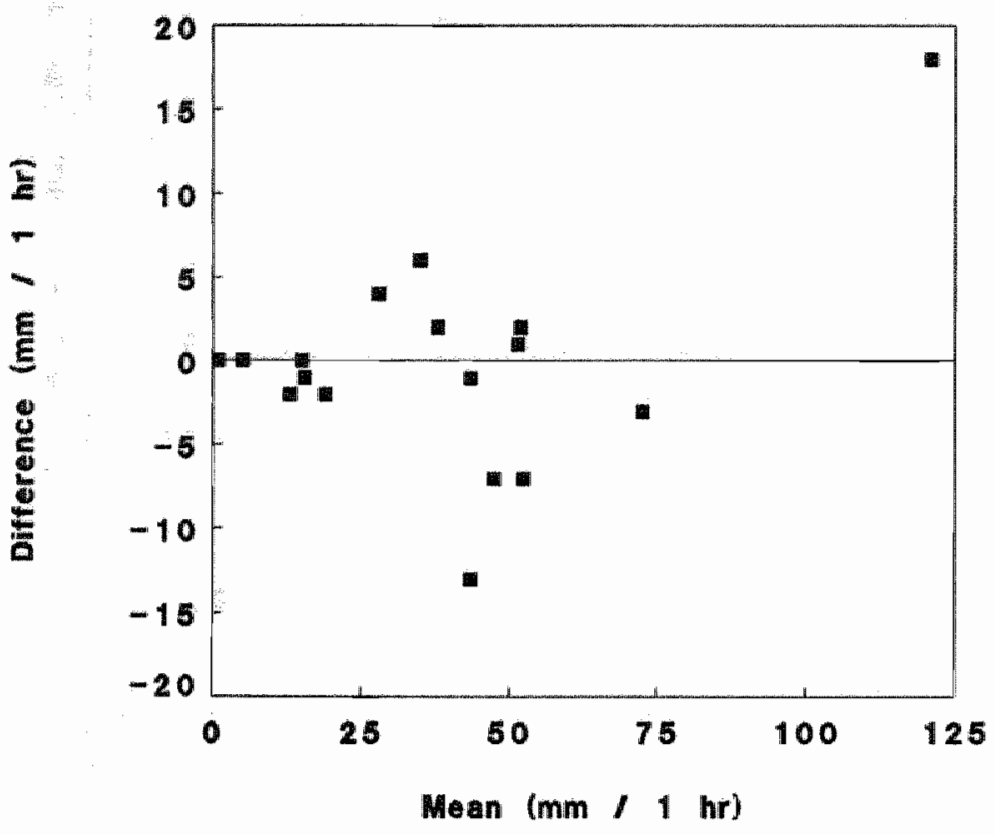

To some extent, therefore, the differences increased with increasing mean ESR values, but there was no blood sample pair where this became clinically relevant. Moreover, the differences did not point systematically into one direction; in eight cases ESR was lower after the transport, in six it was higher. This result is reflected in the extremely high correlation and regression coefficients. Therefore we conclude that blood sample transport does not influence the ESR values, and that other factors must be held responsible for the variability. There may have been some inter-observer variability within the laboratory. On the other hand, the laboratory personnel, knowing that they were involved in a scientific experiment, may have performed the ESR determinations more accurately than usual (9).

Comparing these results with the clinically important interand intra-practice variability found prewiously, it can be concluded that blood sample transport by car has no substantial 
effect on this variability, which has further been investigated in order to discover its origin (see chapter 2.1).

\section{Litterature}

1. Kelly $\mathbf{M H}$, Barber $\mathbf{J H}$. Use of laboratory services and communication of results to patients in an urban practice: an audit. JR Coll Gen Pract 1988; 38: $64-6$

2. International Committee for Standardization in Hematology. Recommenda tion for measurement of erythrocyte sedimentation rate of human blood. Am J Clin Pathol 1977; 68: 505-7.

3. Landaas S, Juell A. Quality of laboratory analyses in the primary health care. Scand J Prim Health Care 1986; 4: 169-73.

4. Dinant GJ, Knottnerus JA, Wersch JWJ wan, Dolhain JPH. De bezinkingssnellheid der erythrocyten; een onderzoek naar de reproduceerbaktheid van deze bepaling in de huisartspraktijk (abstract in English). Ned Tjidschr Geneeskd 1988; 132: 680-4.

5. Berg $B$, Estborn B, Tryding $N$. Stability of serum and blood constituents during mail transport. Scand J Clin Lab Invest 1981; 41: 425-30.

6. Horder M. Current trends in the collaboration of primary health care and clinical chemistry in the nordic countries. Upsala I Med SCi 1986; 91: 189. 92.

7. Bland JM, Altman DG. Statistical methods for assessing agreement between two methods of clinical measurement. Lancet 1986; i: 307-10.

8 Dixon WJ. BMDP Statistical manual. Callifornia, Berkeley: University of California Press, 1981.

9. Mortimer PP. "Blind" laboratory analysis (letter). Lancet 1988; i: 471 . 

2.3 Reliability of the erythrocyte sedimentation rate in general practice; results from a workshop

G.J. DNANT, J.W.J. VAN WERSCh, J.A. KNOTtNeRus

The essentials of the study have been published as:

Dinant GJ, Wersch JWJ Van, Knottnerus JA. 'De kwaliteit van de BSE in de huisartspraktijk'. Huisarts en Wetenschap 1989; 32: 412-7, 438, 546 [Abstract in English]. 
At the 1988 congress of the Dutch College of General Practitioners a workshop concentrated on aspects of the reliability of the determination of the erythrocyte sedimentation rate (ESR). A case-report, a checklist and an experiment were used. The checklist was answered by all 52 participating general practitioners (GPs) and then discussed in a plenary session, together with the results of the experiment which was performed at the same time. The experiment illustrated the importance of a correct execution of the ESR determination. Despite the frequent use of ESR in the GP's office, many GPs were found to be relatively unfamiliar with several reliability aspects. 
At the 1988 congress of The Dutch College of General Practitioners a workshop on aspects of the diagnostic value of blood tests in general practice was presented by the first author of this report.

\section{Methods}

A case-report was sent to introduce the concepts which determine "discriminating ability" (sensitivity, specificity, predictive value) and their relationship with the prevalence of a disease and the reference values. Measurement of the erythrocyte sedimentation rate (ESR) was used as an example. The second and most important part of the workshop concentrated on the reliability (in terms of reproducibility) of ESR as it is performed in the general practitioner's (GP) office. The results of the study presented in the previous chapters were used to structure the presentation. The participating GP's were asked to fill in a checklist which consisted of 15 statements. The statements were then discussed in a plenary session. Meanwhile, ESR was performed properly as well as in three deliberately incorrect ways, to illustrate the reliability aspects. For this experiment two different blood samples were used, one obtained from a subjectively healthy person and the other from a patient who was known to have an elevated ESR.

\section{Results}

All 52 participants completed the checklist. "Their answers are presented in Table 1, which also shows the correct answers (1). Table 2 shows the results of the ESR measurements as performed during the workshop.

\section{Discussion}

It was only with respect to the necessity of using dry tubes (statement 5), which are situated free of vibrations (statement 
9), that all GPs were in agreement. Unexpectedly, the correct mixture of anticoagulant and blood (statement 2) and the necessity of reading after one hour (statement 12) was not familiar to all GPs. The importance of these aspects was illustrated by the results of the experiment (see Table 2). From this table it can be seen that using proportionally more anticoagulant almost halves a high ESR, whereas it only slightly raises a normal ESR. In all cases a slanting position of the tubes considerably raised ESR (Table 2) which is in agreement with previous findings (2). Several GPs were found to be unfamiliar with this (statements 6 and 7). The statements on the periods of time over which one can keep the anticoagulant (statement 1), the glass tubes (statement 4 ) and the anticoagulant-blood mixture (statements 10 and 11) were formulated in such a way that some discussion was possible. The answers given were in accordance with this expectation. Finally, the opinions about the necessity of verifying one's determinations (statements 14 and 15) were found to differ greatly. We conclude that the GP's knowledge of reliability aspects of ESR determination leaves room for improvement.

\section{References}

1. International Committee for Standardization in Hematology. Recommendation for the measurement of the erythrocyte sedimentation rate of human blood. Am J Clin Path 1977; 68: 505-7.

2. Huygen FJA. Enkele experimenten met bepalingen van de bezinkingssnelheid der rode bloedlichaampjes. Ned Tijdschr Geneeskd 1965; 109: 2476-81. 
Table 1. Checklist answered by 52 GPs, illustrating neliability aspects of the determination of ESR.

\begin{tabular}{|c|c|c|c|c|}
\hline \multirow{2}{*}{ Statement } & \multirow{2}{*}{$\begin{array}{l}\text { correct } \\
\text { answer } \\
\mathrm{Y}=\text { yes } \\
\mathrm{N}=\mathrm{No}\end{array}$} & \multicolumn{3}{|c|}{ score } \\
\hline & & correct & $\begin{array}{c}\text { not } \\
\text { correct }\end{array}$ & $\begin{array}{c}\text { no answer } \\
\text { given }\end{array}$ \\
\hline
\end{tabular}

1. The anticoagulant to be used can be kept for a limited period of time.

2. The anticoagulant-blood mixture must consist of $0.4 \mathrm{ml}$ anticoagulant and $1.6 \mathrm{ml}$ blood.

3. The sedimentation tubes may be cleaned with water.

$Y$

4. Tubes made of glass can be kept for 5 years.

5. Tubes must be dry preliminary to the determination

6. By placing the tube in a 30 degree slanting position, the determination can be performed quicker, yet still reliably.

7. The tube must be placed in a strictly vertical position.

8. The determination will be influenced by the ambient temperature.

9. The tube must be situated free of vibrations, so not on top of a refrigerator or in the neighbourhood of a centrifuge.

10. Preliminary to the determination, the anticoagulant-blood mixture may be kept for several hours.

11. After storing the anticoagullantblood mixture in a refrigerator, the determination may take place the next day (after 8 hours).

12. The reading can take place after one hour $+/-15$ minutes.

13. The use of disposable tubes made of plastic will result in unreliable test outcomes.
$\mathbf{Y}$

N

Y 22

22

29

1

48

4

$38 \quad 13$

1

$\begin{array}{llll}N & 13 & 36 & 3\end{array}$

$\mathrm{Y}$

52

N

15

35

2

Y $\quad 39$

13

Y

43

7

2

Y

51

1

N

27

23

2

$\begin{array}{llll}N & 18 & 32 & 2\end{array}$

N $6 \quad 46$

N

11

39 
14. It is useful to calibrate one"s determinations about twice a year by performing $\mathrm{ESR}$ at the GP office as well as at the local hospital laboratory, using blood samples obtained from one patilent.

$\mathrm{Y}$

27

24

1

15. It is useful to verify one's determinations occasionally by performing ESR twice, using a bigger blood sample obtained from one patient.

Table 2. ESR performed properly (following Westergrem) as well as incorrectly, illustrating reliability aspects of the determination.

\begin{tabular}{|c|c|c|c|c|c|}
\hline \multirow[b]{2}{*}{$\begin{array}{l}\text { blood } \\
\text { samples } \\
\text { obtained } \\
\text { from a }\end{array}$} & \multirow[b]{2}{*}{$\begin{array}{c}\text { sample } \\
\text { codes }\end{array}$} & \multicolumn{4}{|c|}{ determinations of ESR* } \\
\hline & & $\begin{array}{l}\text { following } \\
\text { Westergren }\end{array}$ & $\begin{array}{l}\text { by using } \\
\text { tubes } \\
\text { placed in } \\
20 \text { degrees } \\
\text { slanting } \\
\text { position }\end{array}$ & $\begin{array}{l}\text { by using } \\
0.8 \mathrm{ml} \text { an- } \\
\text { ticoagulant } \\
\text { and } 1.2 \mathrm{ml} \\
\text { EDTA blood }\end{array}$ & $\begin{array}{c}\text { by reading } \\
\text { after } 80 \mathrm{mi} \\
\text { nutes }\end{array}$ \\
\hline healthy & a & 2 & 36 & 4 & 3 \\
\hline person & a & 4 & 14 & 6 & 5 \\
\hline patient & $b$ & 39 & 92 & 17 & 44 \\
\hline & $b$ & 26 & 45 & 14 & 30 \\
\hline
\end{tabular}

* ESR determinations performed at the morning session are listed in the first and third rows, those performed at the afternoon session are listed in the second and fourth rows. 
3.1 Desktop laboratory in general practice; the discriminating ability of the erythrocyte sedimentation rate

G.J. Dinant, J.A. KnotTnerus, J.W.J. Van Wersch

Accepted for publication in The British Journal of General Practice 
Despite its frequent use, little is known about the ability of the erythrocyte sedimentation rate (ESR) to discriminate between "pathology" (= inflammatory diseases and malignancies) and "no pathology" in general practice. We studied the discriminating ability of ESR by a prospective follow-up of 362 patients who were seen by their general practitioner (GP) because of a new complaint, for which the GP wanted to know ESR (the so called indicated population). The test was performed at the local hospital laboratory and the patients were seen again after three months, in order to establish the follow-up diagnoses. In comparing the test results with the follow-up diagnoses (analysed by means of Received Operating Characteristic [ROC] curves and regression analysis), ESR was found to have a reasonable discriminating ability with respect to malignancies and inflammatory diseases (sensitivity $=53 \%$, specificity $=94 \%$, positive predictive value $=48 \%$, negative predictive value $=91 \%$, Odds ratio $=15.1)$. In the indicated population, the arythmically optimall upper limit of the reference range of ESR was situated around $12 \mathrm{~mm} / 1 \mathrm{hr}$ in men and $28 \mathrm{~mm} / 1 \mathrm{hr}$ in women. It needed no correction for age.

We conclude that ESR still deserves a place in the GP's daily routine.

Keywords: erythrocyte sedimentation rate, general practice, discriminating ability, malignancy, inflammatory disease 


\section{Introduction}

Despite its frequent use $(1,2)$, little is known about a most important aspect of the erythrocyte sedimentation rate (ESR) in general practice, viz. its ability to discriminate between serious diseases, requiring for therapy ("pathology") and harmless, often self limiting diseases ("no pathology") $(3,4)$. We report on this common application of ESR.

Reference values, and sometimes sensitivity, specificity and predictive values of ESR have been described in healthy (5-17), as well as in diseased persons (18-41). The suggested upper limits of normal ESR vary from 5 to $50 \mathrm{~mm} / 1 \mathrm{hr}$, depending on the patient's age, gender and the disease concerned. Authors mainly disagree on the appropriate reference values in the elderly and on the ability of ESR to rule in disease. Others discuss special features such as diurnal variations in ESR (42), intra-individual variations (43) and variations in relation to nutrition (44-45). In addition, the effects of stress (46), the correlation between obesity and ESR and between ESR and hypercholesterolemia (11) have been studied. Furthermore, ESR was found to be an unsuitable predictor of ischemic heart disease (47). The influences of cell volume (anemia, polycythemia), pregnancy (elevates ESR) and medication (steroids, oral contraceptives) are well known, though difficult to quantify. Because of these uncertainties, alternative tests have been recommended (48-54). However, until now, no study of ESR has included the full spectrum of patients attending the general practitioner (GP) because of a new complaint for which the GP considers determination of ESR to be indicated (the so called indicated population). By investigating this rather undifferentiated population prospectively, as we did in the present study, ESR is maximally challenged on its discriminating ability (55-58). Moreover, such a study may cast some light on the indications for determining ESR in general practice and may enable a proper assessment of predictive values. The prevalences of the diseases concerned and the appropriate reference values can be derived (59).

With regard to our results, it should be remembered that for the clinical interpretation of ESR a reliable determination is essential. As was recently demonstrated, one must always be aware of the consequences of imprecise and inaccurate test performance $(60-64)$. 
Nine GPs participated in the clinical study, which included the indicated populations of the 9 GPs for 5 successive months. After informed consent had been obtained, the name, date of birth and gender of the patient were recorded and a venous blood sample was taken from the patient's arm by using a vacuum system, with the patient usually sitting on a chair. To prevent clotting, the blood was collected in ethylenediaminetetra-acetate (EDTA-K3) tubes. The samples were collected daily in order to determine Westergren's ESR at the local hospital laboratory. In addition to receiving all normal GP care, the patients were requested to revisit the GP's office after three months. Where necessary, patients received a written reminder or a telephone call after the three months had expired. During the revisits, the investigator established the follow-up diagnosis by interviewing the patient, reviewing the chart and hospital letters, and asking additional information from the GP if necessary. The follow-up diagnoses were classified according to the International Classification of Health Problems in Primary Care (ICHPPC-2-defined) (65), this being the preferred system in assessing unequivocal diagnoses (66).

As far as the classification was concerned, the inter-rater agreement between the investigator and one other GP was found to be $85 \%$. Disagreement existed mainly about psychosocial problems.

Preliminary to the clinical study, a questionnaire concerning reference values and indications for determining ESR in general practice was presented to $20 \mathrm{GPs}$ (see Appendix II). The results were also used to define "pathology". Later on, the same questions were answered by the 9 GPs who participated in the clinical study (See Appendix II).

In the analysis we calculated prevalence, sensitivity, specificity and predictive values (which together constitute the discriminating ability of a test), according to the current definitions of these terms (67). They were derived from a dot plot of measured ESR values and corresponding follow-up diagnoses had been constructed and interpreted $(68,69)$. We used Receiver Operating Characteristic (ROC) curves to study the relation 
between sensitivity, specificity and reference values (cut-off points) (70). Odds ratios, with their $95 \%$ confidence intervals (CI) $(71,72)$, were used in estimating the joint value of sensitivity and specificity in discriminating "pathology" from "no pattiology". Furthermore, the logistic regression function for the simultaneous contributions of ESR, age and gender in predicting "pathology" was calculated, using the BMDP-LR computer program (73). Finally, we computed the gain in diagnostic certainty after performing ESR (74).

\section{Results}

In all, 362 patients, aged 4 to 87 (mean and median 47 years, standard deviation 19 years), participated in the study. From Appendix III it can be seen how the follow-up diagnoses were established. In 10 patients either ESR or the follow-up diagnosis could not be assessed, e.g. because they were tourists travelling through. Table 1 shows the ESR values and corresponding follow-up diagnoses which we found in the remaining $352 \mathrm{pa}-$ tients. On the basis of the results of the questionnaire (Appendix II), we defined "pathology" as inflammatory diseases and malignancies. "No pathology" was taken to mean that the follow-up diagnoses only included the categories "signs, symptoms and ill defined conditions", as well as "adverse effects", "supplementary classification" and "preventive medicine" (in all, $30 \%$ of the follow-up diagnoses). All of these diagnoses concerned minor and spontaneously resolving problems (75). The remaining disease categories are defined as "all other diseases". Using these definitions, ICHPPC-2-defined was partly modified, as can be seen from Table 1, in which we listed the disease categories. Pneumonia, arthritis and fever e causa ignota (e.c.i.) were added to the category "inflammatory \& parasitic diseases", indicated hereafter as inflammatory diseases. As far as possible, inflammations of the other tracts were added to the inflammatory diseases as well. The neoplasms we found were mainly malignant ones, which we refer to as malignancies. We divided the category "genitourinary system diseases" in "urinary system" and "genital organ diseases", the latter including uterine myomatosis. "Injuries" and "perinatal morbidity and mortality" did not occur. The category "preventive medicine", consisting of a 


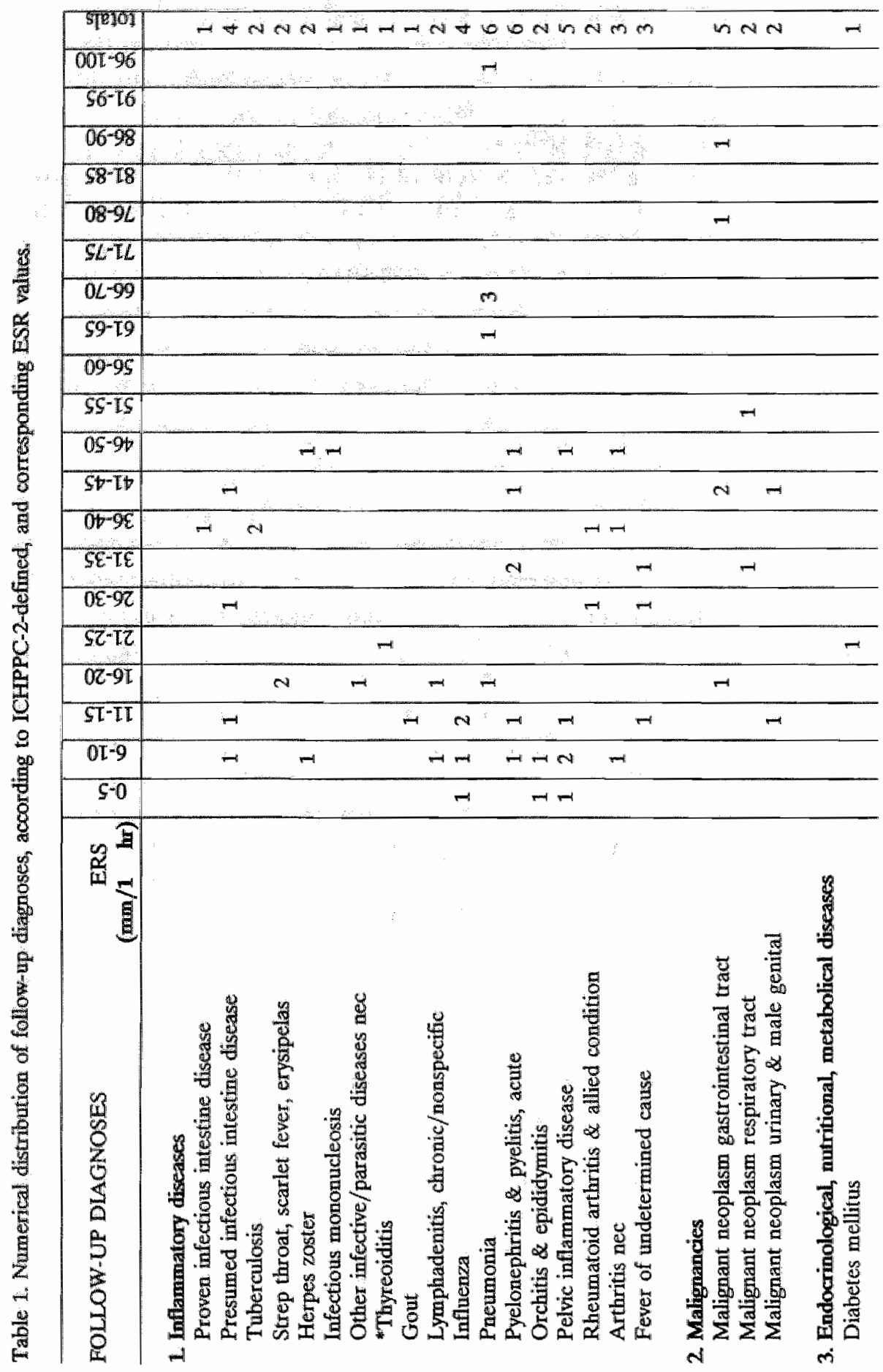




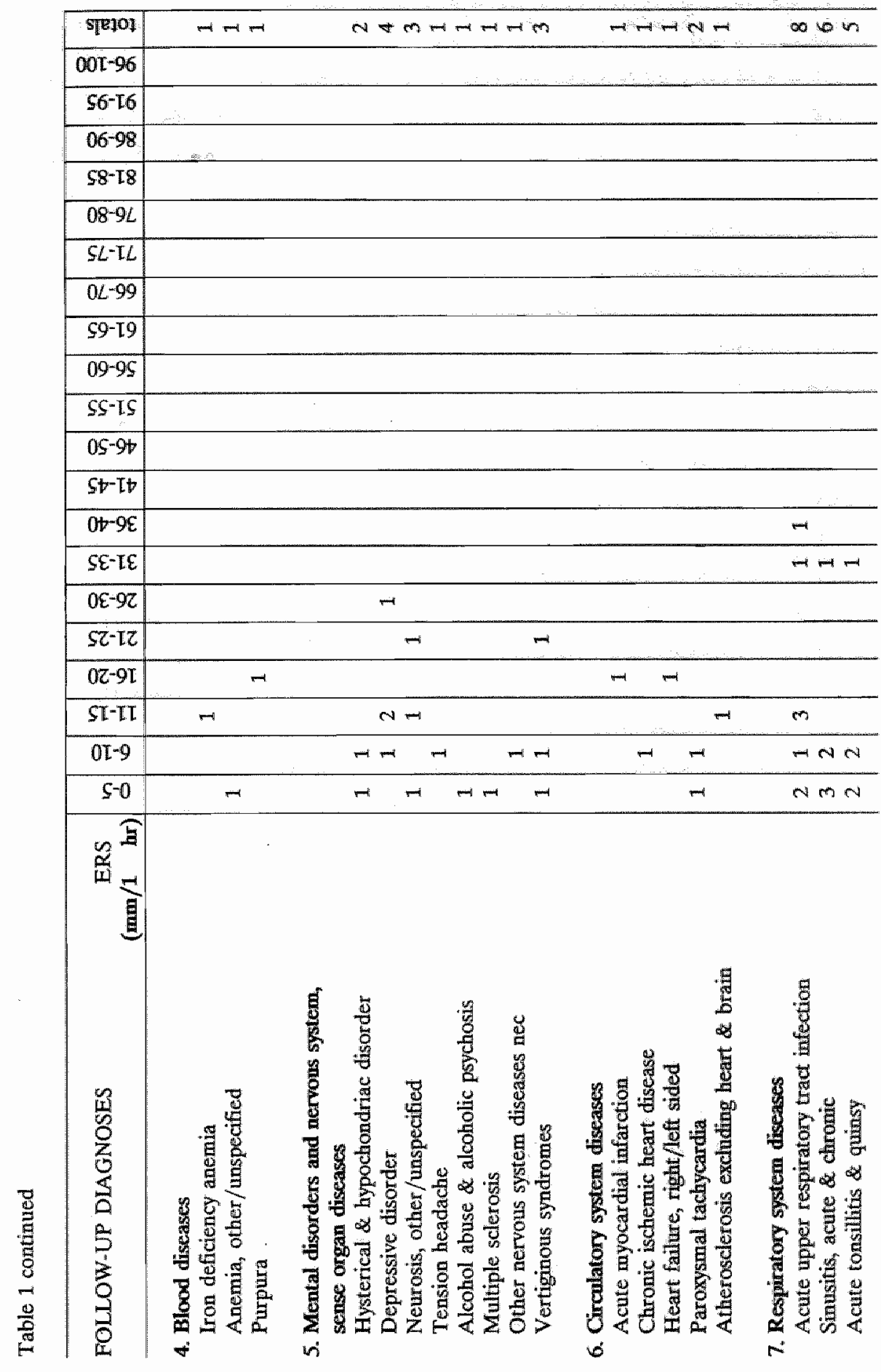




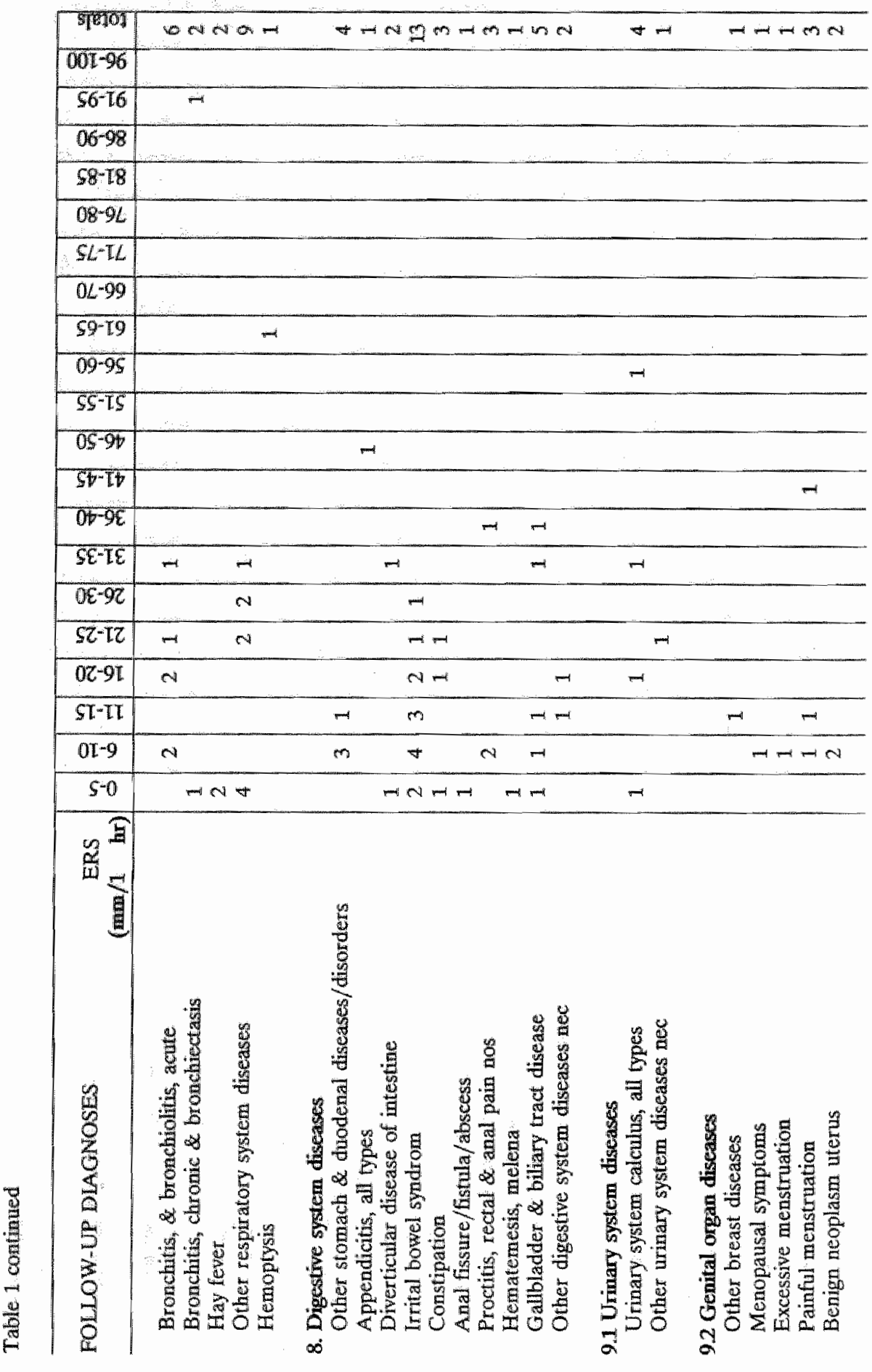




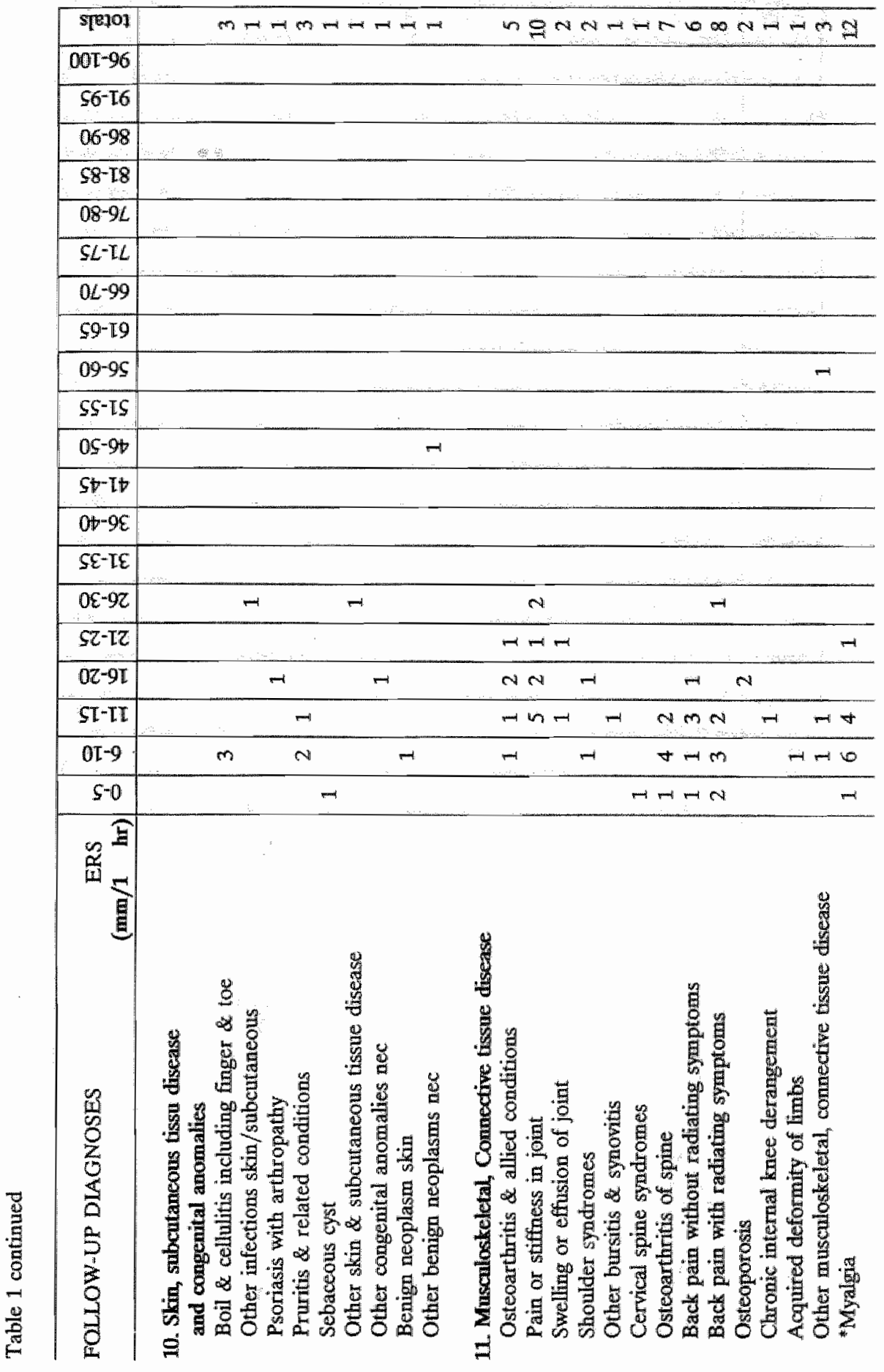




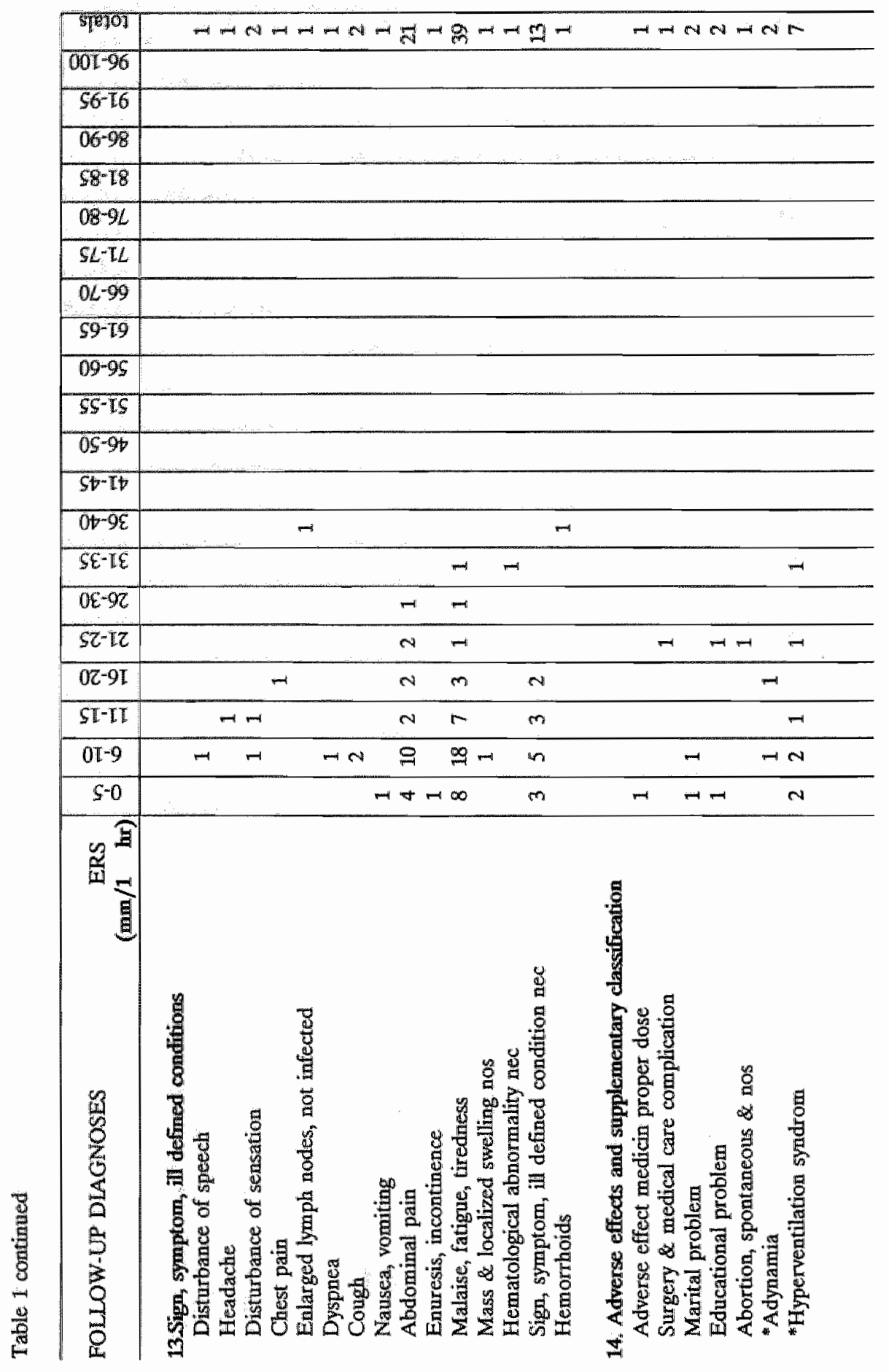




\begin{tabular}{|c|c|c|c|}
\hline spejo & in & N & \\
\hline $00 \tau-96$ & $\because$ & - & \\
\hline s6- $\mathbb{L} 6$ & & $m$ & \\
\hline $06-98$ & 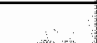 & $-i$ & \\
\hline S8-T8 & & 0 & \\
\hline $08-9 L$ & 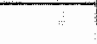 & - & . \\
\hline$S L-\mathbb{L} L$ & & 0 & \\
\hline $0<-99$ & & $m$ & \\
\hline \$9-โ9 & & $N$ & \\
\hline $09-95$ & & $N$ & \\
\hline SS-1S & & -1 & \\
\hline $0 S^{-9}$ & & $\pi$ & \\
\hline$S B-I t$ & & $\infty$ & \\
\hline $0 b^{-9 E}$ & & 9 & \\
\hline$S E-I E$ & -1 & $=$ & \\
\hline $0 \varepsilon-9 \pi$ & & $\mathbb{Z}$ & \\
\hline$S Z-I Z$ & & त) & \\
\hline $0 Z-9 T$ & & $m$ & \\
\hline SI-II & w & 8 & \\
\hline $0 \pi-9$ & $\mathrm{ru}$ & 5 & \\
\hline$s-0$ & & 5 & \\
\hline 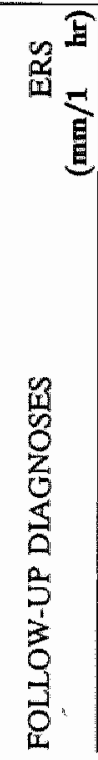 & 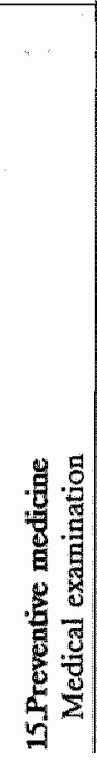 & 疍 & 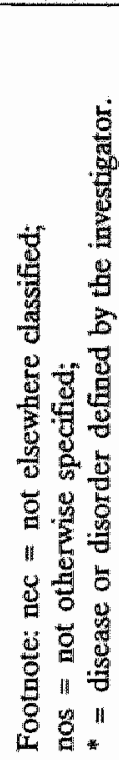 \\
\hline
\end{tabular}


considerable number of medical examinations at the patient's request, was classified separately from the category "supplementary classification". These cases concerned patients who initially presented a new complaint.

From Table 1 it can be seen that many complaints remained at the level of "signs, symptoms and ill defined conditions" (25\%), e.g. fatigue e.c.i.. Furthermore, "musculoskeletal and connective tissue diseases" (17\%), "inflammatory diseases" (14\%), "respiratory system diseases" (11\%) and "digestive system diseases" (10\%) were frequently found. The malignancy patients suffered from carcinoma of the stomach $(2 x)$, colon $(2 x)$, lung ( $2 x)$, prostate ( $1 x)$, testis (1x) and peritoneum (1x). In three of these patients metastases were also found. Several diseases were found to occur only rarely, such as one case of diabetes mellitus wich was also the only disease in the category "endocrinological, nutritional and metabolic diseases"; a single case of "congenital anomalies" (an additional lobe of the liver); and one abortion among the "pregnancy, childbirth and puerperium problems".

These findings illustrate the wide range of disorders found in the population of patients who present new complaints and for whom ESR is determined in general practice.

Since higher ESR values are normally found in children, independently of disease activity, we excluded 11 patients aged 4 to 15 , so that 341 (109 men and 232 women) entered further data analysis. The ability of ESR to discriminate between the more frequently found follow-up diagnoses and "no pathology" is illustrated by the ROC curves in the Figures 1 and 2 . The figures show sensitivity and specificity of ESR with regard to certain diseases, compared to the same qualities with regard to "pathology" and "all other diseases" using "no pathology" as a reference group. In the ROC curves the arithmetically optimal cut-off points are found at the ESR values corresponding to the highest sum of sensitivity and specificity. In choosing these upper limits of reference values, one presumes equal utilities of the test outcomes. However this situation will not always reflect clinical reality. We therefore studied the extent to which sensitivity and specificity changed after we chose their second highest sum. 
Figure 1

ROC curves, illustrating the relation between cut-off points (indicated at the bottom of the figure), sensitivity (SENS) and specificity (SPEC) of ESR with regard to "pathology", and "all other diseases" (ALL DIS), "respiratory system diseases" (RESP), and "musculoskeletal and connective tissue diseases" (MUSCSKEL), using "no pathology" as a reference group.

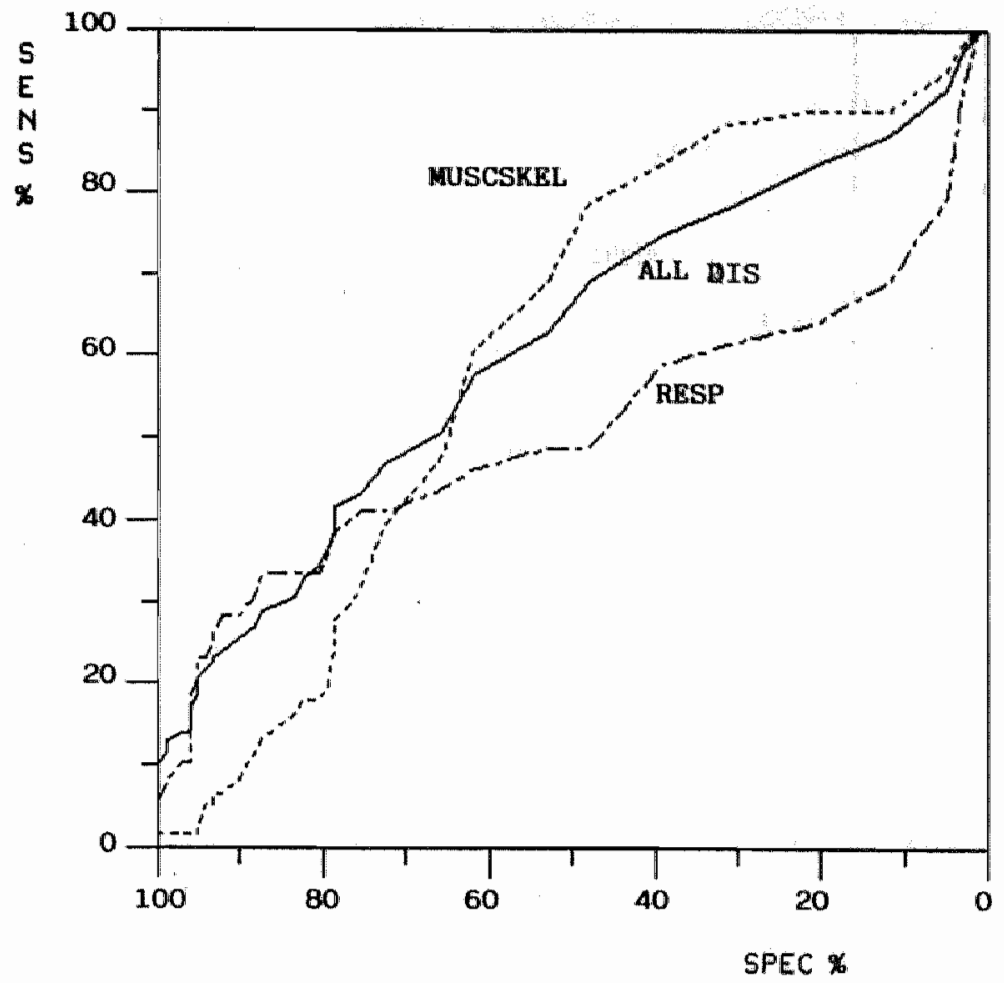

\begin{tabular}{ccccccc}
\hline $\begin{array}{l}\text { upper limits of } \\
\text { reference values } \\
\text { (cut-off points) }\end{array}$ & \multicolumn{2}{c}{ ALL DIS } & \multicolumn{2}{c}{ RESP } & \multicolumn{2}{c}{ MUSCSKEL } \\
ESR in mm/1hr & $\begin{array}{c}\text { SENS } \\
\%\end{array}$ & $\begin{array}{c}\text { SPEC } \\
\%\end{array}$ & $\begin{array}{c}\text { SENS } \\
\%\end{array}$ & $\begin{array}{c}\text { SPEC } \\
\%\end{array}$ & $\begin{array}{c}\text { sENS } \\
\%\end{array}$ & $\begin{array}{c}\text { SPEC } \\
\%\end{array}$ \\
\hline 8 & 69 & 48 & 49 & 48 & 79 & 48 \\
10 & 58 & 62 & 46 & 62 & 61 & 62 \\
12 & 47 & 73 & -41 & 73 & 39 & 73 \\
14 & 41 & 78 & 38 & 78 & 28 & 78 \\
16 & 36 & 79 & 36 & 79 & 20 & 79 \\
19 & 31 & 83 & 33 & 83 & 16 & 83 \\
24 & 24 & 92 & 28 & 92 & 1 & 92 \\
27 & 22 & 94 & 23 & 94 & 11 & 94 \\
28 & 21 & 95 & 23 & 95 & 0 & 95 \\
31 & 17 & 96 & 18 & 96 & 0 & 96 \\
\hline
\end{tabular}


Figuire 2

ROC curves, llustrating the relation between cut-off points (indicated at the bottom of the figure), sensitivity (SENS) and specificity (SPEC) of ESR with regard to pathology" and "all other diseases" (ALLDIS), malignancies (MALIO), inflammatory diseasses (INFECT) and digestive system diseases" (DICEST), using "wo pathology" as a reference group.

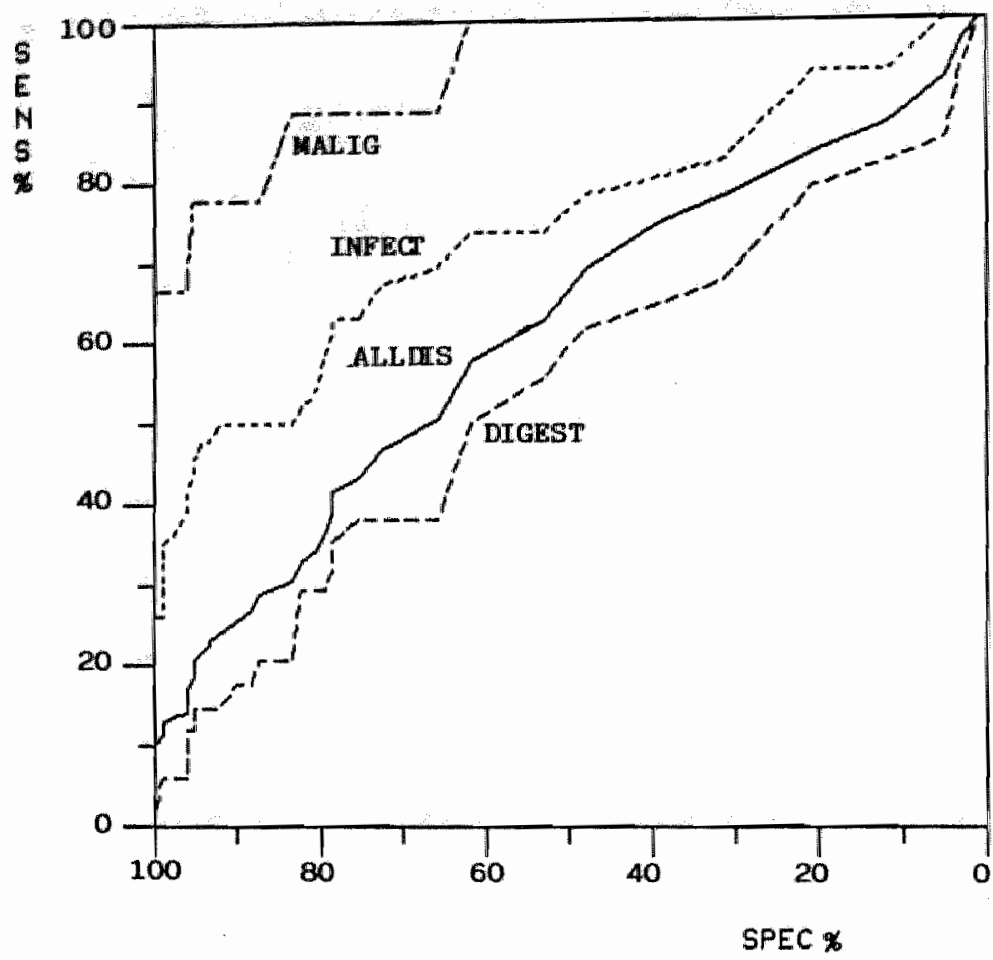

\begin{tabular}{|c|c|c|c|c|c|c|c|c|}
\hline \multirow{2}{*}{$\begin{array}{l}\text { upper limits of } \\
\text { reference values } \\
\text { (cut-off points) } \\
\text { ass in mm/thr }\end{array}$} & \multicolumn{2}{|c|}{ ALL DIS } & \multicolumn{2}{|c|}{ MALIO } & \multicolumn{2}{|c|}{ INFECT } & \multicolumn{2}{|c|}{ DroEsT } \\
\hline & $\begin{array}{c}\text { SENS } \\
\%\end{array}$ & $\begin{array}{c}\text { SPEC } \\
\% \%\end{array}$ & $\begin{array}{c}\text { SENS } \\
\%\end{array}$ & $\begin{array}{c}\text { SPEC } \\
\%\end{array}$ & $\begin{array}{c}\text { SENS } \\
\%\end{array}$ & $\begin{array}{c}\text { SPEC } \\
\%\end{array}$ & $\begin{array}{c}\text { SENS } \\
\%\end{array}$ & $\begin{array}{c}\text { SPEC } \\
\% \%\end{array}$ \\
\hline 8 & 69 & 48 & 100 & 47 & 78 & 48 & 62. & 48 \\
\hline 10 & 58 & 62 & 100 & 62 & 74 & 62 & 50 & 62 \\
\hline 12 & 47 & 73 & 89 & 72 & 67 & 73 & 38 & 73 \\
\hline 14 & 41 & 78 & 89 & 78 & 63 & 78 & 35 & 78 \\
\hline 16 & 36 & 79 & 89 & 79 & 59 & 79 & 29 & 79 \\
\hline 19 & 31 & 83 & 89 & 82 & 50 & 83 & 21 & 83 \\
\hline 24 & 24 & 92 & 78 & 91 & 50 & 92 & 15 & 92 \\
\hline 27 & 22 & 94 & 78 & 94 & 48 & 94 & 15 & 94 \\
\hline 28 & 21 & 95 & 78 & 94 & 46 & 95 & 15 & 95 \\
\hline 31 & 17 & 96 & 67 & 95 & 41 & 96 & 12 & 96 \\
\hline
\end{tabular}


Table 2 shows the sensitivity and specificity at the cut-off points in the "pathology" ROC curve where the highest and second highest sums of sensitivity and specificity were found. The corresponding prevalences and predictive values can be read from the same table. Predictive values were calculated by comparing "pathology", with "no pathology" and "all other diseases". The Odds ratios and their Cls are listed in the two final columns. Interpreting the calculations, we concluded that the upper limit of reference values corresponds to an ESR of $27 \mathrm{~mm} / 1 \mathrm{hr}$. The measures of gain in diagnostic certainty were computed at this value (see Table 3 ).

Table 2. Sensitivity (S) and specificity (T) of ESR with regard to "pathology" (= inflammatory diseases and malignancies), calculated from the ROC curves in Figure 3 at the optimal and suboptimal cul-off points (reference values) (CP). The corresponding prevalences ( $P$ ), positive predictive values (PV+) and negative predictive values (PV-) are listed as well. Odds ratios (OR) and their $95 \%$ confidence intervals (CI) can be read from the eighthth and ninth columms.

\begin{tabular}{lccccccccc}
\hline disease & $\begin{array}{c}\mathrm{CP} \\
\mathrm{mm} / \mathrm{lhr}\end{array}$ & $\begin{array}{c}\mathrm{S} \\
\%\end{array}$ & $\begin{array}{c}\mathrm{T} \\
\%\end{array}$ & $\begin{array}{c}\mathrm{S}+\mathrm{T} \\
\%\end{array}$ & $\begin{array}{c}\mathrm{P} \\
\%\end{array}$ & $\begin{array}{c}\mathrm{PV}+ \\
\%\end{array}$ & $\begin{array}{c}\mathrm{PV}- \\
\%\end{array}$ & $\mathrm{OR}$ & $95 \% \mathrm{CI}$ \\
\hline inflammatory & & & & & & & & & \\
diseases & 24 & 50 & 92 & 142 & 13 & 40 & 92 & 9.2 & $3.6-24.3$ \\
& 27 & 48 & 94 & 142 & 13 & 41 & 91 & 12.4 & $4.4-36.7$ \\
malignancies & 19 & 89 & 82 & 171 & 3 & 16 & 99 & 37.3 & $4.2-162.9$ \\
& 28 & 78 & 94 & 172 & 3 & 18 & 99 & 56.0 & $7.9-192.0$ \\
\hline \multirow{2}{*}{ "pathology" } & 24 & 55 & 92 & 146 & 16 & 46 & 91 & 11.0 & $4.4-28.1$ \\
& 27 & 53 & 94 & 147 & 16 & 48 & 91 & 15.1 & $5.5-43.2$ \\
\hline
\end{tabular}

* Odds ratios were calculated by using the original two by two crosstable, instead of the figures of sensitivity and specificity given here; the latter are rounded off.

Gender was found to be relatively important in predicting "pathology", as can be seen from Table 4 and from the ROC curves in Figure 3. From this figure we calculated optimal and suboptimal cut-off points of 12 and $14 \mathrm{~mm} / 1 \mathrm{hr}$ in men, and 28 and $27 \mathrm{~mm} / 1 \mathrm{hr}$ in women. Sensitivities and specificities at these cut-off points are given in Table 5 . Age was found to be a reasonable predictor of "pathology" in very old patients only (see Table 4). 
Table 3. Measure of gain in diagnostic certainty with regard to "pathology" (= inflammatory diseases and malignancies), based on the upper limit of references values all $\mathbb{E S R}=27 \mathrm{~mm} / 1 \mathrm{hr}(67)^{*}$.

name of measure

gain from

a positive test (\%) gain from

negative test $(\%)$ net gein in certhainty

percent gain in certainty ( $x 100 \%)$

percent maximum gaún

in certainty $(x 100 \%)$

$\begin{array}{rr}32 & 7 \\ 200 & 8 \\ 38 & 44\end{array}$

* The corresponding prevalences and predictive values are listed in Figure 2. Definitions: net gain in certainty from a positive test $=$ pos $\mathrm{PV}-\mathbb{P}_{\text {; }}$ net gain in certainty from a negative test $=$ negPV $-(100-P)$; percent gaim in certainty from a positiwe test $=($ posPV $-\mathrm{P}) / \mathbf{P}_{\text {; }}$ percent gain in certainty from a negative test $=[$ megPV $-(100-P)] /(100-P)$; percent maximum gain in certainty from a positive test $=($ posPV $-P) /(100-P)$; percent maximum gain in certainty from a negative test $=[n e g P V-(100-\mathbb{P})] / P$. $\mathbb{P}=$ prevalence, $S=$ sensitivity, $T=$ specificity, pos $P V=$ positive predictive value, negPV = negative predictive value.

Table 4. Frequency distribution of "pathology" (= inflammatory diseases and malignancies) and all other diseases except "pathology", in relation to age and gender $(\mathrm{N}=341)$.

\begin{tabular}{|c|c|c|c|c|c|c|c|c|c|c|}
\hline \multirow{3}{*}{$\begin{array}{l}\text { age } \\
\text { (years) }\end{array}$} & \multicolumn{4}{|c|}{ "patloology" } & \multicolumn{4}{|c|}{ all other diseases } & \multicolumn{2}{|c|}{ totals } \\
\hline & \multicolumn{2}{|c|}{ men } & \multicolumn{2}{|c|}{ women } & \multicolumn{2}{|c|}{ men } & \multicolumn{2}{|c|}{ women } & & \\
\hline & $\mathrm{N}$ & $(\%)$ & $\mathrm{N}$ & $(\%)$ & $\mathrm{N}$ & $(\%)$ & $\mathrm{N}$ & $(\%)$ & $N$ & $(\%)$ \\
\hline $15-30$ & 3 & (4) & 7 & (10) & 16 & (24) & 42 & (62) & 68 & $(100)$ \\
\hline $31-40$ & 4 & (6) & 6 & (10) & 19 & (31) & 33 & $(53)$ & 62 & $(100)$ \\
\hline $41-50$ & 3 & (7) & 3 & $(7)$ & 16 & (35) & 23 & (51) & 45 & $(100)$ \\
\hline $51-60$ & 3 & (5) & 4 & $(6)$ & 17 & $(27)$ & 39 & (62) & 63 & $(100)$ \\
\hline $61-70$ & 3 & (6) & 5 & $(10)$ & 111. & (23) & 30 & (61) & 49 & $(100)$ \\
\hline $71-80$ & 6 & (14) & 3 & $(7)$ & 7 & (16) & 27 & (63) & 43 & $(100)$ \\
\hline $81-87$ & 0 & (0) & 5 & $(46)$ & 3 & $(27)$ & 3 & $(27)$ & 11 & $(100)$ \\
\hline otal & & 6 & 33 & 10 & 89 & 26 & 197 & 58 & 341 & 100 \\
\hline
\end{tabular}

The results are illustrated even better by the logistic regression

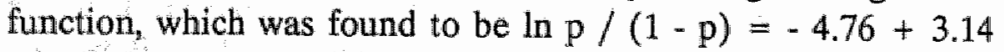
$x \log E S R-0.86 \times$ gender $(p=$ probability of "pathology"; gender $0=$ malle, $1=$ female). The $95 \%$ CIs of the coefficients of $\operatorname{logESR}$ and gender were calculated as $2.15-4.12$ and $-1.54-$ -0.19 , respectively. ESR was transformed to $\operatorname{logESR}$ because of its skew distribution; most of the values found were low. Age 
did not appear in this equation. The regression function also illustrates the ability of ESR to predict "pathology", independent of the choice of cut-off point. The probability of "pathology", given the gender and several ESR intervals, were calculated from the logistic regression function and are given in Table 6.

Table 5. Sensitivity (S) and specificity (T) (\%) of ESR with regard to "pathology" (= inflammatory diseases and malignancies), calculated from the ROC curves in Figure 4 at the optimal and suboptimal cutoff points.

\begin{tabular}{llcccc}
\hline $\begin{array}{l}\text { cut-off } \\
\text { point }(\mathrm{mm} / 1 \mathrm{hr})\end{array}$ & $\mathrm{S}$ & $\mathrm{T}$ & $\begin{array}{c}\text { cut-off } \\
\text { point }(\mathrm{mm} / 1 \mathrm{hr})\end{array}$ & $\mathrm{S}^{\text {women }}$ & $\mathrm{T}$ \\
\hline 12 & 73 & 84 & 28 & 55 & 95 \\
14 & 68 & 88 & 24 & 58 & 91 \\
\hline
\end{tabular}

Table 6. Probability of "pathology" (= inflammatory diseases and malignan* cies) (\%), given gender and ESR. Numbers of patients are listed in the last column $(\mathrm{N}=341)$.

\begin{tabular}{cccr}
\hline ESR (mm/1 hr) & male & female & N \\
\hline $0-10$ & 16 & 8 & 163 \\
$10-20$ & 33 & 17 & 97 \\
$20-30$ & 46 & 27 & 32 \\
$30-40$ & 56 & 36 & 25 \\
$40-60$ & & & \\
$60-80$ & 69 & 50 & 15 \\
$80-100$ & 77 & 58 & 6 \\
\hline
\end{tabular}

\section{Discussion}

ESR was found to be a useful test for GPs in diagnosing patients who are suspected of having inflammatory diseases or malignancies. In these cases, the arythmically optimal upper limit of reference values was situated around $12 \mathrm{~mm} / 1 \mathrm{hr}$ in men and $28 \mathrm{~mm} / 1 \mathrm{hr}$ in women. Using the overall limit of 27 $\mathrm{mm} / 1 \mathrm{hr}$, probabilities of having "pathology" are twice as high in men as in women. ESR needs no further correction for age.

The ROC curves demonstrated that ESR had a reasonably high sensitivity and specificity with respect to inflammatory diseases and malignancies only (see Figures 1 and 2). 


\section{Figure 3}

ROC curves, illustrating the relation between cut-off points (indicated at the bottom of the figure), sensitivity (SENS) and specificity (SPEC) of ESR with regard to "pathology" and "all other diseases" in males (I) and fernales (II), as well as "pathology" ( = inflammatory diseases and malignancies) in males (III) and females (IV), using "no pathology" as a reference group.

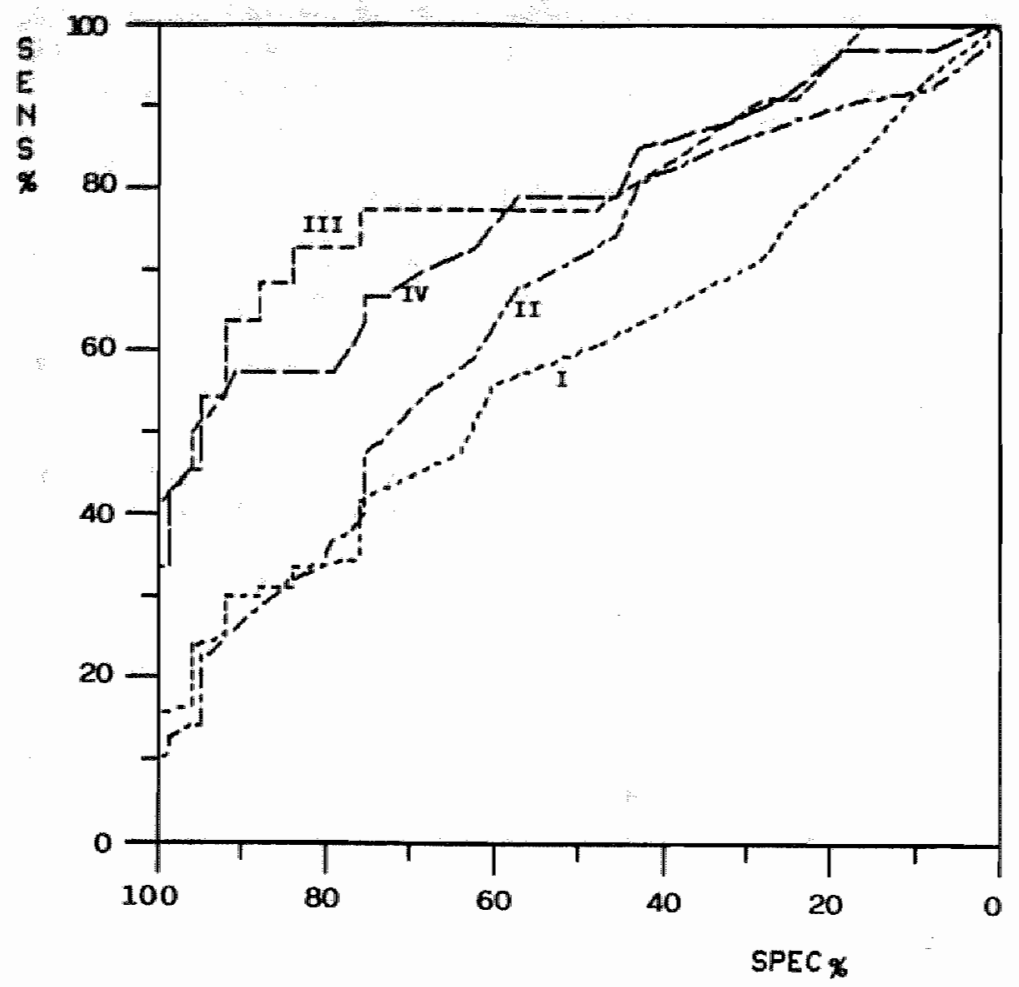

\begin{tabular}{|c|c|c|c|c|c|c|c|c|}
\hline \multirow{2}{*}{$\begin{array}{l}\text { upper limits of } \\
\text { reference values } \\
\text { (cut-off points) } \\
\text { ESR in mm/1hr }\end{array}$} & \multicolumn{2}{|c|}{$\mathbb{I}$} & \multicolumn{2}{|c|}{ III } & \multicolumn{2}{|c|}{ III } & \multicolumn{2}{|c|}{ IV } \\
\hline & $\begin{array}{c}\text { SENS } \\
\%\end{array}$ & $\begin{array}{c}\text { SPEC } \\
\%\end{array}$ & $\begin{array}{c}\text { SENS } \\
\text { Or }\end{array}$ & $\begin{array}{c}\text { SPEC } \\
\%\end{array}$ & $\begin{array}{c}\text { SENS } \\
\%\end{array}$ & $\begin{array}{c}\text { SPEC } \\
\%\end{array}$ & $\begin{array}{c}\text { SENS } \\
\%\end{array}$ & $\begin{array}{c}\text { SPEC } \\
\% \%\end{array}$ \\
\hline 8 & 48 & 64 & 81 & 43 & 77 & 64 & 85 & 43 \\
\hline $10[11]$ & 39 & 76 & 68 & 57 & {$[73]$} & {$[76]$} & 79 & 57 \\
\hline 12 & 33 & 84 & 54 & 69 & 73 & 84 & 70 & 69 \\
\hline 14 & 31 & 88 & 47 & 75 & 68 & 88 & 67 & 75 \\
\hline 16 & 30 & 92 & 40 & 75 & 64 & 92 & 64 & 75 \\
\hline 19 & 25 & 92 & 34 & 81 & 55 & 92 & 58 & 81 \\
\hline $24[20]$ & values & available & 26 & 91 & {$[50]$} & {$[96]$} & 58 & 91 \\
\hline $27[25]$ & [19] & {$[96]$} & 23 & 94 & no values & available & 55 & 94 \\
\hline 28 & 17 & 96 & 23 & 95 & 45 & 96 & 55 & 95 \\
\hline 31 & 15 & 100 & 18 & 95 & 41 & 100 & 48 & 95 \\
\hline
\end{tabular}


In comparison to the reference group, $\mathrm{ROC}$ curves for the other diseases generally showed to be far less discriminatory. Because of the numerically minor, yet clinically important contribution of malignancies, the "pathology" ROC curve almost equalled the inflanmatory diseases curve. Therefore we did not include the "pathology" curve (inflammatory diseases and malignancies) in Figures 1 and 2.

Whereas ESR was most frequently performed in patients suffering from minor and spontaneously resolving problems, the GPs apparently used the test for ruling out rather than ruling in disease (76). Consequently, the false negative rate of ESR should preferably be low (77). Unlike the situation with respect to specificity, a reasonable sensitivity of ESR was found only with respect to malignancies and at the suboptimal (lower) cutoff point. However, at higher cut-off points, specificity improved with regard to malignancies as well as inflammatory diseases (see Table 2). In view of the relatively low prevalence of "pathology" in general practice, a good specificity will be useful. This dilemma was partly solved by taking the predictive values into consideration (see Table 2). Whereas negative predictive values of ESR hardly changed after altering the cut-off points, positive predictive values consistently improved at the higher corresponding ESR values. We therefore conclude that the upper limit of reference values of ESR in diagnosing "pathology" lies around $27 \mathrm{~mm} / 1 \mathrm{hr}$. This conclusion is supported by the corresponding Odds ratios, these being the joint parameters of the likelihood ratios for a positive and negative test result (see Table 2). The Odds ratios also illustrate the much greater discriminating ability of ESR with regard to malignancies, as compared to inflammatory diseases. Within the malignancy patients ESR values were mostly high (see Table 1). As for the reference values, our study did not investigate the possible significance of intra-individual variations. It should be kept in mind that whenever measured ESR values are considered to be doubtful with respect to a diagnostic conclusion, these values should be measured again $(78,79)$.

The relation between prevalence and predictive values may be considered important in quantifying the change in the clinical estimation of a patient's chance of having "pathology". The net ("real") gain in diagnostic certainty in case of a positive test. 
result was calculated by subtracting prevalence from the positive predictive value (32\%, see Table 3). The percent gain in diagnostic certainty from a positive test was found to be $200 \%$. This means that an ESR of $27 \mathrm{~mm} / 1 \mathrm{hr}$ or more will treble the certainty of a correct diagnosis of "pathology", despite the low positive predictive value. Futhermore, this $200 \%$ was found to be $38 \%$ of the theoretical maximum possible gain. These figures contrast with the relatively poor measures of gain from a negative test. The fairly high negative predictive value looks low in comparison to the prior probability of not having "pathology" (91\% versus $84 \%$ ).

Whereas at the $27 \mathrm{~mm}$ cut-off point specificity and measures of gain in diagnostic certainty from a positive test were found to be higher than sensitivity and measures of gain in diagnostic certainty from a negative test, an ESR above $27 \mathrm{~mm} / 1 \mathrm{hr}$ may be considered a better predictor of "pathology" than an ESR under $27 \mathrm{~mm} / 1 \mathrm{hr}$ is of "no pathology".

From the logistic regression function it can be seen that age is unimportant in predicting "pathology", independent of the chosen cut-off point. We also found that the frequency distribution of "pathology" hardly changed in relation to age (see Table 4). Hence, an intercollinearity between age and gender cannot be held responsible for our findings. The influence of gender is best illustrated by its logistic regression coefficient $(0.86$, which is equivalent to an Odds ratio of 2.4) and by the figures in Table 6. The latter show the increasing probability of having "pathology" with higher ESR. These probabilities are consistently higher for men than for women, which is partly explained by the higher prevalence of "pathology" in men (see Table 4). The largest differences in probability were found at ESRs between 10 and $30 \mathrm{~mm}$.

Among the participating GPs only one reported using an upper limit of reference values above $20 \mathrm{~mm} / 1 \mathrm{hr}$, at least in elderly patients. Since several reference laboratories advise the use of ESR reference values up to $10 \mathrm{~mm} / 1 \mathrm{hr}$, we also calculated our discriminating ability figures at this limit. The results (see Table 7) show a considerable increase of sensitivity and a decrease in specificity. Hence, for our study, using an upper limit of 10 
$\mathrm{mm} / 1 \mathrm{hr}$ would mean that ESR becomes better in ruling out rather than ruling in "pathology".

Table 7 also shows a comparison between our conclusions and those of a recent study from Israell (36). Despite the almost equal study population sizes and the nearly identical upper limits of reference values, Stayer found a lower specificity and better sensitivity. It is possible that serious diseases were more frequent in his study population. However, his report does not clearly differentiate between "disease" and "no disease", and the population was studied retrospectively.

Finally, Table 7 shows the $95 \%$ Cls of the discriminating ability figures at our $27 \mathrm{~mm} / 1 \mathrm{hr}$ cut-off point (67). The relatively low number of patients suffering from "pathology" is reflected in higher CIs around sensitivity and positive predictive values.

Table 7. Discriminating ability figures and $95 \%$ confidence intervals (CI) at the optimal cut-off point of $\mathbb{E S R}(27 \mathrm{~mm} / 1 \mathrm{hr}$ ), according to Dinant $(\mathrm{N}=341)$, and in comparison to local hospital $(\mathrm{LH})$ reference values $(10 \mathrm{~mm} / 1 \mathrm{hr})$ applied to our data. The results from Stayer (36) are listed in the final column $(N=368)$.

\begin{tabular}{lcccc}
\hline & & Dinant & LH & Stayer \\
cut-off point $(\mathrm{mm} / 1 \mathrm{hr})$ & 27 & $(95 \% \mathrm{Cl})$ & 10 & 30 \\
\hline sensitivity $(\%)$ & 53 & $(40-66)$ & 78 & 61 \\
specificity $(\%)$ & 94 & $(89-99)$ & 62 & 76 \\
positive predictive value $(\%)$ & 48 & $(35-61)$ & 52 & 46 \\
negative predictive value $(\%)$ & 91 & $(88-94)$ & 84 & 85 \\
\hline
\end{tabular}

Several investigators have demonstrated a clear relation between age and upper limits of reference values. From the figures in Table 8 we calculated that, according to Böttiger, the $27 \mathrm{~mm} / 1$ $\mathrm{hr}$ cut-off point applies only to women who are almost 50 years old, whereas Miller claims that it corresponds to women aged 44 or men aged 54. Lewis considers an ESR of $27 \mathrm{~mm} / 1 \mathrm{hr}$ to be abnormal at any age in men or women. The results of our questionnaire showed that three GPs did not regard age as relevant with respect to reference values of ESR, whereas one GP mentioned neither age nor gender. 
Table 8. Upper limits of normal ESR, according to prior studies.

\begin{tabular}{lccc}
\hline awthor & age (years) & $\begin{array}{c}\text { ESR }(\mathrm{mm} / 1 \mathrm{hr}) \text {, in } \\
\text { males }\end{array}$ \\
\hline Lewalles (51) & $17-50$ & 10 & 12 \\
& $51-60$ & 12 & 19 \\
Bottiger (6) & $>60$ & 14 & 20 \\
Miller (9) & $<50$ & 15 & 25 \\
& $>50$ & 20 & 30 \\
& & age/2 (age +10$) / 2$
\end{tabular}

The performance of ESR is cheap, relatively simple and easy to incorporate in day to day general practice. However, a false negative or positive interpretation of ESR may result in potentially harmful policies for the patient. Studying the discriminating ability of ESR is therefore clinically relevant. According to other investigators, the discriminating ability of diagnostic technologies is best evaluated by measuring the therapeutic impact of the test results (80). We met this criterion to some extent, because malignancies and inflammatory diseases will most often lead to therapeutic actions, whereas "no pathology", as defined in our study, justifies a wait-and-see policy. Others have preferred to evaluate a diagnostic test by means of medical decision analysis (81,82). However, clinical utilities and benefitto-cost ratios are difficult to assess and require further exploration (83).

In our study, each GP performed ESR nearly twice a week. This frequency approximates what we had estimated beforehand, and makes it less likely that bias by indication or dilution of the study population occurred. Futhermore, because we deliberately did not define inclusion criteria in advance, nor asked the GPs to exclude children and tourists from the study, we obtained clear information on the composition of the indicated population.

Since the index ("pathology") and control ("no pathology") groups both derived from the indicated population, our results may be considered applicable to everyday general practice. The number of patients in our study can be seen as a compromise between desirability and feasibility. Whereas a bigger study 
population could have reduced the CIs of the discriminating ability figures (see Table 7), the inevitably prolonged study period would have diminished the amount of attention the GPs paid to the study and therefore possibly result in bias by indication. Similar compromises were made in the follow-up procedure. A panel of clinicians might have been able to formulate more accurate follow-up diagnoses. However, such a panel would have deterred patients from entering the study, which, again, could result in bias by indication. Furthermore, a followup period of more than 3 months could have enabled the investigator to formulate even more appropriate diagnoses, but at the same time it would have increased the risk of recall bias and intercurrent new pathology. Finally, not knowing what kind of pathology is to be expected makes it far more difficult to organize a set of standardized follow-up investigations. Such investigations would also be far too invasive, and carry a considerably high rate of false-positive, clinically irrelevant "standard-findings" (84). The limited study and follow-up periods partly account for the minor number of patients with malignancies in the study, and for possibly not detecting each false negative diagnosis. Hence, our main conclusions concentrate on ESR test characteristics for "pathology" as a combination of malignancies and inflammatory diseases.

These dilemmas concerning the subjects of sample size and gold standard show up especially in general practice studies, in which scientific research may easily lead to a considerable interference with the GP's workup routine. However, our study illustrates that these problems can be solved by cooperating with enthusiastic GPs.

\section{References}

1 Kelly $\mathrm{MH}$, Barber $\mathrm{JH}$. Use of laboratory services and communication of results to patients in an urban practice: an audit. $J R$ Coll Gen Pract 1988; 38: 64-6

2 Pop P, Winkens RAG. A diagnostic centre for general practitioners" results of individual feedback on diagnostic actions. J R Coll Gen Pract 1989; 39: 507.8

3 Knottnerus JA, Kerkhof PD, Schouten LJ. De hoge bezinking. Een literatuuroverzicht, aangevuld met enkele onderzoekgegevens. Huisans en Wetenschap 1984; 27: 123-9.

4 Birthwhistle RV. Diagnostic testing in family practice. Car Fam Physician $1988 ; 34: 327-31$ 
5 Belsey $R_{\text {, Speicher }} \mathrm{CE}$, Winkelman JW, Bronfarber PJ. Afwijkende laboratoriumescultaten. Pathent Care [Dutch edition] 1989, 16: 16-37.

6 Bothiger $L E$ syedberg CA. Normal erythrocyte sedimentation rate and age. Br Med J 1967; 255: 85-7

7 Corberand $J_{s}$ Latharrague $F$, Fillola $G$. Blood cell parameters do not change during physiological human ageing. Gerontology $1987: 33: 72-6$

8 Froom $P$, Margaliot $S_{\text {, Caine }} Y$, Benbassat I. Sugnuficance of erythrocyte sedimentation rate in young adults. Am I Chn Pathol 1984, 82:198-200.

9 Miller cs. Simple rule for calculating normal erythrocyte sedimentation rate: Br Med I 1983:286:266

10 Nayba S. Normal variation un erythrocyte sedimentation rate in males over 50 years old. Scand I Prim Healh Care 1987; 5: 5-8

11 Pincherle $G$, Shanks $\mathbb{J}$. Value of the erythrocyte sedimentation rate as a screening test. BrJ Prev Soc Med 1967; 21: 133-6

12 Pop P. Laboratoriumdiagnostick bij de bejaarde patient. The Practitioner [Dutch edition] 1989: 6: 173-9.

13 Schapera R. The significance of erythrocyte sedimentation rates in aged persons: $S$.Afr Med J 1982; 62:394-6

14 Sharland DE. Erythrocyte sedimentation rate: the normal range in the elderly. $J$ Am Geriat Soc 1980; 28: $346-8$

15 Sox HC, Liang MH. The erythroote sedimentation rate. Guidelines for rational use. Am Intern Med 1986; 104:515-23.

16. Wersch JWJ Van. Moeten laboratoriumwaarden bij ouderen anders worden geinterpreteerd? Vademecum Penmanente Nascholing Huisantsen 1989; 7: no 34.

17 Zauber NP, Zauber AG. Hematologic data of healthy very old people. JAMA 1987; 257: 2181-4

18 Asbjornsen $G$. Serum copper compared to erythrocyte sedimentation rate as indicator of disease activity in Hodgkin's disease. Scand J Haemarol 1979; 22: $193-6$

19 Biller J, Asconape J, Weinblatt ME, Toole JF. Temporal arteritis associated with normal sedimentation rate. JAMLA 1982; 247; 486-7

20 Boyd RV, Hoffbrand BI. Erythrocyte sedimentation rate in elderly hospital in-patients. Br Med J 1966; 252: 901-2

21 Coffman DA. Estimating the ESR in general practice. Update 1989; 39: 154-5

22. Crawford J, Eye-Boland MK, Cohen HJ. Clinical utility of erythronyte sedimentation rate and plasma protein analysis in the elderly. A $1 \mathrm{~m} / \mathrm{Med}$ $1987 ; 82: 239-46$

23 Iijk EA Van. Appendicitis in de graviditeit. Patient Care [Dutch edition] 1988; 15: 23.

24 Gambert SR, Csuka ME, Duthie EH, Tiegs R. Interpretation of laboratory results in the elderly. Postgrad Med 1982; $72: 147-52$

25 Gibson IIJM. The value of the erythrocyte rate in the aged. Gerontol $\mathrm{Clm}$ $1972 ; 14: 185-90$

26 Criffiths $\mathbb{R}^{2}$, Good WR, Watson NP, O'Donnell HF, Shakespeare JM. Normal arythrocyte sedimentation rate in the elderly. Br Med J 1984; 289: $724-5$

27 Hoeven I van der. Evaluation of a programme of periodic medical examination [Thesis]. Nijmegen: Katholieke Universiteit Nijmegen, 1971: 59-61

28 Kenny MW, Worthington DJ, Stuart J, Davis AJ, Farr M, Davey PG, et al. Efficiency of haematological screening tests for detecting disease. Chin $L a b$ Haematol 1981; $3: 299-305$ 
29 Knuth UA, Mublenstedt D, Schneider HPG. Zur effectiwinet won Kurzwellenbelastungstests, Blutkoerperchensenkungsgeschwindigkeit und Leukozytenzahl bei der Diagmose der subakuten Adnexitus [Summary in English]. Gebunthilfe frowenhailkd 1982;42:52-5

30 Liljestrand A, Olhagen B. Persistently high erythrocyte sedimentation rate. Aci Med Scand 1955; 151: 425-39

31 Peyman MA. The effect of malignant disease on the erythrocyte sedimenta tion rate. Br J Concer 1962; $16: 56-71$

32. Rafnsson $V$, Bengtsison $C_{y}$ Lennartsson J, Lindquist $O$, Nappa $H$, Tibblin $E$. Erythrocyte sedimentation rate in a population sample of women with special reference to its clinical and prognostic significance. Acta Med Scand 1979; 206: 207-14

33 Rai GS. Erythrocyte sedimentation rate and disease in the elderly. $J A m$ Geriat Soc $1979 ; 27: 382-3$

34 Salter RH. Gastrointestimal malignancy and the ESR. Practitioner 1981; 225: $566-8$

35 Shumuely $\mathrm{H}$, Shapira $\mathrm{G}$, Fridental R, Rosenfeld JB. Erythrocyte sedimentation rate in patients with multiple myeloma, infective endocarditis and hypernephroma. Fam Physician 1989; 17: 76

36 Stayer $M$, Stuloy $A$, Reiss $S$. The erythrocyte sedimentation rate (ESR) as a marker and predictor of disease. Fam Physician 1989; 17: 80

37 Wasserman $M$, Levimstein $M$, Keller $E_{\text {, Lee }}$, Yoshikawa $T$. Utility of fever, white blood cells, and differential count in predicting bacterial infections in the elderly. I Am Geriatr Soc 1989; 37; $537-43$

38. Wilimas J, Thompson E, Simith KL. Value of serum copper levels and erythrocyte sedimentation rates as indicators of disease activity in childrem with Hodgkin's disease. Cancer 1978; 42:1929-35

39 Wright WB. Geriatric diagnosis, a survey. Gerontol Clin 1969; 11: 75-91

40 Wyler DJ. Diagnostic implications of markedly elevated erythrocyte sedimentation rate: a re-evaluation. South Med J 1977; 70: 1428-30.

41 Zacharski LR, Kyle RA. Significance of extreme elevation of erythrocyte sedimentation rate. JAMA $1967 ; 202: 264-6$

42 Vaandrager K. De betekenis van de bloedbezinkingssnelheld in de praktijk [Thesis]: Groningen: Schut \& Van der Molen, 1946 [summary in English]

43 Fraser CG, Fogarty Y. Interpreting laboratory results. Br Med J 1989; 298: $1659-60$

44 Mallya RK, Mace BEW, Beer FC de, Pepys MB. Diurnal variation of erythrocyte sedimentation rate related to feeding. Lancet $1982 ;$ i: 389.90

45 Bottiger LE. Is the ESR outdated? [Letter]. Lancet 1982; 1: 571

46. Palmblad J, Karlsson $\mathrm{CG}_{4}$ Levi $\mathrm{L}_{4}$ Lidberg $\mathrm{L}$. The erythrocyte sedimentation rate and stress. Acta Med Scand 1979; 205: 517-20

47 Tibblin $G$, Wilhelmsen $L$, Werko $L$ Risk factors for myocardial infarction and death due to ischemic heart disease and other causes. Am I Cardiol $1975 ; 35: 514-22$

48 Dieijen-Visser MP van, Go PMNYH, Munting JDK, Brombacher PJ. The value of laboratory investigations in patients suspected of acute appendicitis. [poster]. Pont a Mousson: 7th Collegue International, 3-7 Oktober 1988. Ann Biol Clin 1988; 46:

49 Harkness $\mathrm{J}$. The viscosity of human blood plasma; its measurement in health and disease. Biorheology 1971; 8: 171-93

50 Editorial. The ESR, an outdlated test? Lancet 1982; i: 377

51 Lewis SM. Erythrocyte sedimentation rate and plasma viscosity. Broadsheet: Association of Clinical Pathologists 1980; 94: 1-7 
52 3toneham M, Wisniewglki T. Towards earlier diagnosis of colorectal malignancy. Practitioner 198; 232: $1309-13$

53 Stuart 3, Kenny MW. Simple rule for calculating normal erythrocyte sedimentation rate [Letter]. Br Med I $1983 ; 286: 557$

54 Stuart J, Lewis SM. Monitoring the acute phase response. Br Med J I988; 297: 1143-4

55 Hlatky MA. Evaluation of diagnostic tests./Chonic Dis 1986, 39, 357-8

56 Kriotnerus JA, Knipschild $\mathrm{PG}_{4}$ Sturmans $\mathrm{F}$. Symptoms and selection bias: the influence of selection towards specialists care on the relationship berween symptoms and diagnoses. Theoretical Medicine 1989; 10:67-81

57 Nierenberg. A, Feinstein AR. How to evaluate a diagnostic marker test. JAMA 1988; 259: 1699-702

58 Ransohoff DF, Feinstein AR. Problems of spectrum and bias in evaluating the efficacy of diagnostic tests. New Engl J Med 1978; 299:926-30

59 Dixon T. Diagnostic testing the problem of prevalence. Can Fam Physician $1988 ; 34: 243-4$

60 Komaroft AL. The variability and inaccuracy of medical data. Proc of the IEEE 1979;67:1196-207

61 Dinant GJ, Knottnerus JA, Wersch JWJ van, Aubel PGJ van. Reliability of ESR in general practice. Scand J Prim Heath Care 1989; 7: 231-5

62 Dinant GJ, Knottnerus JA, Wersch JWJ wan. Blood sample transportation and the erythrocyte sedimentation trate. [Letter] $J$ Coll Gen Pract 1989; 39: 302

63 International Committee for standardization in haematology. Recommendation for measurement of erythrocyte sedimentation rate of human blood. Ant I Clin Pathol 1977; 68: 505-7

64 Stott NCH. Desktop laboratory technology in general practice. Br Med J 1989; 299: 579-80

65 Classification Committee of WONCA. ICHPPC-2-defined. Inclusion criteria for the use of the nubrics of the Intemational Chassification of Health ProbLems in Primary Care. Oxford: Oxford University Press, 1983

66 Meijer JS, Brouwer $\mathrm{H}_{4}$ Lamberts $\mathrm{H}$. De ICPC als diagnostische classificatie II [Synopsis in english]. Huisarts en Wetenschap 1987; 30: 44-8, 60

67 Gerhardt W, Keller H. Evaluation of test data from clinical studies. Sicand $J$ Clin Lab Invest 1985. Supplement

68 Krieg AF, Beck JR, Bongiovanni MB. The Dot Plot. JAMA 1988; 260: 3309-12

69 Godfry $\mathrm{K}$. Statistics in practice. Comparing the means of several groups. New Eng J Med 1985; 313: 1450-6

70 Feinstein AR. Cinical epidemiology. The architecture of clinical research, Philadelphia: WB Saunders Company, 1985

71 Knottinerus JA, Volovics A. Het onderscheidend vermogen van diagnostische tests [abstract in English]. Huisarts en Wetenschap 1989; 32: 338-46

72 Gustafison TL. True Epistat. Manual Texas, Richardson: Epistat Services, 1987

73 Dixon WJ. BMDP Siatistical Manual. California, Berkeley: University of California Press, 1981

74. Connell FA, Koepsell TD. Measures of gain in certainty from a diagnostic test. Am J Epidemiol, 1985; 121: 744-53

75 Sawrey SA. All other signs, symptoms and ill defined conditions. N Z Fam Physician 1988; 15: 46

76 Hobday PJ, Price J. Direct access to hospital investigative facilities: threats and opportunitues. $J$ R Coll Gen Pract 1989; 39: 135-7 
77 Griner PF, Glaser RJ. Sounding boards. Misuse of laboratory tests and diagnostic procedures. Now Eng J Med 1982; 307. 1336-9.

78 Costongs GMPJ. Intra-individwal wariations and critical differences of chinical laboratory paraneters. Voerendaal: Schrijen-Lipperti, 1984 [thesis].

79 Fraser CG, Fogarty Y. Interpreting laboratory results. Analytical and bionogical variation must be taken into account. Br Med J 1989; 298: 1659. 60.

80 Guyatt GH, Tugwell PX, Feeny $\mathrm{DH}_{x}$ Drummond MF, Haynes RB. The role of before-after studies of therapeutic impact in the evaluation of diagnostic technologies. I Chron Dis 1988; 39: 295-304

81 Alperovitch $\mathrm{A}$. Controlled assessment of diagnostic techniques: methodologicall problems. Effective Health Care 1983; 1: 187-90

82 Cabe JB Mc. Decision making in laboratory test studies. Emergency Medicine Clinics of North America 1986; 4: 1-14

83 Boyd NF, Sutherland $\mathrm{HJ}$, Haesman KZ, Tritchler DL, Cunnings BJ. What utilities for decision amalysis? Med Decis Mak 1990; 10: 58-67.

84 Warndorff D, Kmottnerus JA, Huynen LGJ, Starmans R. How well do general practitioners manage dyspepsia? JR Coll Gen Pract 1989; 39; 499502. 

3.2 Diagnostic impact of the erythrocyte sedimentation rate in general practice; a beforeafter analysis

G.J. Dinant, J.A. Knotminerus, J.W.J. Van Wersch

Accepted for publication in Family Practice 
Despite its frequent use and long history, little is known about the diagnostic impact of the measurement of the erythrocyte sedimentation rate (ESR) in general practice. We prospectively followed 362 patients who were seen by their general practitioner (GP) because of a new complaint, for which the GP wanted to know ESR. The GPs recorded the most probable diagnoses, as well as their clinical judgements in terms of "pathology" and "no pathology", and the expected ESR values, before and after the determination of the ESR in the locall hospital laboratory. The patients were seen again after three months, in order to establish the follow-up diagnoses. Having compared the results before ESR determination as well as the follow-up diagnoses, we concluded that the determination of ESR contributes to establishing more appropriate diagnoses. Furthermore, ESR is valuable in reassuring the patient and the doctor when "no pathology" is suspected, rather than in confirming the presence of inflammatory diseases and malignancies.

Keywords: erythrocyte sedimentation rate, before-after study, general practice, malignancy, inflammatory disease, diagnosis 


\section{Introduction}

Despite its frequent use (1-3) and long history, little is known about the impact of the measurement of the erythrocyte sedimentation rate (ESR) on the process of establishing diagnoses in general practice. This lack of knowledge may have contributed to the fact that ESR is used mostly as a non-specific indicator of disease. We expected that a clinical evaluation of ESR could cast more light on the use of the test in daily practice.

\section{Methods}

Nine general practitioners (GPs) participated in the study. For 5 successive months they identified each patient who attended the office because of a new complaint for which the GP considered the determination of ESR to be indicated in order to establish the diagnosis (the so called indicated population). After informed consent had been obtained, the name, date of birth and gender of the patient were noted. The GP recorded the possible diagnoses (to a maximum of 4), with the most likely one at the top (hereafter referred to as the "diagnosis before"), as well as a general judgement of each diagnosis in terms of "pathology" and "no pathology". These intuitively used terms are defined as serious diseases, requiring for therapy ("pathology") and harmless, often self limiting diseases ("no pathology"). In addition he was requested to predict ESR in terms of "very high", "high", "normal" or "low" (see Appendix IV). Subsequently a venous blood sample was taken from the patient's arm. To prevent clotting, the blood was collected in ethylenediamine-tetraacetate (EDTA-K3) tubes. The samples were collected daily in order to determine Westergren's ESR at the local hospital laboratory under standardized conditions. After having received the measured ESR value(s) within three hours, the GP again wrote down the possible diagnoses, starting with the most likely one ("diagnosis after") and a general judgement on each. He then answered the question whether the measured ESR value(s) had influenced his judgements.

The patients who received all normal GP care, were requested to revisit the GP's office three months later. Where necessary, 
patients received a written reminder or a telephone call after the three months had expired. During the revisits, the investigator established the follow-up diagnosis by interviewing the patient, reviewing the chart and hospital letters, and asking for additional information from the GP if necessary. The follow-up diagnoses were established without prior knowledge of the "diagmoses before" and diagnoses after". They were classified according to the International Classification of Health Problems in Primary Care (ICHPPC-2-defined) (4), this being the preferred system in establishing standardized diagnoses in general practice (5). ICHPPC-2-defined was partly modified by adding pneumonia, arthritis and fever e causa ignota to the category of "inflammatory and parasitic diseases", indicated hereafter as inflammatory diseases. As far as possible, inflammations of the other tracts were added to the inflammatory diseases as well. We defined "pathology" as inflammatory diseases or malignancies, since it was concluded from a previous questionnaire that GPs considered "pathology" to correspond with inflammatory diseases or malignancies. "No pathology" was defined to include the categories "signs, symptoms and ill defined conditions", "adverse effects", "supplementary classification" and "preventive medicine". Within these categories, the cases involved minor and spontaneously resolving problems (6). The remaining follow-up diagnoses are referred to below as "all other diseases".

In our analysis we first evaluated the agreement between the GPs' general judgements ("pathology" or "no pathology"), and the "diagnoses before" and "diagnoses after" (categorized by the investigator). The diagnostic impact of ESR was analyzed by comparing the "diagnoses before" with the "diagnoses after", as well as with the corresponding GPs' general judgements. The impact of ESR on the percentage of correct diagnoses was investigated by studying the relationship between the "diagnoses before", the "diagnoses after", and the follow-up diagnoses. We also compared the predicted ESR values with the measured ones, as well as their relationship with the "diagnoses before" and the "diagnoses after". For the purpose of testing the results, Chi-squares for independent and paired samples were calculated (7). 
In all, 362 patients, aged 4 to 87 (mean and median 47 years; standard deviation 19 years), two third of them female, participated in the study. The relationships between the GPs' general judgements and the "diagnoses before" and "diagnoses after", as categorized by the investigator, can be seen from Table 1. The GPs failed to fill in their judgements or diagnoses in 44 and 74 cases, respectively. Overall, a reasonable agreement was found. "All other diseases" were mostly judged to be "non-pathological". The greatest level of disagreement was found between "pathology" on the level of "diagnoses after" and the corresponding GPs' judgements. Apparently, "pathology" was judged to be less severe after the determination of ESR.

Table 1. Numerical relationship between the GPs' general judgements in terms of "pathology" and" "no pathology", and the "diagnoses before". $(\mathrm{N}=318)$ and "diagnoses after" $(\mathrm{N}=288)$ (determination of ESR) in terms of "pathology" ( = inflammatory diseases and malignancies) ( + +), "no pathology" ( $\mathrm{P}$-) and "all other diseases" (all other), categorized by the investigator and following ICHPPC-2defined.

\begin{tabular}{lcrrrrrr}
\hline $\begin{array}{l}\text { general judgements } \\
\text { following the GPs }\end{array}$ & \multicolumn{3}{c}{ "diagnoses before" } & \multicolumn{3}{c}{ "diagnoses after" } \\
& P+ & P & all other & P+ & P- & all other \\
\hline "pathology" & 38 & 35 & 50 & 20 & 14 & 26 \\
"no pathology" & 14 & 69 & 112 & 28 & 77 & 123 \\
\hline totals & 52 & 104 & 162 & 48 & 91 & 149 \\
\hline
\end{tabular}

Chi-square for paired samples, combining the categories "all other diseases" and "no pathology" $=50.9(p<0.001$; "diagnoses before") and $2.1(p<0.25$; "diagnoses after").

Table 2 shows the relationship between the established diagnoses at each phase of the diagnostic process. The calculations are based on the 305 cases for which the GPs filled in the "diagnosis after". After determination of ESR the "diagnoses before" were confirmed by the GPs in $68 \%$ (36/53, with respect to "pathology"), 84\% (83/99, "no pathology") and $92 \%$ (141/ 153 , "all other diseases") of the cases respectively. Determination of ESR was frequently found to confirm the doctor's expectations, mostly resulting in reassurance of the patient and 
the doctor. This conclusion is supported by the results from Table 3 , in which the general judgements before and after ESR determination are compared. Table 2 further shows the level of agreement between the "diagnoses before" and the follow-up diagnoses, which was found for these groups to be $53 \%(28 / 53$, "pathology"), 54\% (53/99, "no pathology") and 74\% (113/153, "all other diseases"). Between the "diagnoses after" and the follow-up diagnoses we calculated $78 \%$ (28/36, "pathology"), $64 \%$ (53/83, "no pathology") and $80 \%$ (113/141, "all other diseases") levells of agreement. It may therefore be concluded that the determination of ESR resulted in establishing more appropriate diagnoses. In only 3 patients was a "pathology" follow-up diagnosis established despite a "no pathology" diagnosis "before" and "after", while 8 patients received a "pathology" diagnosis "before" and "-after", even though in the end they were found to have "no pathology". The greatest contrasts between initiall and final diagnoses were found for these 11 patients. Of the 153 patients who initially received a diagnosis in the "all other diseases" category, 16 patients $(10 \%)$ in the end received a "pathology" diagnosis and 19 patients $(12 \%)$ a "no pathology" diagnosis.

Table 2. Numerical relationship between "diagnoses before", "diagnoses after" (determination of ESR) and follow-up diagnoses, in terms of "pathology" (= inflammatory diseases and malignancies) $(\mathrm{P}+$ ), "no pathology" ( $\left.\mathrm{P}_{-}\right)$and "all other diseases" (all other) $(\mathrm{N}=305)$, categorized by the investigator and following ICHPPC-2-defimed.

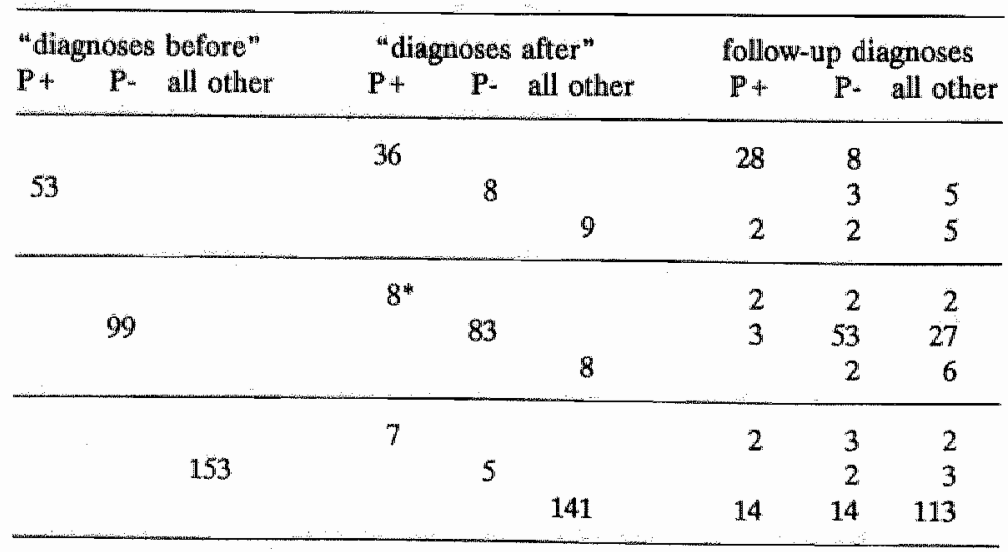

* in two cases the follow-up diagnosis could not be established. 
Table 3. Numerical relationship between GPs general judgements in terms of "pathology" and "no pathology", before and after determination of ESR.

\begin{tabular}{|c|c|c|c|}
\hline \multirow{2}{*}{$\begin{array}{l}\text { before } \\
\text { "pathology" }\end{array}$} & \multicolumn{2}{|c|}{$\begin{array}{c}\text { after } \\
\text { "pathology" "no pathology" }\end{array}$} & totals \\
\hline & 50 & 68 & 118 \\
\hline "no pathology" & 9 & 160 & 169 \\
\hline totals & 59 & 228 & 287 \\
\hline
\end{tabular}

Chi-square for paired samples $=45.2(\mathrm{p}<0.001)$.

The relationship between the established diagnoses at each phase of the diagnostic process (Tables 1 and 2) and the corresponding ESR values can be seen from Tables 4-6. Table 4 shows the extent to which the GPs regarded the "diagnoses after" as having been influenced by the measured ESR values. The GPs failed to answer this question in 111 cases. According to the GPs, the measured ESR values in most cases (207/251, $82 \%$ ) confirmed the initial diagnosis.

Table 4. Numerical relationship between answers given (yes and no) to the question whether the measured ESR values had influenced the establishment of the "diagnoses after", and corresponding results in terms of presence or absence of differences between the "diagnoses before" and "diagnoses after".

\begin{tabular}{lccc}
\hline $\begin{array}{l}\text { answers } \\
\text { given }\end{array}$ & $\begin{array}{c}\text { "diagnoses after" differed } \\
\text { from "diagnoses before" } \\
\text { yes }\end{array}$ & totals \\
\hline yes & 34 & 137 & 171 \\
no & 10 & 70 & 80 \\
\hline totals & 44 & 207 & 251 \\
\hline
\end{tabular}

Chi-square for paired samples $=110(\mathrm{p}<0.001)$.

It cannot be excluded that the answers given were partly influenced by the GP's estimation of his own clinical competence. In any case, the figure of $82 \%$ clearly exceeds the overall agreement between the "diagnoses before" and the follow-up diagnoses, which was found to be only $68 \%$ (205/303, see Table 2). 
The figure of $82 \%$ accords reasonably with the overall $85 \%$ (260/305) agreement between the "diagnoses before" and "the diagnoses after", which can be calculated from the figures given in Table 2.

From Table 5 the relationship between the subjectively predicted and measured ESR values can be seen. To some extent the results are similar to those in Table $4 ; 86 \%(146 / 169)$ of the ESR values predicted to be "normal" (169/283, 60\%) turned out to lie between 0 and $20 \mathrm{~mm} / 1 \mathrm{~h}$. However, in only $35 \%(38 /$ $110)$ of the cases predicted to have "high" $\operatorname{ESR}(110 / 283,39 \%)$ did we measure values above $20 \mathrm{~mm} / 1 \mathrm{~h}$. Hence, the conclusion here, like that of Tables 2 and 3, must be that the measuring of ESR most likely results in reassurance of the GP. With respect to the predicted ESR values, the GPs never filled in "low", and in only 4 cases did they predict "very high" values, whereas we found ESR values above $60 \mathrm{~mm} / 1 \mathrm{hr}$ in 7 cases.

Table 5. Numerical relationship between predicted and measured ESR values.

\begin{tabular}{|c|c|c|c|c|c|}
\hline \multirow{2}{*}{$\begin{array}{l}\text { predicted ESR } \\
(\mathrm{mm} / 1 \mathrm{hr})\end{array}$} & \multicolumn{4}{|c|}{ measured ESR $(\mathrm{mm} / 1 \mathrm{hr})$} & \multirow[t]{2}{*}{ totals } \\
\hline & $0-20$ & $21-30$ & $31-60$ & $>60$ & \\
\hline "very high" & 2 & 0 & $\mathbb{1}$ & 1 & 4 \\
\hline "high" & 72 & 13 & 22 & 3 & 110 \\
\hline "normal" & 146 & 14 & 6 & 3 & 169 \\
\hline "low" & 0 & 0 & 0 & 0 & 0 \\
\hline totals & 220 & 27 & 29 & 7 & 283 \\
\hline
\end{tabular}

Chi-square for independent samples (not using the empty category "low", and combining the categories "high" and "very high", as well as ESR $=31-60$ and $>60)=22.7(\mathrm{p}<0.001)$.

Table 6 shows that before determination ESR was predicted to be "(very) high" in $66 \%$ (33/50) of the "pathology" cases, whereas after the determination only $45 \%(22 / 49)$ of these patients were found to have an ESR above $20 \mathrm{~mm} / 1 \mathrm{hr}$. In 74\% (71/96) of the "no pathology" cases ESR was predicted to be "normal". In $84 \%(76 / 91)$ of these cases ESR was found to be lower than 21 $\mathrm{mm} / 1 \mathrm{hr}$. Apparently, then, ESR values withim the normal range were prone to be related to "no pathology", while the higher values did not necessarily confirm "pathology". This conclusion supports the findings mentioned above. 
Table 6. Numerical relationship between predicted and measured ESR values, and the "diagnoses before" (Table 6A, $N=291$ ) and "diagnoses after" (Table 6B, $N=298$ ) respectively, in terms of "pathology" (= inflammatory diseases and malignancies) $(\mathrm{P}+$ ), "no pathology" ( $\mathrm{P}$ ) and "all other diseases" (all other), categorized by the investigator and following ICHPPC-2 2 defined.

\begin{tabular}{|c|c|c|c|c|c|c|c|}
\hline \multirow{2}{*}{$\begin{array}{l}\text { predicted ESR } \\
(\mathrm{mm} / 1 \mathrm{hr})\end{array}$} & \multicolumn{3}{|c|}{ "diagnoses before" } & \multirow{2}{*}{$\begin{array}{c}\text { measured ESR } \\
(\mathrm{mm} / 1 \mathrm{hr})\end{array}$} & \multicolumn{3}{|c|}{ "diagnoses after" } \\
\hline & $P+$ & P- & lll other & & $P+$ & P. & all other \\
\hline "very high" & 2 & 1 & 1 & $>60$ & 1 & 0 & 7 \\
\hline "high" & 31 & 24 & 56 & $31: 60$ & 13 & 7 & 18 \\
\hline "normal" & 17 & 71 & 88 & $21-30$ & 8 & 8 & 16 \\
\hline "low" & 0 & 0 & 0 & $0-20$ & 27 & 76 & 117 \\
\hline totals & 50 & 96 & 145 & & 49 & 91 & 158 \\
\hline
\end{tabular}

Chi-square for paired samples; not using the empty category " "low" " and combining the categories "high" and "very high" $=42.6(\mathrm{p}$ $<0.001$ ).

In both samples the categories "all other diseases" and "no pathology" were combined.

\section{Discussion}

With respect to the indicated population in general practice, we found a more appropriate establishment of diagnostic categories after ESR measurement. Moreover, after ESR the patient and the doctor are more likely to be reassured, rather than that ESR confirming the presence of "pathology".

In principle, it would be best to investigate the diagnostic value of a test by studying its therapeutic impact, using a randomized control trial (RCT) model $(8,9)$. However, in general practice ESR is often determined to exclude disorders and to reassure the patient and the doctor, rather than to prove the presence of disease. The differentiation between pathology and no pathology often preceeds further decision making. Studying its diagnostic impact would therefore be more appropriate. Apart from practical problems, the RCT model does have several advantages. However, it has the disadvantages of high costs and the need for large sample sizes (3). Furthermore, in our case the GP's should then be randomly informed of the measured ESR values, despite the use of the test in the indi- 
cated population only. Hence, the before-after study of the diagnostic impact of ESR presented here may be considered a reasonable altemative and a valuable addition to a recent study on the efficacy of ESR (10).

A previous study allowed the conclusion that the relation between measured ESR values and the presence of "pathology" was independent of age (10). Hence, age did probably not bias the results presented here.

On average, each participating GP measured ESR nearly twice a week. This frequency approximates the estimations we made in advance and makes it less likely that bias by indication or dilution of the study population occurred.

The GPs failed to answer various questions on several occasions: Apart from limited and controlled problems at the beginning of the study period, this failure could not be attributed to one or a few GPS, nor to a specific period during the study, or even to specific diseases or ESR values. Hence, we have no reason to assume that the missing answers biased the results of the study.

As we already stated with respect to the results presented in Tables 2 and 4, the GPs probably felt inclined, at least to some extent, to answer the "after" questions in accordance with the "before" answers, which may have partly biased these particular results. However, in view of the fact that the answers given were to be compared with the results of the follow-up procedure, including chart review, this biased answering may be assumed to he af limitad impartance.

At the time when he established the follow-up diagnoses, the investigator did not know the "before" and "after" answers which had been given, nor could he be assumed to be interested in a good or even poor similarity between the follow-up conclusions and the diagnoses "before" and "after". Hence, the information which he obtained by chart review, and which sometimes included the measured ESR values, is not likely to have resulted in biased follow-up diagnoses.

Finally, it might be questioned to what extent ESR really contributed to the establishment of more appropriate diagnoses. Despite a relatively short lapse of time between the assessment of the "diagnoses before" and the "diagnoses after", several other factors, including just thinking about the cases, may have 
contributed to the GP's diagnostic considerations. This situation, however, reflects daily practice. Within the present study it would have been clinically unrealistic to reduce the factors concerned to a minimum and thus force the GPs into a laboratory experiment. However, in a future study it would be interesting to compare the influence of a short lapse of time per se versus a lapse of time plus test result. The present before-after study was concluded to have been useful in the clinical evaluation of a well-established and still widely used blood test in general practice.

\section{References}

1. Kelly $\mathrm{MH}$, Barber JH. Use of laboratory services and communication of results to patients in an urban practice: an audit. $J R$ Coll Gen Pract 1988; 38: 64-6.

2. Pop P, Winkens RAG. A diagnostic centre for general practitioners: results of individual feedback on diagnostic actions. $J$ R Coll Gen Proct 1989; 39: 507-8.

3. Sox $\mathrm{HC}$, Liang $\mathrm{MH}$. The erythrocyte sedimentation rate. Guidelines for rational use. Ann Intem Med 1986; 104: 515-23.

4. Classification Committee of WONCA. ICHPPC-2-defined. Inclusion criteria for the use of the mibrics of the International Classification of Health Problems in Primary Care. Oxford: Oxford. University Press, 1983.

5. Mejjer JS, Brouwer H, Lamberts H. De ICPC als diagnostische classificatie II [synopsis in English]. Huisants en Wetenschap 1987; 30: 44-8, 60.

6. Sawrey SA. All other sings, symptoms and ill defined conditions. $N$ Z Fam Physician 1988; 15: 4-6.

7. Colton T. Statistics in medicine. Boston: Little, Brown and Company, 1974.

8. Alperovitch A. Controlled assessment of diagnostic techniques: methodological problems. Effective Heath Care 1983; 1: 187-90.

9. Guyatt GH, Tugwell PX, Feeny DH, Drummond MF, Haynes RB. The role of before-after studies of therapeutic impact in the evaluation of diagnostic technologies. J Chron Dis 1986; 39: 295-304.

10. Dinant GJ, Knottmerus JA, Wersch JWJ Van. Desktop laboratory in general practice; the discriminating ability of the erythrocyte sedimentation rate. Accepted for publication. 

4.1 Erythrocyte sedimentation rate versus plasma viscosity in diagnosing rheumatoid arthritis and ankylosing spondylitis

G.J. Dinant, J.W.J. Van Wersch, H.S. Goei The, J.A. KNOTTNERUS

Submitted for publication 
Plasma viscosity (PV) and erythrocyte sedimentation rate (ESR) are considered to be general parameters of disease activity. Both tests were studied with regard to their ability to monitor rheumatic disease actiwity. We compared the ability of PV and ESR to discriminate between outpatients suffering from rheumatoid arthritis (RA) $(\mathrm{n}=105)$ and ankylosing spondylitis (AS) $(n=64)$ on the one hand, and patients presenting with new complaints of the locomotor system which were ultimately diagnosed to be of non-inflammatory origin $(n=192)$ on the other. Three rheumatologists followed the patients and established diagnoses. PV and ESR were measured using the Coulter Viscometer II and the Westergren method, respectively. ESR was found to be a better parameter for both RA and AS than PV, independent of the chosen reference values, age, gender and the presence of anemia. ESR may still be regarded as an acceptable parameter for diagnosing inflammatory diseases.

Keywords: plasma viscosity, erythrocyte sedimentation rate, rheumatoid arthritis, ankylosing spondylitis, discriminating ability 
There is no consensus about the ability of plasma viscosity measurement (PV) to discriminate between patients suffering from inflammatory rheumatic disorders and patients presenting with new complaints of the locomotor system, ultimately stemming from non-inflammatory rheumatic disorders, an ability which must be compared to that of the erythrocyte sedimentation rate measurement (ESR). We report on this diagnostic ability of PV and ESR. The relatively recent availability of a more convenient plasma viscometer means that the subject has become an interesting one in medical practice.

Several tests are used to assess the concentrations of individual acute phase proteins. But, until now, only PV and ESR have been considered to reflect the joint acute phase protein concentrations (1-3). For this reason, both PV and ESR are important as general parameters of inflammatory disease activity. Furthermore, in contrast to specific measurements of the individual acute phase proteins, both PV and ESR are useful in diagnosing inflammations 24 hours after their onset, rather than at the very acute stage of disease $(1,4,5)$. ESR has already been found to be a better parameter for monitoring disease activity in rheumatoid arthritis (RA) than PV (6-8). However, contrary conclusions have been published as well (9-11). Most studies on the subject have concentrated on monitoring rather than on diagnostic aspects, or were found to lack a proper control group $(9,12)$.

The clinical interpretation of ESR suffers from the necessity to correct for the patient's age and gender, as well as for the packed cell volume (anemia, polycythemia) (1), pregnancy and the use of drugs (steroids, oral contraceptives) (13). These corrections are usually difficult to quantify. Moreover, authors disagree on the extent to which correction is needed (11). Since PV is measured in a plasma sample instead of in whole-blood, the test is generally regarded as insensitive to at least gender, anemia and polycythemia $(9,14)$. Furthermore, age is considered to be important in the clinicall interpretation of PV only in so far as young children or very old people are concerned $(9,15)$. 
These considerations illustrate the relevance of comparing PV and ESR in a clinical setting. We investigated the discriminating ability of PV and ESR, in terms of sensitivity and specificity, with respect to patients suffering from RA and ankylosing spondylitis (AS), comparing them with a control group consisting of patients who presented with new complaints ultimately diagnosed as non-inflammatory disorders or complaints.

\section{Methods}

Three rheumatologists and one resident, all attached to the De Wever Hospital in Heerlen, cooperated in the study. Patients visiting the outpatient clinic in order to receive gold injections because of RA, as well as patients who were known to be suffering from AS, underwent a venepuncture, in order to measure PV and ESR. Diagnoses had been established previousily, using the American Rheumatic Association (ARA) criteria for RA and the (modified) New York criteria for AS (16), respectively. These patients were entered into the index group.

The rheumatologists were requested to identify each patient who visited the outpatient clinic because of a new complaint, or a new diagnostic episode. Age and gender were recorded. Venous blood samples were taken from the patient's arm, in order to measure PV and ESR, as well as other parameters, if requested. The latter parameters were determined by the usual procedures. Measured ESR values were passed on only after the rheumatologists had established the diagnoses; usually after one revisit from the patient. The control group was recruited from this patient group as described below. Whenever the rheumatologists considered it important to be immediately informed of the ESR, the patient was excluded from the study.

In the analysis, those patients from the new patient group who were found to be suffering from RA or AS were added to the index group. Patients suffering from other inflammatory diseases (e.g. gout or polymyalgia rheumatica) were excluded from the analysis. In this way we established a control group consisting 
only of patients with non-inflammatory disorders (e.g. asteoarthrosis or soft tissue rheumatism) or complaints e causa ignota (e.g. pain in joint).

To prevent clotting, the PV samples from both index and control groups were collected in ethylenediaminetetra-acetate (EDTA-K3) tubes and the EDTA-plasma was frozen at -20 degrees $C$. At the end of the study PVs were measured using a Coulter Viscometer II (Coulter Electronics Limited, Luton, England). ESR was measured in the usual way, following Westergren. Diagnoses of all patients were established independent of PV and ESR test outcomes.

We used sensitivity, specificity and predictive values in accordance with the current definitions of these terms (17). We first compared the distributions of age and gender, as well as PV and ESR values, with respect to the diagnoses. Secondly, we studied the relations between sensitivity, specificity and reference values of PV, as compared to ESR, by means of Receiver Operating Characteristic (ROC) curves (18). We expected a larger clinical contrast between the index group diseases and the non-inflammatory complaints e.c.i., than between the index group diseases and non-inflammatory disorders. In addition, we expected PV and ESR to be more frequently in the normal range of reference values in cases of "complaints e.c.i." than in "disorders". We therefore constructed ROC curves using the diagnosed non-inflammatory disorders and complaints e.c.i. as separate control groups. Furthermore, separate ROC curves were used in studying the possible influence of the patient's gender, age and anemia on the discriminating ability of PV and ESR. Finally, we calculated $95 \%$ confidence intervals (CI) of sensitivity and specificity (19). The statistical significance test which we used in the analysis was Pearson's Chi-Square test for independent proportions.

\section{Results}

In all, 387 patients were included in the study. In 26 patients other inflammatory diseases were diagnosed. The remaining 361 patients were entered into further data analysis. The index and control groups consisted of $169(47 \%)$ and $192(53 \%)$ patients, 
respectively. The numerical distribution of age and gender, in relation to the diagnoses, can be seen from Table 1 . The index group included nearly as many males as females. However, unequal distributions of gender were found within the RA (70\% females) and AS (83\% males) subgroups. The "disorders" subgroup included $67 \%$ females, whereas the "complaints" subgroup consisted of $72 \%$ females.

Table 1. Numerical distribution of age and gender $(m=$ male, $f=$ female), in relation to the diagnoses ( $\mathrm{RA}=$ rheumatoid arthritis; $\mathrm{AS}=$ ankylosing spondylitis).

\begin{tabular}{|c|c|c|c|c|c|c|c|c|}
\hline \multirow{4}{*}{$\begin{array}{l}\text { age } \\
\text { (years) }\end{array}$} & \multicolumn{8}{|c|}{ gender } \\
\hline & \multicolumn{4}{|c|}{ index group } & \multicolumn{4}{|c|}{ control group } \\
\hline & \multicolumn{2}{|c|}{ RA } & \multicolumn{2}{|c|}{ AS } & \multicolumn{2}{|c|}{ disorders } & \multicolumn{2}{|c|}{ complaints } \\
\hline & $\mathrm{m}$ & $f$ & m & $\mathrm{f}$ & $\mathrm{m}$ & $\mathrm{f}$ & $\mathrm{m}$ & $f$ \\
\hline $16-20$ & 0 & 0 & 0 & 0 & 2 & 1 & 0 & 0 \\
\hline $21-30$ & 3 & 6 & 9 & 7 & 3 & 12 & 1 & 2 \\
\hline $31-40$ & 3 & 5 & 21 & 1 & 7 & 16 & 1 & 6 \\
\hline $41-50$ & 8 & 14 & 16 & 2 & 12 & 36 & 7 & 9 \\
\hline $51-60$ & 9 & 14 & 7 & 1 & 13 & 27 & 3 & 6 \\
\hline $61-70$ & 7 & 23 & 0 & 0 & 3 & 19 & 0 & 1 \\
\hline $71-82$ & 2 & 11 & 0 & 0 & 3 & 2 & 0 & 0 \\
\hline totals & 32 & 73 & 53 & 11 & 43 & 113 & 12 & 24 \\
\hline
\end{tabular}

The age range was from 16 to 82 years. The distribution of age was found to be relatively skew in the direction of higher ages as far as the RA subgroup was concerned (mean = 55 years), and in the direction of lower ages in the AS subgroup (mean = 39 years). Within the control subgroups we found an almost symmetrical distribution of age with respect to diagnosed disorders (mean $=48, \mathrm{SD}=13$ years), as well as complaints e.c.i. ( mean $=45, \mathrm{SD}=9$ years).

Table 2 shows the measured PV values in relation to the diagnoses. Within the index group, high PV values were more frequently found for patients with RA. Within the control group, the distribution of PV values in the "disorders" subgroup was quite similar to that in the "complaints" subgroup. The distribution of ESR values in relation to the diagnoses can be seen from Table 3. The frequency of low (normal) ESR values is 
clearly higher in the control group than in the index group. High ESR values (above $30 \mathrm{~mm}$ ) were found mostly in the RA subgroup.

Table 2. Frequency distribution of PV values in relation to the diagnoses ( $\mathrm{RA}=$ rheumatoid arthritis, $\mathrm{AS}=$ ankylosing spondylitis).

\begin{tabular}{lrrrrrrrrr}
\hline PV*: & \multicolumn{3}{c}{ index group } & \multicolumn{4}{c}{ control group } \\
(mPa.s) & \multicolumn{2}{c}{ RA } & \multicolumn{2}{c}{ AS } & \multicolumn{2}{c}{ disorders } & \multicolumn{2}{c}{ complaints } \\
& $\mathrm{N}$ & $\%$ & $\mathrm{~N}$ & $\%$ & & $\mathrm{~N}$ & $\%$ & $\mathrm{~N}$ & $\%$ \\
\hline $0-1.50$ & 0 & 0 & 2 & 3 & & 2 & 1 & 0 & 0 \\
$1,51-1,72$ & 40 & 38 & 50 & 78 & 115 & 74 & 29 & 81 \\
$>1,72$ & 65 & 62 & 12 & 19 & 39 & 25 & 7 & 19 \\
\hline totals & 105 & 100 & 64 & 100 & & 156 & 100 & 36 & 100 \\
\hline
\end{tabular}

* PV is expressed in millipascal $x$ seconds (mPa.s). According to the International Committee for Standardization in Haematology (29), reference values should be situated between 1,50 and 1,72 mPa.s.

Table 3. Frequency distribution of ESR values in relation to the diagnoses ( $R A=$ rheumatoid arthritis, $A S=$ ankylosing spondylitis).

\begin{tabular}{|c|c|c|c|c|c|c|c|c|}
\hline \multirow{3}{*}{$\begin{array}{l}\text { ESR } \\
(\mathrm{mm} / 1 \mathrm{hr})\end{array}$} & \multicolumn{4}{|c|}{ index group } & \multicolumn{4}{|c|}{ control group } \\
\hline & \multicolumn{2}{|c|}{ RA } & \multicolumn{2}{|c|}{$\mathrm{AS}$} & \multicolumn{2}{|c|}{ disorders } & \multicolumn{2}{|c|}{ complaints } \\
\hline & $\mathrm{N}$ & $\%$ & N & $\%$ & $\mathrm{~N}$ & $\%$ & $\mathrm{~N}$ & $\%$ \\
\hline $0-10$ & 29. & 28 & 31 & 48 & 113 & 72 & 28 & 78 \\
\hline $11-20$ & 22 & 21 & 16 & 25 & 24 & 15 & 5 & 14 \\
\hline $21-30$ & 18 & 17 & 9 & 14 & 12 & 8 & 3 & 8 \\
\hline $31-40$ & 13 & 12 & 5 & 8 & 6 & 4 & 0 & 0 \\
\hline $41-50$ & 8 & 8 & 3 & 5 & $\mathbb{1}$ & 1. & 0 & 0 \\
\hline $51-60$ & 11 & 10 & 0 & 0 & 0 & 0 & 0 & 0 \\
\hline $61-70$ & 2 & 2 & 0 & 0 & 0 & 0 & 0 & 0 \\
\hline $71-80$ & 2 & 2 & 0 & 0 & 0 & 0 & 0 & 0 \\
\hline totals & 105 & 100 & 64 & 100 & 156 & 100 & 36 & 100 \\
\hline
\end{tabular}

The relation between measured $\mathrm{PV}$ and ESR values can be seen from Table 4. After dichotomising ESR at 20 and $30 \mathrm{~mm}$, Pearson's Chi-Squares were calculated as 104.94 ( $\mathrm{p}<0.0001)$ and 77.56 ( $\mathrm{p}<0.0001)$, respectively $(2$ degrees of freedom). Using ESR reference values of $0-30 \mathrm{~mm}$, high PVs $(>1,72$ $\mathrm{mPa} . \mathrm{s}$ ) were not infrequently found in patients with normal 
ESR walues (78 out of 310 cases), whereas only 6 cases with increased ESR were found in the 234 patients with normal PV values (between 1.50 and $1.72 \mathrm{mPa} . \mathrm{s}$ ).

Table 4: Relahon between measured PV and ESR values. The numbers of corresponding measurements are listed.

\begin{tabular}{|c|c|c|c|c|}
\hline \multirow[t]{2}{*}{ ESR (mim/ $/ 1$ hr) } & \multicolumn{3}{|c|}{ PV (mPas) } & \multirow[t]{2}{*}{ totals } \\
\hline & $0-150$ & $1.51-1.72$ & $>1.72$ & \\
\hline $0-10$ & 4 & 171 & 26 & 201 \\
\hline $11-20$ & 0 & 42 & 25 & 67 \\
\hline $21-30$ & 0 & 15 & 27 & 42 \\
\hline $31-40$ & 0 & 5 & 19 & 24 \\
\hline $41 \cdot 50$ & 0 & 1 & 11 & 12 \\
\hline $51-60$ & 0 & 0 & 11 & 11 \\
\hline $61 \cdot 70$ & 0 & 0 & 2 & 2 \\
\hline $71-80$ & 0 & 0 & 2 & 2 \\
\hline totals & 4 & 234 & 123 & 361 \\
\hline
\end{tabular}

The ROC curves in Figure 1 show the relation between sensitivity, specificity and reference values (cut-off points) of PV and ESR with respect to $R A$ and $A S$, using non-inflammatory disorders and complaints as a combined control group. The discriminating ability of ESR was found to be better than that of PV, for both RA and AS, independent of the chosen reference values. When the separate control subgroups ("disorders" and "complaints e.c.i.") were used in constructing ROC curves, similar results were found, as can be seen from Figure 2. In this figure the complete index group, instead of the separate RA and $S A$ subgroups, was used. From the ROC curves in Figure 1 we computed the optimal cut-off points, corresponding with the maximum sum of sensitivity and specificity. For these theoretically optimal upper limits of reference values, sensitivity, specificity, as well as their Cls can be seen from Table 5. Since we were interested in the stability of these limits, in other words in the changes in sensitivity and specificity after shifting from optimal to suboptimal cut-off points, we listed the latter figures as well (see Table 5). With respect to AS, we calculated equal sums of sensitivity and specificity at the 12 and $14 \mathrm{~mm}$ cut-off points of the ESR curve. 
Figure 1

ROC curves illustrating the relation between sensitivity (SENS), specificity (SPEC) and refference values (given at the bottom of the figure) of PV and ESR in rheumatoid arthritis (RA) and ankylosing spondylitis (AS), using noninflammatory disorders and complaints as a combined control group. $I=E S R, R A ; I I=P V, R A ; I I=E S R, A S ; I V=P V, A S$.

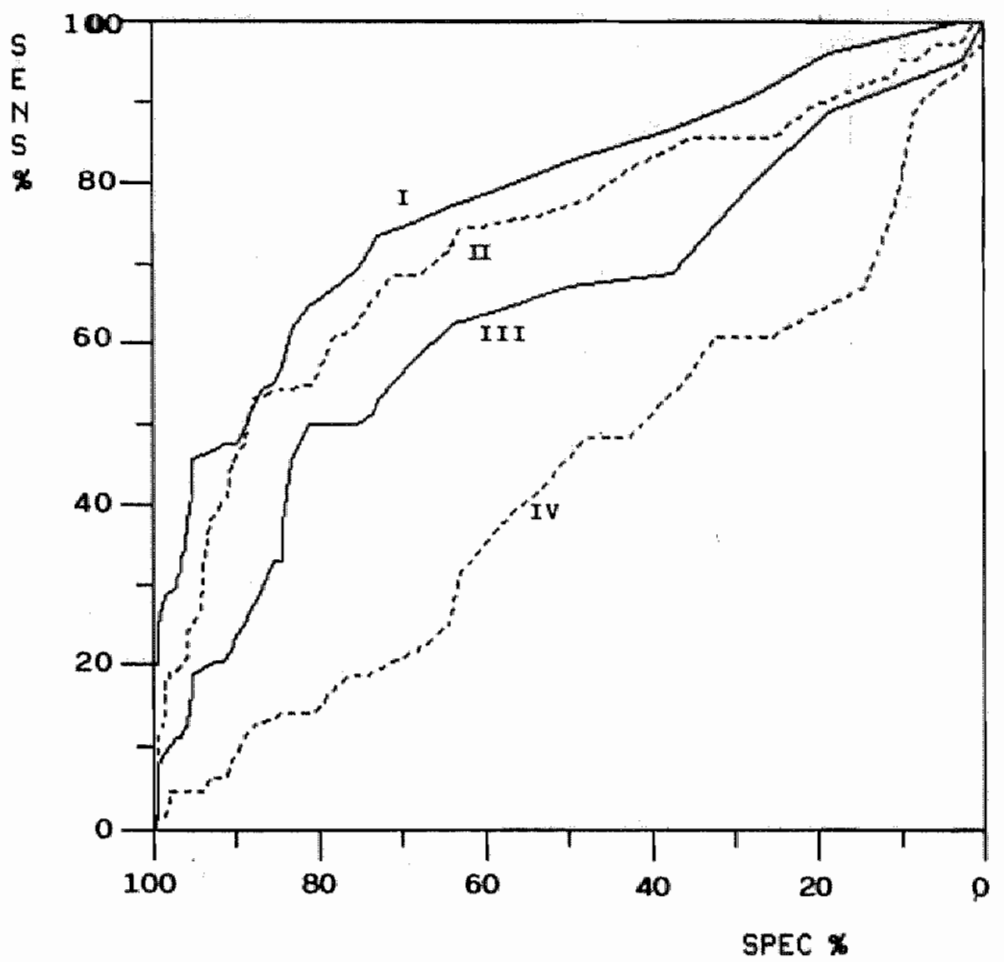

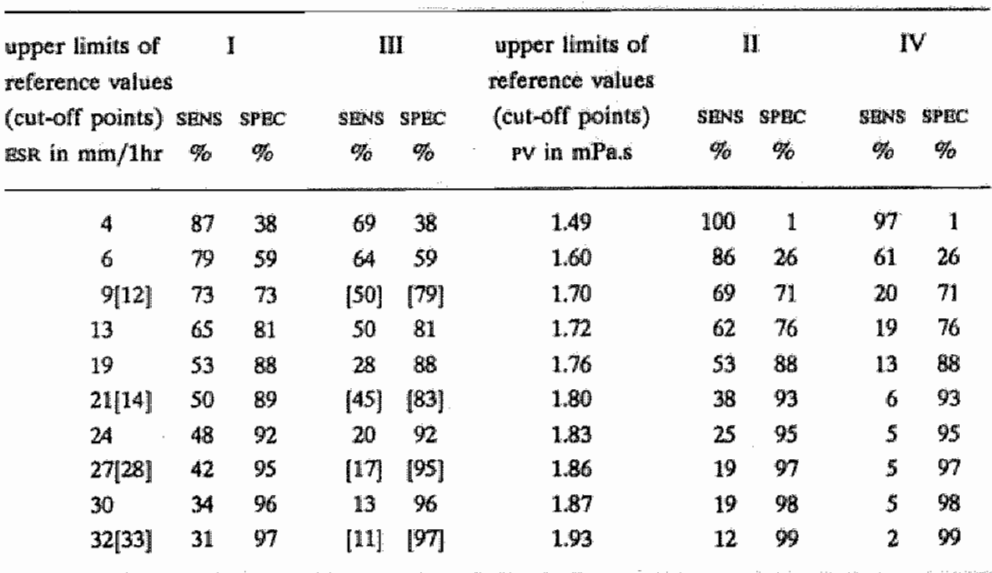


Pigure 2

ROC carves illustrating the relation between senisitiwity (SENS), specificity (SPEC) and reference walues (given at the botton of the figure) of PV and ESR for the complete index group ( m reumatoid arthritis and ankylosing spondylitis), using non-inflammatory disorders and complaints as separate control groups.

$I=E S R$, complaints; $I I=E S R$, disorders; $I I=P V$, complaunts; $I V=P V$, disorders.

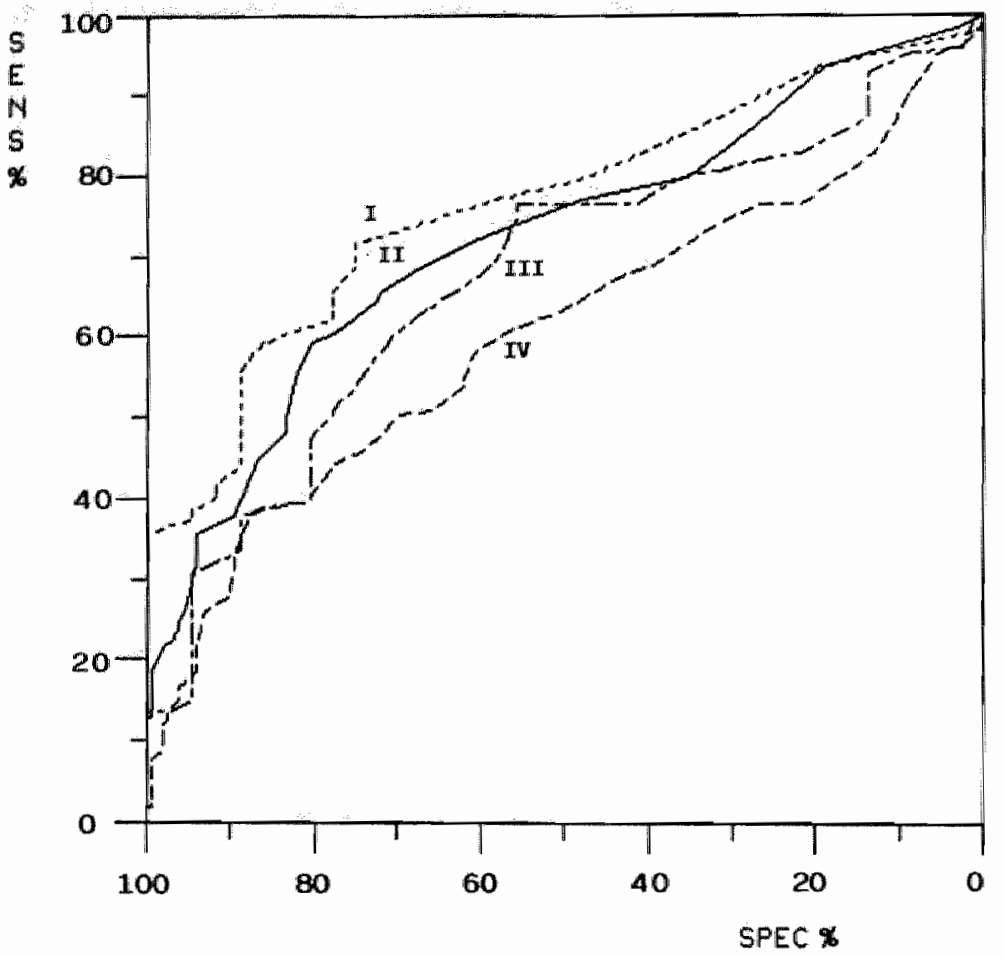

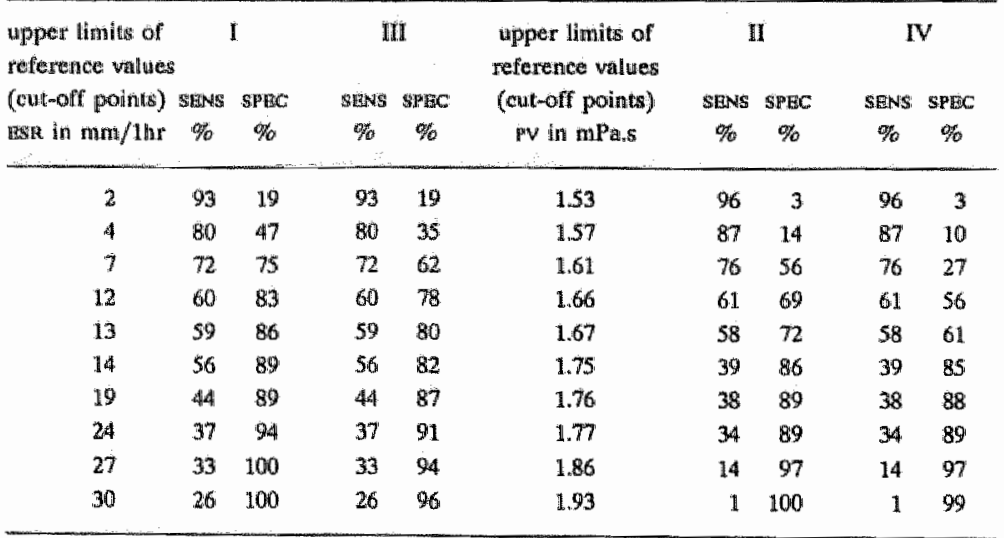


Table 5. Sensitivity (SENS) and specificity (SPEC) of PV and ESR for rheumatoid arthritis and ankylosing spondylitis, at the optimal (OP) and suboptimal (SO) upper limits (cut-off points) of reference values: The confidence intervals (C) are listed as well.

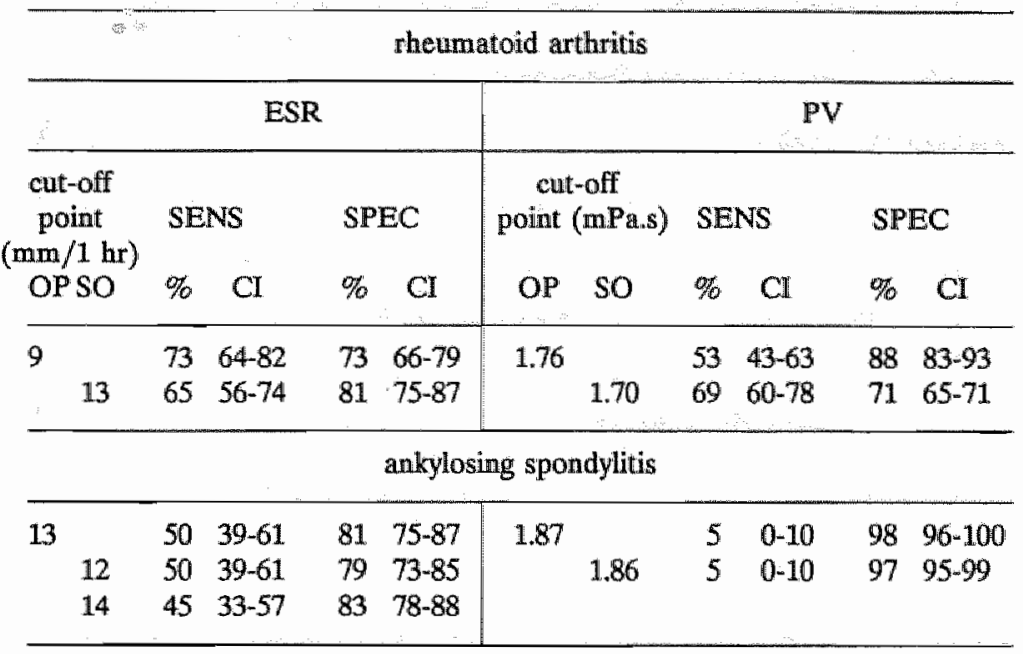

For both PV and ESR, ROC curves with respect to RA and AS are presented separately for males and females (see Figures 3 and 4). The optimal cut-off points (as well as sensitivities and specificities) of PV calculated from the ROC curves in Figure 3 were found to be the same for males and females, for RA. In contrast, gender was found to be a relatively important covariate for ESR in discriminating $\mathrm{RA}$ and $\mathrm{AS}$ from the noninflammatory control group. The cut-off points, sensitivities and specificities concerned can be seen from Table 6.

Table 6. Sensitivity (SENS) (\%) and specificity (SPEC) (\%) of ESR for rheumatoid arthritis and ankylosing spondylitis, at the optimal upper limits (cut-off points) of reference values, in males (m) and females (f).

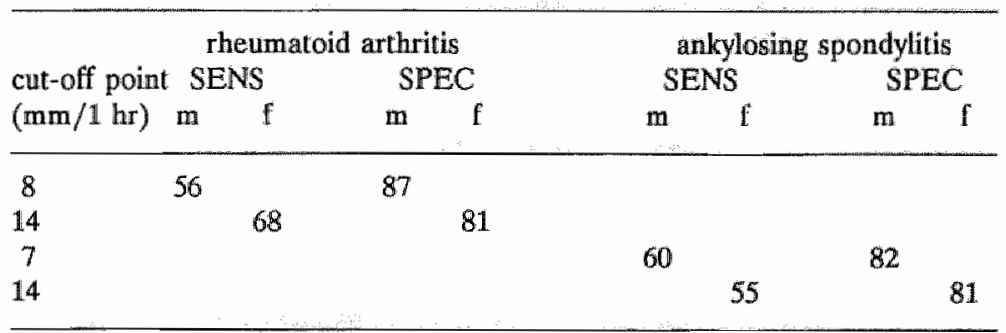


Figute 3

ROC curves illustrating the relation between sensitinty (SENS), specificiry (SPEC) and reference walues (given at the bottom of the figure) of PV for theimatout arthritis (RA) and ankylosing spondylitis AS), for males and females separately, using non-inflammatory disorders and complaints as a combined control group.

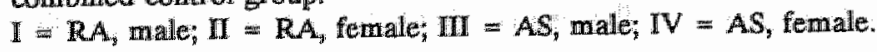

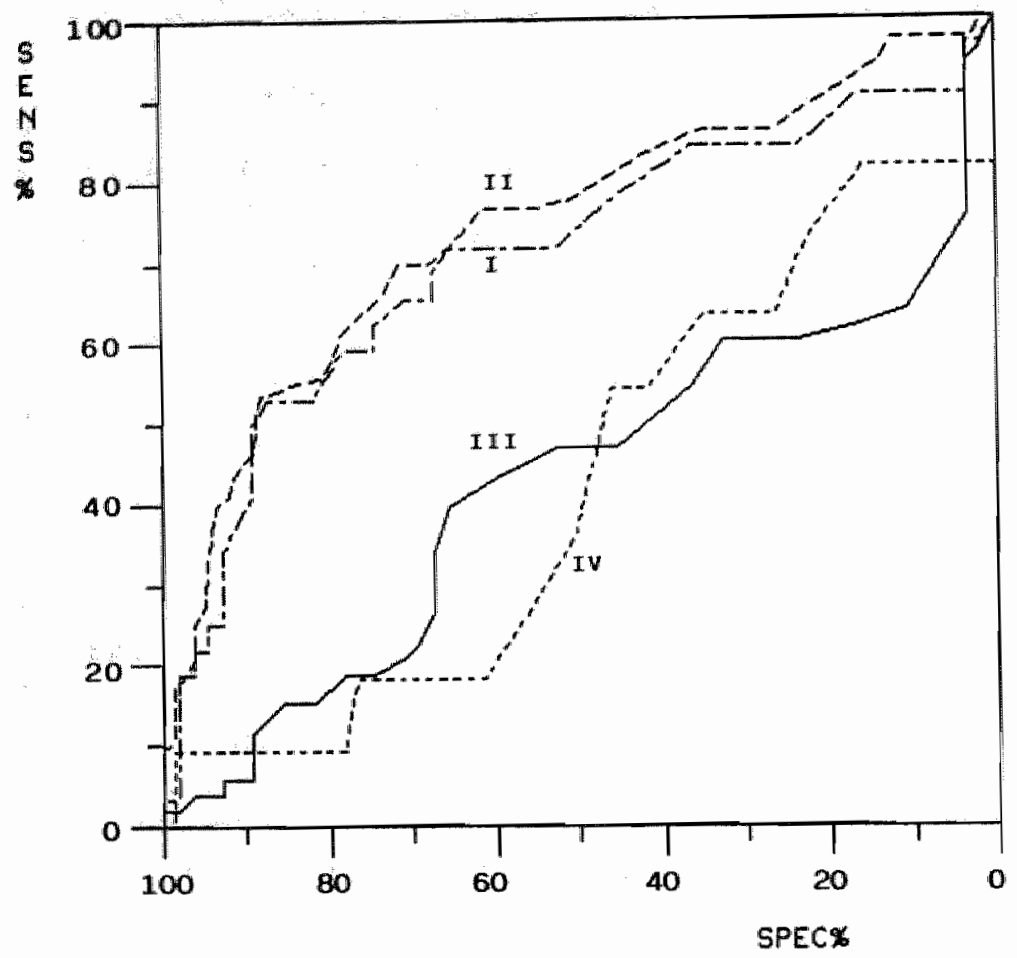

\begin{tabular}{|c|c|c|c|c|c|c|c|c|}
\hline \multirow{3}{*}{$\begin{array}{l}\text { upper limits of } \\
\text { reference values } \\
\text { (cul-off points) } \\
\text { PV in mPa.s }\end{array}$} & \multicolumn{2}{|c|}{1} & \multicolumn{2}{|c|}{ II } & \multicolumn{2}{|c|}{ III } & \multicolumn{2}{|c|}{ IV } \\
\hline & SBNS & SPEC & SENS & $\mathrm{SPBC}$ & SENS & SPEC & SENS & SPEC \\
\hline & $\%$ & $\%$ & $\%$ & $\not F$ & $\%$ & $\%$ & $\%$ & $\mathscr{\%}$ \\
\hline 1.53 & 97 & 18 & 97 & 3 & 96 & 2 & 82 & 3 \\
\hline 1.60 & 84 & 24 & 86 & 26 & 60 & 24 & 64 & 26 \\
\hline 1.70 & 66 & 71 & 70 & 72 & 21 & 71 & 18 & 72 \\
\hline 1.73 & 59 & 78 & 62 & 78 & 19 & 78 & 1 & 78 \\
\hline 1.75 & 53 & 85 & 55 & 85 & 15 & 85 & 1 & 85 \\
\hline 1.76 & 53 & 87 & 53 & 88 & 13 & 87 & 1 & 88 \\
\hline 1.77 & 50 & 89 & 47 & 89 & 11 & 89 & 1 & 89 \\
\hline 1.86 & 22 & 96 & 18 & 98 & 4 & 96 & 1 & 98 \\
\hline $1.94[1.91]$ & 16 & 98 & [12] & {$[99]$} & \multicolumn{4}{|c|}{ no values available } \\
\hline $1.97[1,93]$ & 1. & 98 & {$[1]$} & [99] & no values & availa & le $[0]$ & {$[100]$} \\
\hline
\end{tabular}


Figure 4

ROC curves illustrating the relation between sensitivity (SENS), specificity (SPEC) and reference values (guven at the bottom of the figure) of ESR for rheumatoid arthritis (RA) and ankylosing spondylitis (AS), for males and females separately, using nom-inflammatory disorders and complaints as a combin d control group.

$I=R A$, male; $I=R A$, female; $I I=A S$, male; $I V=A S$, female.

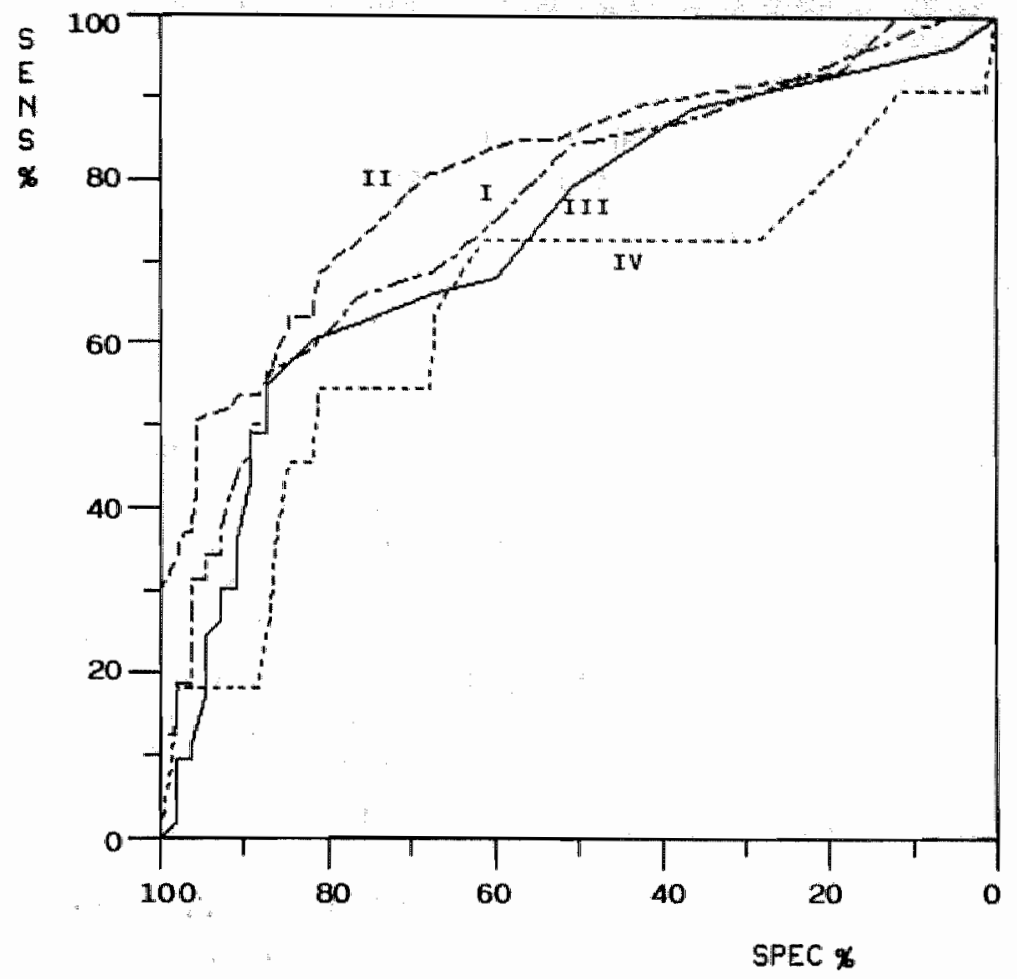

\begin{tabular}{|c|c|c|c|c|c|c|c|c|}
\hline \multirow{2}{*}{$\begin{array}{l}\text { upper limits of } \\
\text { reference walues } \\
\text { (cut-off points) } \\
\text { ESR in mm/1hr }\end{array}$} & \multicolumn{2}{|c|}{$\mathbb{I}$} & \multicolumn{2}{|c|}{ II } & \multicolumn{2}{|c|}{ IIII } & \multicolumn{2}{|c|}{ IV } \\
\hline & $\begin{array}{c}\text { SENS } \\
\%\end{array}$ & $\begin{array}{c}\text { SPEC } \\
\%\end{array}$ & $\begin{array}{c}\text { SENS } \\
\%\end{array}$ & $\begin{array}{c}\text { SPEC } \\
\%\end{array}$ & $\begin{array}{c}\text { SENS } \\
\%\end{array}$ & $\begin{array}{c}\text { SPBC } \\
\%\end{array}$ & $\begin{array}{c}\text { SENS } \\
\%\end{array}$ & $\begin{array}{c}\text { SPEC } \\
\%\end{array}$ \\
\hline $2[3]$ & 88 & 36 & [93] & [19] & 89 & 36 & 91 & 12 \\
\hline 4 & 75 & 60 & 92 & 28 & 68 & 60 & 73 & 28 \\
\hline 7 & 59 & 82 & 85 & 57 & 60 & 82 & 73 & 57 \\
\hline 8 & 56 & 87 & 84 & 61 & 55 & 87 & 73 & 61 \\
\hline 14 & 47 & 89 & 68 & 81 & 43 & 89 & 55 & 81 \\
\hline $19[20]$ & 34 & 95 & 62 & 85 & 25 & 95 & {$[36]$} & {$[86]$} \\
\hline $27[28]$ & 31 & 95 & 47 & 96 & {$[17]$} & [95] & no $v$ & $\begin{array}{l}\text { alues } \\
\text { lable }\end{array}$ \\
\hline $30[31]$ & 28 & 96 & 37 & 96 & [1] & {$[96]$} & 18 & 96 \\
\hline $32[33]$ & 19 & 96 & [36] & {$[98]$} & no values & availabl & {$[18]$} & [98] \\
\hline $36[35]$ & 13 & 98 & [33] & [99] & [1] & {$[98]$} & [1] & [99] \\
\hline
\end{tabular}


The relation between age on the one hand and sensitivity and specificity of ESR in diagnosing RA and AS on the other can be seen from the ROC curves in Figure 5. For patients over 60 years of age sensitivity and specificity of ESR increased.

The ROC curves from Figure 1 were reconstructed (see Figure 6) using only those patients who were found to have normal hemoglobin concentrations $(\mathrm{Hb})(>8.4 \mathrm{mMol} / \mathrm{l}$ in males and $>7.4 \mathrm{mMol} / 1$ in females). Abnormal $\mathrm{Hbs}$ were found in 9 control group patients, 30 RA patients and 3 AS patients. $\mathrm{Hb}$ could not be traced in 16 control group patients and 3 RA patients.

\section{Discussion}

For the outpatient rheumatology clinic, ESR was found to be a better parameter than PV in discriminating between patients suffering from RA and AS on the one hand, and patients presenting with new complaints which were ultimately diagnosed to be of non-inflammatory origin on the other. The conclusion can be regarded as independent of the chosen reference values and of gender (Figure 1, Table 5). Moreover, it is supported by the PV values, which were less frequently found to be abnormal than the measured ESR values (Table 4).

Our results demonstrate that gender is not important as a covariate in diagnosing RA, as far as PV is concerned (Figure 3). The discriminating ability of PV, in both males and females, was found to be very poor for AS, as can be seen from the ROC curves in Figure 3. We therefore conclude that, as far as PV is concerned, gender may be considered unimportant in diagnosing $A S$ as well. This conclusion is in agreement with previous studies on the subject $(9,14)$.

In contrast, gender must be taken into account in the clinical interpretation of ESR (Figure 4, Table 6). The finding of higher upper limits of reference values in females than in males corresponds with the results of a recent prospective study on the discriminating ability of ESR in diagnosing malignancies and inflammatory disorders, including $\mathbf{R A}$, in general practice (20). The same study allowed the conclusion that age may be considered unimportant in predicting malignancies and inflam- 
matory disorders. Despite the greater discriminating ability of ESR which we found with respect to patients over 60 years of age (see figure 5), the optimal cut-off point in these cases $(15 \mathrm{~mm} / \mathrm{hh}$ ) hardly differed from those given in Table 6 . We therefore conclude that in the present study, differences in frequency distributions of age for the RA and AS patients, as compared to those for the control group patients, did not distort the results with respect to ESR. Since no young children and only one very old patient ( $>80$ years old) were entered into the study, the same conclusion may be drawn concerning PV (9).

Since anemia is frequently found in patients suffering from chronic inflammatory diseases, it may have elevated ESR and, hence, have resulted in over-optimistic conclusions with regard to ESR, as compared to PV, as far as RA is concerned. The anemia in RA is not merely of the iron deficiency type, and is therefore difficult to treat $(21,22)$. Nevertheless, we did not find anemia to be a clinically relevant covariate, as can be seen from the ROC curves in Figure 6. Furthermore, for the generally non-anemic patients who suffered from AS, the discriminating ability of ESR was even found to be much better than that of PV (Figure 1). Finally, the influence of anemia on ESR may have been partly compensated by the reduction of inflammatory activity as a result of gold injections in the RA patients.

As for the patients who presented new complaints, the rheumatologists may have been informed of the ESR measured by the general practitioner before referring the patient. One might ask whether this information could have affected the diagnostic process. However, in general, ESR plays a minor role among the criteria for diagnosing and referring rheumatic diseases. Furthermore, whenever the rheumatologists considered it clinically important to be immediately informed of the ESR, the patient was excluded from the study. However, this was never the case, so there cannot have been any selection bias on disease severity. Selection bias may have developed in comparing the prevalent cases of RA and AS (which were already being treated) with the new, incident cases of "non inflammatory disorders and complaints e.c.i.". For day to day practice, a comparison between the control group and the newly diagnosed cases of RA and AS might have been more appropriate. 
Figure 5

ROC curves llustrating the relation between sensitivity (SENS), specificity (SPEC) and reference values (given at the botton of the figure) of ESR for the complete index group (=theumatoid arthritis and ankylosing spondylitis), in different age ranges, using non-inflammatory disorders and complaints as a combined control group.

$I=0-30$ years; $I=31-45$ years; $I I=46-60$ years; $I V=>60$ years.

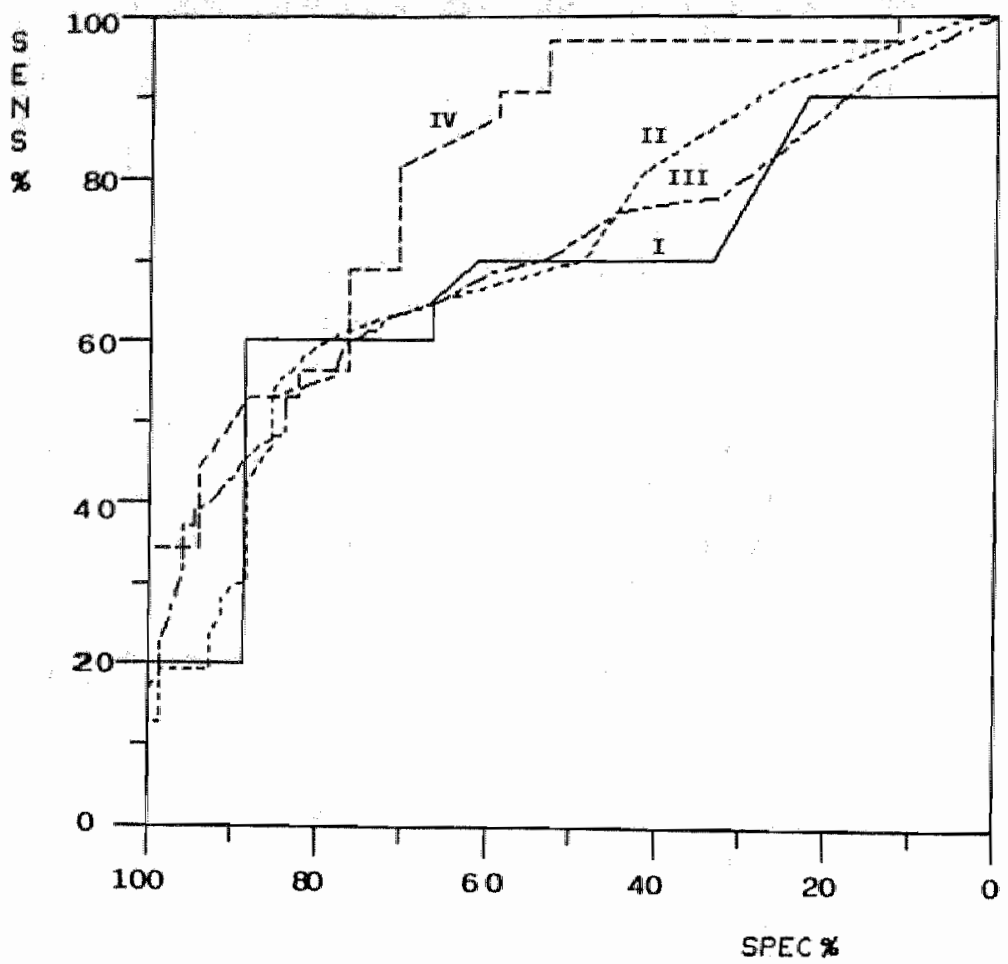

\begin{tabular}{|c|c|c|c|c|c|c|c|c|}
\hline \multirow{2}{*}{$\begin{array}{l}\text { upper limits of } \\
\text { reference values } \\
\text { (cut-off points) } \\
\text { HSR in mm/lhr }\end{array}$} & \multicolumn{2}{|c|}{1} & \multicolumn{2}{|c|}{ II } & \multicolumn{2}{|c|}{ III } & \multicolumn{2}{|c|}{ IV } \\
\hline & $\begin{array}{c}\text { SENS } \\
0 \%\end{array}$ & $\begin{array}{c}\text { SPEC } \\
\%\end{array}$ & $\begin{array}{c}\text { SENS } \\
\%\end{array}$ & $\begin{array}{c}\text { SPEC } \\
\text { Of }\end{array}$ & $\begin{array}{c}\text { SENS } \\
\%\end{array}$ & $\begin{array}{c}\text { SPEC } \\
\text { o\% }\end{array}$ & $\begin{array}{c}\text { SENS } \\
\%\end{array}$ & $\begin{array}{c}\text { SPEC } \\
\% \%\end{array}$ \\
\hline $4[3]$ & 70 & 39 & 70 & 49 & 78 & 32 & {$[97]$} & [12] \\
\hline $7[6]$ & 65 & 67 & 60 & 80 & 69 & 59 & {$[97]$} & {$[35]$} \\
\hline 9 & 60 & 72 & 53 & 86 & 63 & 72 & 97 & 53 \\
\hline 11 & 60 & 78 & 47 & 86 & 61 & 74 & 91 & 53 \\
\hline $13[12]$ & 60 & 89 & {$[43]$} & [89] & {$[59]$} & {$[77]$} & 91 & 59 \\
\hline $14[15]$ & 50 & 89 & 40 & 89 & 54 & 84 & {$[81]$} & {$[71]$} \\
\hline $15[17]$ & 35 & 89 & 32 & 89 & 52 & 84 & [78] & {$[71]$} \\
\hline $21[22]$ & 25 & 89 & 21 & 93 & 41 & 92 & {$[72]$} & {$[71]$} \\
\hline $23[26]$ & 20 & 94 & [19] & [99] & [33] & {$[96]$} & [69] & {$[76]$} \\
\hline $26[29]$ & 20 & 100 & [13] & [99] & {$[26]$} & [97] & {$[59]$} & {$[76]$} \\
\hline
\end{tabular}


Figure 6

ROC curves illustrating the relation between sensitivity (SENS), specificity (SPEC) and reference values (given at the bottom of the figure) of PV and ESR for theumatoid arthritis (RA) and ankylosing spondylitis (AS), using only those patients with normal hemoglobin concentrations $(>8.4 \mathrm{mMol} / /$ in males, $>7.4 \mathrm{~m}: \mathrm{Mol} / \mathrm{l}$ in females), and using non-inflammatory disorders and complaints as a combined control group.

I = ESR, RA; II = PV, RA; III = ESR, AS; IV = PV, AS.

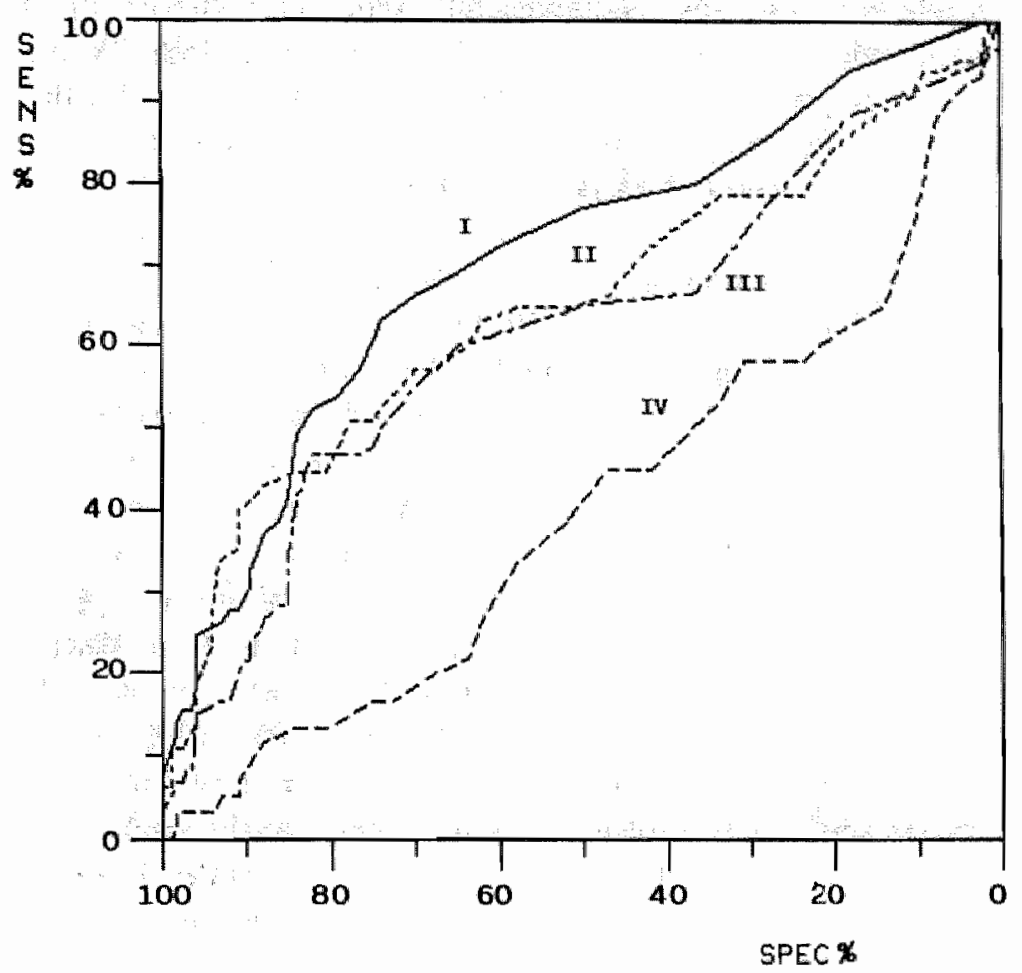

\begin{tabular}{|c|c|c|c|c|c|c|c|c|c|}
\hline \multirow{2}{*}{$\begin{array}{l}\text { upper limits of } \\
\text { reference values } \\
\text { (cut-off points) } \\
\text { ast in mm/lhr }\end{array}$} & \multicolumn{2}{|c|}{1} & \multicolumn{2}{|c|}{ III } & \multirow{2}{*}{$\begin{array}{l}\text { upper limits of } \\
\text { reference values } \\
\text { (cut-off pointsi) } \\
\text { pv in nis? }\end{array}$} & \multicolumn{2}{|c|}{ III } & \multicolumn{2}{|c|}{ IV } \\
\hline & $\begin{array}{c}\text { SENS } \\
\text { 吸 }\end{array}$ & $\begin{array}{c}\mathrm{SPEC} \\
\% \%\end{array}$ & $\begin{array}{c}\text { SENS } \\
00\end{array}$ & $\begin{array}{c}\text { SPEC } \\
\%\end{array}$ & & $\begin{array}{c}\text { SENS } \\
\% \%\end{array}$ & $\begin{array}{c}\text { SPEC } \\
\%\end{array}$ & $\begin{array}{l}\text { SENS } \\
\%\end{array}$ & $\begin{array}{c}B H C \\
\%\end{array}$ \\
\hline 3 & 86 & 27 & 78 & 27 & 1.49 & 100 & 1 & 97 & 1 \\
\hline 8 & 66 & 70 & 55 & 70 & 1.53 & 95 & 5 & 93 & 2 \\
\hline 9 & 63 & 74 & 50 & 74. & 1.60 & 78 & 24 & 58 & 24 \\
\hline 10 & 62 & 75 & 48 & 75 & 1.70 & 57 & 70 & 18 & 70 \\
\hline 12 & 54 & 79 & 47 & 79 & 1.76 & 43 & 88 & 12 & 88 \\
\hline 13 & 52 & 82 & 47 & 82 & 1.77 & 42 & 89 & 10 & 89 \\
\hline 14. & 49 & 84 & 42 & 84 & 1.78 & 40 & 91 & 1 & 91 \\
\hline 21 & 31 & 90 & 22 & 90 & 1.86 & 11 & 98 & 3 & 98 \\
\hline 28 & 18 & $98:$ & 13 & 96 & 1.87 & 11 & 98 & 3 & 98 \\
\hline 35 & 11 & 99 & 1 & 99 & 1.93 & 6 & 99 & 0 & 99 \\
\hline
\end{tabular}


However, in our opinion, the lack of comparable results from other studies and the low incidence of new cases justifies the choice of the present study design.

Since in our study ESR was an inclusion criterium for neither RA nor AS, one may also question the relevance of comparing these diseases with the control group. However, the aim of our study was to compare inflammatory with non-inflammatory diseases, with respect to PV and ESR. Both PV and ESR are assumed to reflect inflammatory conditions, and they are used for that purpose. ESR was still described as a useful aid in diagnosing RA recently (23-25).

The rheumatologists in our study assessed diagnoses by using all information except PV and ESR. Other methods, like consensus analysis and computerized models have been used by several investigators $(6,7,26)$. After ranking 31 laboratory tests by consensus analysis, PV and ESR were found to be most useful in following treatment effects in patients suffering from clinically active synovitis (6). Consensus analysis was also used to monitor disease activity in RA, using 7 different laboratory tests (7). In this study ESR was found to be a better guide to disease severity than all other tests, including the measurement of the Zeta sedimentation rate (ZSR), which is not influenced by anemia (27). ZSR could be a reasonable alternative to PV as well as ESR because of its low dependency on the packed cell volume, which strongly influences ESR (1). However, the complexity of measuring ZSR means that it is at present not a very interesting method.

The diagnostic value of the measurement of C-reactive protein (CRP) has been investigated several times. The authors mainly conclude that, compared to ESR, CRP will be of interest for monitoring response to treatment in the (outpatient) clinic $(1,5,28)$. Furthermore, CRP was found of no use in addition to body temperature and ESR for the diagnosis of infections in an internal medicine emergency unit (29). A recent comparitive study on ESR and several acute phase proteins showed no advantage of the latter in detecting underlying infections or inflammations in elderly people (30). Finally, ESR was found to be a reasonably good test for measuring the joint concentrations of blood plasma proteins in patients with elevated ESR (31). 
The advantages of measuring PV instead of ESR include its good reproducibility (32). PV blood samples can be examined up to a week after collection, or even later, after being frozen. The Viscometer II, which may be considered more convenient than the older Harkness viscometer $(33,34)$, can be tested in less than 60 seconds, with each PV measurement taking less than a minute. An appropriate correction for room temperature is performed automatically (32), and results from different laboratories are directly comparable. A disadvantage of the Viscometer II is that it is still necessary to centrifuge blood samples before measuring PV $(1,34)$. ESR may be considered more sensitive to inaccurate test performance (35). In general practice, the quality of the desktop laboratory is especially important (36), and a high quality measurement might be more easily obtained for PV.

The relatively poor discriminating ability of PV which we found in our study allows no conclusion about the ability of PV to discriminate between more contrasting diseases. However, we preferred the present study design, since it was carried out within one out-patient clinic with clearly diseased patients and well defined controls. Moreover, we used diseases which are well known and frequently treated in general practice $(37,38)$. The results are directly applicable: our conclusions make it less interesting to investigate the discriminating ability of PV in a less diverging spectrum of diseases, such as that found in general practice (18). For the time being, we conclude that general practitioners will not benefit from measuring PV instead of ESR, as far as diagnostic activities are concerned. Furthermore, whereas general practitioners frequently and cheaply perform ESR in their own surgery, switching over to PV would require an important financial investment.

After all these years, ESR still lives up to its reputation.

\section{References}

1. International Committee for Standardization in Haematology. Guidelines on selection of laboratory tests for monitoring the acute phase response. $J$ Clin Pathol 1988; 41: 1203-12.

2. Crawford J, Eye-Boland MK, Cohen HJ. Clinical utility of the erythrocyte sedimentation rate and plasma protein analysis in the elderly. Am $J \mathrm{Med}$ 1987; $82: 239-46$. 
3. Bartolin $R$, Bowvenot $G$, Sermet $\mathbb{E}$, Pteschi $M$, Delby $C$. Que penser de la mesure simultane de la vitessse de sedimantation de la fibrinemie et de lalpha-2 globulinemie dans la cadre du "syndrome inflammatoire biologique" en pratique medicale courante? [summary in English] Sermin Hosp Paris 1987; 57: 1424-5.

4. Calwin $J$, Nealle $G$, Fotherby $K J$, Price CP. The relative merits of acute phase proteins in the recognition of inflammatory conditions. Ann Clin Biochen $1988,25,60-6$.

5. Stuart I, Lewis SM. Monitoring the acute phase response; alternative tests to measuring erythrocyle sedimentation rate. Br Med J 1988; 297:1143-4.

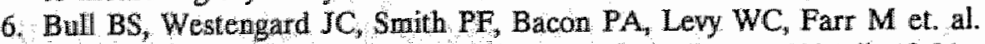
Ranking of laboratory tests by consensus analysis. Lancet 1986; i: 18-21.

7. Bull BS, Farr M, Meyer PJ, Westengard JC, Bacon PA, Stuart J. Efficacy of tests used to monitor rheumatoid arthritis. Lancet 1989 ; i: 965-7.

8. Sox HC, Liang MH. The erythrocyte sedimentation rate; guidelines for rational use. Ann Intem Med 1986; 104: 515-23.

9. Harkness $J$. The viscosity of human blood plasma; its measurement in health and discase. Blorheology 1971;8:171-93.

10. Hutchinson RM, Eastham RD. A comparison of the erythrocyte sedimentation rate and plasma viscosity in detecting changes in plasma proteins. Chis Pathol 1977; 30: 345-9.

11. Crook L, Liu PI, Gadsden RH, Turner RE. Erythrocyte sedimentation, viscosity, and plasma protein in disease detection. Ann Clin Lab Sci 1980; 10: $368-76$.

12. Pickup ME, Dixon JS, Hallett C, Bird HA, Wricht V. Plasma viscosity - a new appraisal of its use as an index of disease actiwity in rheumatoid arthritis. Ann Rheum Dis 1981; 40: 272-5.

13. The ESR - an outdated test? [editorial] Lancel 1982; i: 377-8.

14. Lewis SM. Erythrocyte sedimentation rate and plasma viscosity. Association of Clinical Pathologists. Broadsheet 94: June 1980.

15. Eastham RD. Simple rule for calculating normal erythrocyte sedimentation rate. [letter] $\mathrm{Br}$ Med $I 1983 ; 286: 557-8$.

16. Goel The HS. The clinical spectrum of chronic inflammatory back pain in hospital referred patients. [thesis] Voerendaal: Schrijen-Lippertz, 1987.

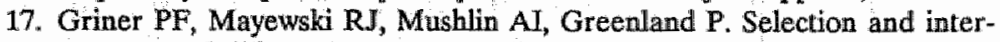
pretation of diagnostic tests and procedures. Ann Intern Med 1981; 94: $553=600$.

18. Feinstein AR. Clinical epidemiology" the architecture of clinical research. Philatelphia: WB Saunders Company, 1985.

19. Oerhardt $W$, Keller $H$. Evautuation of test data from clinical studies. Scand $J$ Chin Lab lnvest, 1985. Supplement.

20. Dinant GiJ, Knottmerus JA, Wersch JWJ Van. Desktop laboratory in general practice; the discriminating ability of the erythrocyte sedimentation rate. Accepted for publication.

21. Kenny MW, Worthington DJ, Stuart $J$, Dawies $\mathrm{AJ}_{\text {, Farr }} \mathrm{M}$, Davey $\mathbf{P G}_{\text {, t }}$ al. Elficiency of haematological screening tests for detecting disease. Clin Lab Haematol 1981; 3: 299-305.

22. Dinant HJ. Ferrokinetiek bij reumatoide arthrits. [thesis, summary in English] Oroningen: VRB, 1978.

23. Aaron SL. Laboratory tests in rheumatic diseases. Can Fam Physician $1988 ; 34: 357-61$.

24. Wright V. Osteoarthritis. Br Med J 1989; 299:1476-7. 
25. Rafisson V, Bengtsson $C$, Lurie $M$. Erythrocyte sedimentation rate in women with different manifestations of joint disease. Scand $J$ Rheuntatol 1982; 11: $87-95$.

26. Stoneham M, Wisniewwsi T. Towards earlier diagnosis of colorectal malignancy. Practitioner 1988; 232: 1309-13.

27. Bull BS, Brailsford JD. The Zeta sedimentation ratio. Blood 1972; 40: 550-9.

28. Leeuwen MA van, Rijswijk MH van, Westra J, Jong HJ de, Marrink J. Creactieve proteine; een dure bezinking? Ned Twdschr Geneeskd 1986;130: 1391-5.

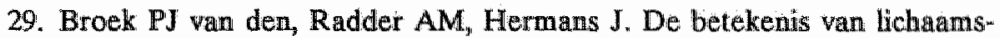
temperatuur, bezinking, C-reactief proteine, leukocytenaantal en -differentiatie voor de diagnostiek van infecties op een eerstehulpafdeling voor inwendige geneeskunde. [summary in English] Ned Tijdschr Geneeskd 1990, 134: $2536-40$.

30. Katz PR, Karuza I, Gutman SI, Bartholomew W, Richman G. A comparison between erythrocyte sedimentation rate (ESR) and selected acutephase proteins in the elderly. Am I Clin Pathol 1990; 94: 637-40.

31. Ruhenstroth-Baver $G_{3}$ Schedler $K$, Scherer $R$, Vesterberg $O$. On the possibility of differential diagnosis at elevated erythrocyte sedimentation rate by analysis of the concentrations of blood plasma proteins - A model study. J Clin Chem Clin Biochem 1990; 28: 845-50.

32. Metz M De, Calseyde JF Van De. Viscositeitsmeting met de Coulter Viscometer II [summary in english]. Tijdschr NLKC 1989; 14: 42-6.

33. International Committee for Standardization in Haematology. Recommendation for a selected method for the measurement of plasma viscosity. $J$ Clin Pathol 1984; 37: 1147-52.

34. Cooke BM, Stuart J. Automated measurement of plasma viscosity by capillary viscometer. J Clin Pathol 1988; 41: 1213-6.

35. Dinant GJ, Knotmerus JA, Aubel PGJ Van, Wersch JWJ Van. Reliability of ESR in general practice. Scand I Prim Fiealth Care 1989; 7: 231-5.

36. Stott NCH. Desktop laboratory technology in general practice. Br Med $J$ 1989; 299: $579-80$.

37. Vetter NJ, Carny M, Lewis PA, Farrow S. Prevalence and treatment of symptoms of rheumatism and arthritis among over 65 year olds: a community profile. Br I Gen Pract 1990; 40: 69.71.

38. Treasure E, Scott DL, Katona PM, Toon P. Arthritis in inner city general practices. Br J Gen Pract 1990; 40: 81-2. 

4.2 The leucocyte count in general practice; its discriminating ability in relation to the erythrocyte sedimentation rate

G.J. Dinant, J.A. Knottnerus, J.W.J. VAN Wersch

Accepted for publication in the Scandinavian Journal of Primary Health Care 
We investigated the abillity of the determination of the leucocyte count to discriminate between "pathology" (= inflammatory diseases and malignancies) and "no pathology" in general practice, and compared this ability with that of the erythrocyte sedimentation rate (ESR). In cooperation with nine general practitioners (GP) we prospectively followed 151 patients who were seen by their GP because of a new complaint for which the GP wanted to know their ESR. ESR and two different leucocyte count measurements (Technicon H6000 and Sysmex E-4000) were performed at the local hospital laboratory. The patients were seen again after three months, in order to determine the follow-up diagnoses. The agreement between the two leucocyte count test outcomes was found to be high (correlation coefficient $=96.5 \%$, regression coefficient $=0.99$ ). By comparing the test results with the follow-up diagnoses, ESR was found to have a better discriminating ability than both leucocyte count tests (ESR: sensitivity $=53 \%$, specificity $=$ $84 \%$, positive predictive value $=29 \%$, negative predictive value $=93 \%$, Odds Ratio $=5.73$ ). Using Receiver Operating Characteristic (ROC) analysis, this conclusion could be shown to be independent of the chosen reference values. We conclude that the determination of the leucocyte count is not a clinically interesting alternative to ESR.

Keywords: leukocyte count, erythrocyte sedimentation rate, discriminating "ability, inflammatory disorder, malignancy 


\section{Introduction}

Little is known about the ability of of the leucocyte count determination to reveal serious diseases in general practice. The determination of the erythrocyte sedimentation rate (ESR) is frequently used for that purpose, and is regarded as a nonspecific indicator. We therefore studied the ability of the leucocyte count, as compared to ESR, to discriminate between serious diseases, requiring for therapy ("pathology") and harmless, often selflimiting diseases ("no pathology") in everyday general practice.

The leucocyte count and ESR are well known as parameters for the detection of inflammatory conditions. The physiological relation between these two parameters is partly causal; immunoglobulins increase red cell rouleaux formation and hence ESR. Both the leucocyte count and ESR have been investigated with respect to the clinical indications for their use, as well as with respect to interpretation of the results and aspects of reliability (1).

Most reports on the discriminating ability of the leucocyte count and ESR concentrate on patients referred to the hospital, on the suspicion of having a certain disease (1), e.g. appendicitis (2), adnexitis (3), or diverticulitis (4). With respect to appendicitis, the leucocyte count was found to be a better diagnostic parameter than ESR (2). Leukocytosis appeared to be a good predictor of bacterial infections in the elderly (5). ESR was found to be an unsuitable predictor of ischemic heart disease (6). With respect to all-cause mortality, the leucocyte count was found to be an independent predictor (7). Cardio-vascular and cerebro-vascular diseases, as well as cancer, have been related to the leucocyte count levels (8-14).

Age and gender may be considered relatively important in the clinical interpretation of ESR with respect to diagnosing "pathology". The leucocyte count decreases in women during aging, but increases in men $(15,16)$. The clinical importance of these changes is not clear. The interpretation of ESR suffers from the necessity to adjust for the red cell volume, pregnancy and medication (17). 
Despite its easy determination, ESR was found to be fairly sensitive to inaccurate test performance in the general practice office (18). The microscopical chamber count of leucocytes, and particularly its differentiation, requires a reasonably experienced laboratory worker and is therefore less frequently performed in the general practice surgery. A study of the quality of laboratory analysis in primary health care revealed large variations in measurements of ESR and leukocyte counts $(18,19)$. Our study pays attention to these aspects of reliability by comparing leucocyte counts measured by two different fully automated counters.

\section{Methods}

Nine general practitioners (GP) participated in the study. During 5 successive months they identified each patient presenting with a new complaint for which the GP considered determination of ESR to be indicated (the so-called indicated population). Children (aged 0-15) were excluded from the study. After informed consent, the name, date of birth and gender of the patient were recorded and a venous blood sample was taken from the patient's arm. To prevent clotting, the blood was collected in ethylenediaminetetra-acetate (EDTA-K3) tubes. The samples were collected daily in order to determine Westergren's ESR and the leucocyte count at the local hospital laboratory. The leucocyte count was measured using a Technicon H6000 (Technicon, Gorinchem, the Netherlands) (leuco1) and a Sysmex E-4000 (Goffin, IJsselstein, the Netherlands) (leuco2). The patients were requested to revisit the GP's office after three months. Where necessary, patients received a written reminder or a telephone call after the three months had expired. During the revisits, the investigator established the follow-up diagnosis by interviewing the patient, reviewing the chart and hospital letters, and asking additional information from the GP if necessary. The follow-up diagnoses were classified according to the International Classification of Health Problems in Primary Care (ICHPPC-2-defined) (20), this being the preferred system in assessing unequivocal diagnoses (21). ICHPPC-2defined was partly modified by adding pneumonia, arthritis and fever e causa ignota to the original category of "infective and parasitic diseases", indicated hereafter as inflammatory diseases. 
As far as possible, inflammations involving the other tracts wrere also added to the category of inflammatory diseases. In the "neoplasms" category we found two malignant cases, referred to below as malignancies. "Pathology" was defined as inflammatcry diseases and malignancies. "No pathology" was taken to mean that the follow-up diagnoses included only the categories "signs, symptoms and ill defined conditions", as well as "adverse effects", "supplementary classification" and "preventive medicine". Within these categories our cases were minor and spontaneously resolving problems (22). Hence, the category of "all other diseases" excluded "pathology" and "no pathology".

In the analysis we calculated sensitivity, specificity and predictive values (which together constitute the discriminating ability of a test), according to the current definitions of these terms (23). The values were derived from crosstables of measured leucocyte count and ESR values and the corresponding followup diagnoses. We used Receiver Operating Characteristics (ROC) curves to study the relation between sensitivity, specificity and reference values (24). Odds Ratios were computed to illustrate the value of a combination of sensitivity and specificity in discriminating "pathology" from "no pathology" and "all other diseases". Pearson's Chi Square test for independent proportions was used to test the level of statistical significance of the relations between measured leucocyte counts and ESR values. Finally, we calculated Pearson's correlation coefficient and the linear regression coefficients for the agreement between both sets of leucocyte count measurements.

\section{Results}

A total of 151 consecutive patients (43 males, 108 females) were entered into the study. Their ages varied between 16 and 87 (mean 49 , median 51 , mode not unique, SD 18 years). Table 1 shows the distribution of age and gender in relation to the categories "pathology", "no pathology" and "all other diseases". "Pathology" was more frequently found for advanced age (over 70 years: $25 \%[5 / 20]$; versus $9 \%[12 / 131]$ in younger subjects) and for males (12\%[5/41], versus $11 \%$ [12/110] in females). The numerical distribution of the measured ESR values as well 
as of the two leucocyte counts, in relation to "pathology" and all diagnoses except "pathology" is given in Table 2. We did not find any important differences between the distributions of the leuco1 and leuco2 values. High ESR values were more frequently found in the "pathology" group.

Table 1. Numenical distribution of age and gender in relation to the followup diagnoses "pathology" (= inflammatory diseases and mallignancies), "no pathology" and "all other diseases".

\begin{tabular}{lccccccc}
\hline $\begin{array}{l}\text { age } \\
\text { (years) }\end{array}$ & $\begin{array}{c}\text { "pathology" } \\
\text { male female }\end{array}$ & male female & $\begin{array}{l}\text { tothology" } \\
\text { male female }\end{array}$ & tother \\
\hline $16-20$ & 0 & 0 & 1 & 4 & 0 & 0 & 5 \\
$21-30$ & 1 & 1 & 1 & 12 & 4 & 8 & 27 \\
$31-40$ & 0 & 2 & 3 & 8 & 6 & 8 & 27 \\
$41-50$ & 1 & 1 & 0 & 1 & 6 & 6 & 15 \\
$51-60$ & 1 & 2 & 2 & 7 & 3 & 17 & 32 \\
$61-70$ & 1 & 2 & 1 & 4 & 3 & 14 & 25 \\
$71-87$ & 1 & 4 & 1 & 2 & 5 & 7 & 20 \\
\hline totalls & 5 & 12 & 9 & 38 & 27 & 60 & 151 \\
\hline
\end{tabular}

Table 2. Numerical distribution of ESR and leucocyte count values measured by the Technicon H6000 (leuco1) and the Sysmex E-4000 (leuco2), in relation to the follow-up diagnoses "pathology" ( = inflammatory diserases and malignancies) $(\mathrm{P}+)$ and all diagnoses except "pathology" (P-).

\begin{tabular}{|c|c|c|c|c|c|c|c|}
\hline \multirow[b]{2}{*}{$\begin{array}{l}\text { I }^{2} \text { ange } \\
(\mathrm{mm} / 1 \mathrm{hr})\end{array}$} & \multicolumn{2}{|c|}{$\mathrm{ESR}$} & \multirow[b]{2}{*}{$\begin{array}{l}\text { range } \\
\left(\times 10^{\circ} / 1\right)\end{array}$} & \multicolumn{2}{|c|}{ leuco1 } & \multicolumn{2}{|c|}{ leuco2 } \\
\hline & $\mathrm{P}+$ & P. & & $P+$ & $\mathrm{P}$ & $P+$ & P. \\
\hline $0-10$ & 3 & 66 & $0-3.0$ & 0 & 0 & 0 & 0 \\
\hline $11-20$ & 5 & 38 & $3.1-6.0$ & 7 & 41 & 6 & 35 \\
\hline $21-30$ & 2 & 17 & $6.1-9.0$ & 6 & 67 & 4 & 60 \\
\hline $31-60$ & 5 & 11 & $9.1-12.0$ & 2 & 18 & 3 & 9 \\
\hline$>60$ & 2 & 2 & $>120$ & 1 & 5 & 0 & 3 \\
\hline totals* & 17 & 134 & & 16 & 131 & 13 & 107 \\
\hline
\end{tabular}

- Lencol could not be measured in 4 cases, while leuco 2 could not be measured in 31 cases. At least one leucocyte count measurement was performed in all patients (see Discussion). 
The relation between measured ESR values and the two leucocyte counts can be seen from Table 3. After dichotomising the leucocyte counts at $9.0 \times 10^{\circ} / 1$ and ESR at 20 and $30 \mathrm{~mm} / 1 \mathrm{hr}$, Pearson's Chi Squares were calculated as $1.27(0.25<\mathrm{p}<0.5$, ESR cut-off point at $20 \mathrm{~mm} / 1 \mathrm{hr})$ and $8.94(0.001<\mathrm{p}<0.01$, ESR cut-off point at $30 \mathrm{~mm} / 1 \mathrm{hr}$ ) for leuco1, and 7.94 as $(0.001<\mathrm{p}<0.01$, ESR cut-off point at $20 \mathrm{~mm} / 1 \mathrm{hr})$ and 20.38 ( $\mathrm{p}<0.001$, ESR cut-off point at $30 \mathrm{~mm} / 1 \mathrm{hr}$ ) for leuco2 (in each case one degree of freedom). Pearson's correlation coefficient for the agreement between the measured leucol and leuco 2 values was found to be $96.5 \%$ ( $p<0.001$ ). The linear regression coefficient was 0.99 (confidence interval $[\mathrm{CI}]=$ $0.95-1.00$, intercept $=3.9$ ).

Table 3. Relation between ESR and leucocyte counts* measured by the Technicon H6000 (leuco1) and the Sysmex E-4000 (leuco2). Numbers. of corresponding measurements are listed.

\begin{tabular}{lrrrrrr}
\hline $\begin{array}{l}\text { ESR } \\
(\mathrm{mm} / 1 \mathrm{hr})\end{array}$ & \multicolumn{3}{c}{$\begin{array}{c}\text { leuco1 } \\
\left(\mathrm{x} 10^{9} / 1\right)\end{array}$} & & \multicolumn{3}{c}{$\begin{array}{c}\text { lenco2 } \\
\left(\times 10^{9} / 1\right)\end{array}$} \\
& $3.1-9.0$ & $9.1-12.0$ & $>12.0$ & $3.1-9.0$ & $9.1-12.0$ & $>12.0$ \\
\hline $0-20$ & 92 & 13 & 4 & 84 & 4 & 3 \\
$21-30$ & 18 & 1 & 0 & 14 & 1 & 0 \\
$>30$ & 11 & 6 & 2 & 7 & 7 & 0 \\
\hline totals & 121 & 20 & 6 & 105 & 12 & 3 \\
\hline
\end{tabular}

* Leucocyte counts below $3.1\left(\times 10^{\circ} / 1\right)$ were not found.

The relation between sensitivity and specificity with respect to "pathology" and "all other diseases", for varying cutwoff points, can be seen from the ROC curve in Figure 1. In constructing the ROC curves, "no pathology" was used as a reference group. Figure 2 illustrates the ability of the tests, in terms of sensitivity and specificity, to discriminate between "pathology" and "no pathology". For the ROC curves in Figure 3 we combined "no pathology" and "all other diseases" into one reference group. Both leucocyte counts failed to discriminate with regard to "pathology" and "all other diseases", as well as with regard to "pathology" allone, irrespective of the chosen reference group. From the ESR curve in Figure 3 we calculated the optimal cutoff point, corresponding with the maximum sum of sensitivity 
Rugure 1

$\mathrm{ROC}$ etryes illustrating the relation between sensitivity (SENS), specificity (SPEC) and reference yalues (indicated at the bottom of the figure) of ESR and leucocyte counts, measured by the Technicon H6000 (leuco1) and the Sysmex E-4000 (letco2), with respect to "pathology (= inflammatory diseases and malignancies) and "all other diseases" $(N=104)$ combined, using "no pathology $(N=47)$ as a reference group.

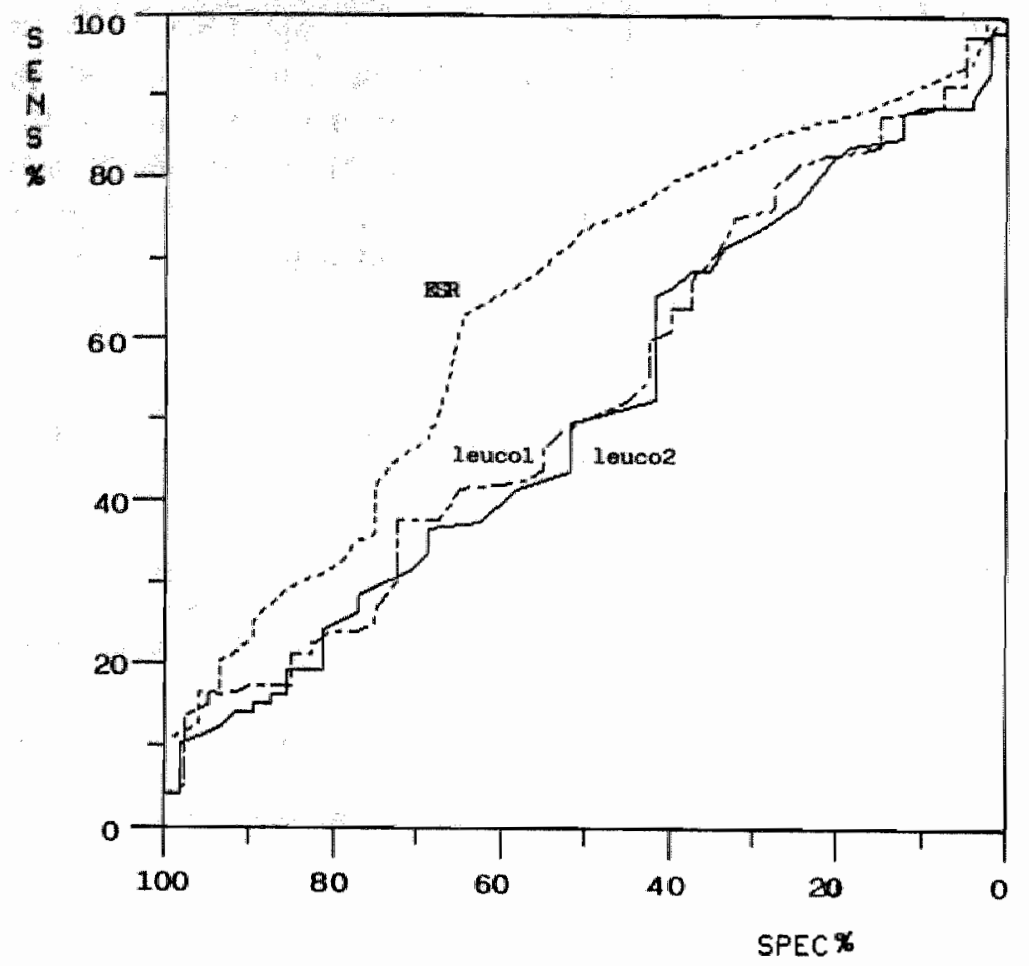

\begin{tabular}{|c|c|c|c|c|c|c|c|}
\hline \multirow{2}{*}{$\begin{array}{l}\text { upper limits of } \\
\text { reference values } \\
\text { (cut-of points) } \\
\text { ESR in min/Lhr }\end{array}$} & \multicolumn{2}{|c|}{ ERS } & \multirow{2}{*}{$\begin{array}{l}\text { upper limits of } \\
\text { reference values } \\
\text { (cut off points) } \\
\text { leuco in } 10^{9} / 1\end{array}$} & \multicolumn{2}{|c|}{ lenco 1} & \multicolumn{2}{|c|}{ leuco 2} \\
\hline & $\begin{array}{c}\text { SENS } \\
\%\end{array}$ & $\begin{array}{c}\text { SPEC } \\
\text { W }\end{array}$ & & $\begin{array}{c}\text { SENS } \\
\% \%\end{array}$ & $\begin{array}{c}\text { SPEC } \\
\%\end{array}$ & $\begin{array}{c}\text { SENS } \\
\%\end{array}$ & $\begin{array}{c}\text { SPEC } \\
\%\end{array}$ \\
\hline 2 & 98 & 2 & 3.9 & 98 & 0 & 98 & 5 \\
\hline 9 & 68 & 56 & 5.6 & 77 & 25 & 75 & 33 \\
\hline 10 & 63 & 65 & 6.4 & 66 & 42 & 60 & 43 \\
\hline 14 & 42 & 75 & 7.5 & 37 & 63 & 35 & 73 \\
\hline 19 & 32 & 79 & 8.4 & 25 & 79 & 21 & 85 \\
\hline 24 & 25 & 90 & 9.4 & 15 & 88 & 13 & 98 \\
\hline 27 & 21 & 92 & 10.4 & 10 & 98 & 7 & 98 \\
\hline 28 & 20 & 94 & 10.7 & 9 & 98 & \multicolumn{2}{|c|}{$\begin{array}{l}\text { no values } \\
\text { available }\end{array}$} \\
\hline 31 & 17 & 96 & 11.4 & values & available & 5 & 98 \\
\hline 34 & 12 & 98 & 12.1 & 4 & 98 & $\begin{array}{l}\text { no } w \\
\text { avail }\end{array}$ & $\begin{array}{l}\text { alues } \\
\text { able }\end{array}$ \\
\hline
\end{tabular}


Figure 2

ROC eurves Ilustrating the relation between sensitivity (SENS), specificity (SPEC) and reference values (indicated at the bottom of the figure) of ESR and leveocyte counts, measured by the Technicon H6000 (leucol) and the Sysmex E-4000 (leuco2), with respect to "pathology" (- inflammatory diseases and malignancies $)(N=17)$, using "no pathology" $(N=47)$ as a reference group.

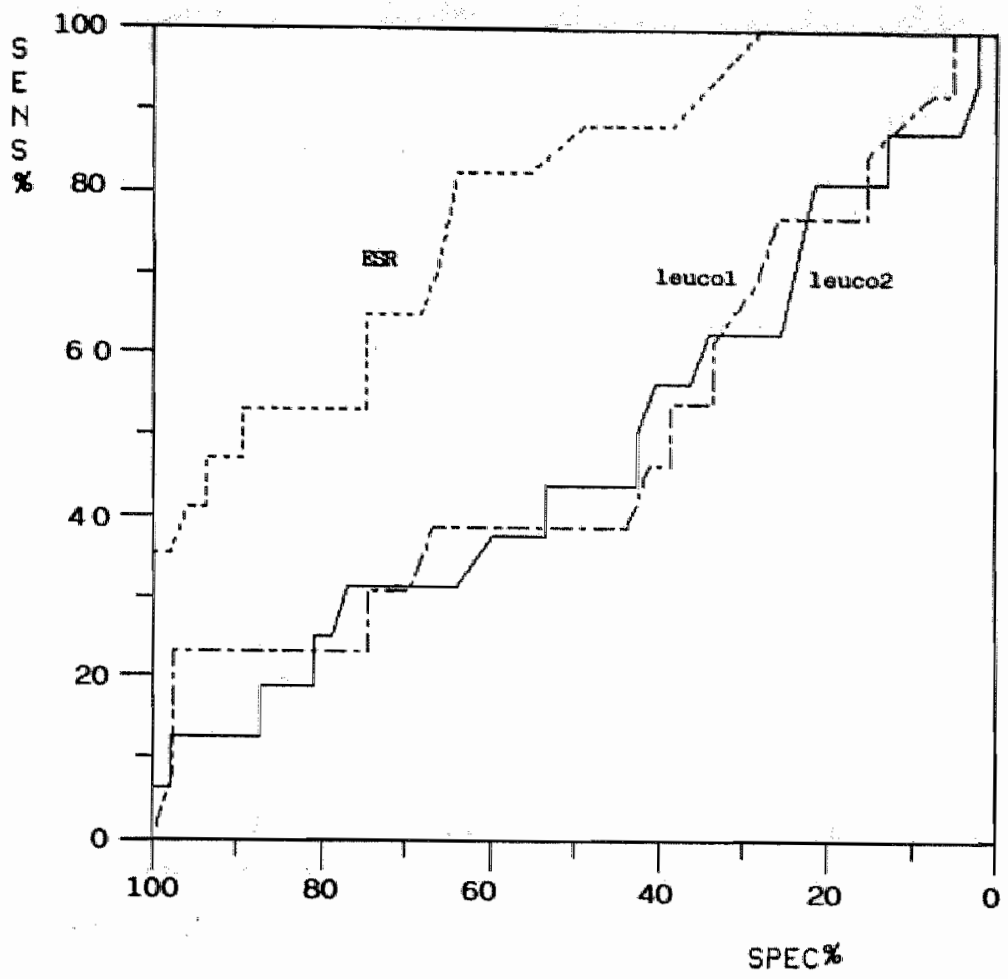

\begin{tabular}{|c|c|c|c|c|c|c|c|}
\hline \multirow{2}{*}{$\begin{array}{l}\text { upper limits of } \\
\text { reference values } \\
\text { (cut-off points) } \\
\text { ESR in mm/1hr }\end{array}$} & \multicolumn{2}{|c|}{ ERS } & \multirow{2}{*}{$\begin{array}{l}\text { upper limits of } \\
\text { reference values } \\
\text { (cut-off points) } \\
\text { leuco in } 10^{\circ} / 1\end{array}$} & \multicolumn{2}{|c|}{ loneo 1} & \multicolumn{2}{|c|}{ letuco 2} \\
\hline & $\begin{array}{c}\text { SENS } \\
\%\end{array}$ & $\begin{array}{c}\text { SPEC } \\
\%\end{array}$ & & $\begin{array}{c}\text { SENS } \\
\%\end{array}$ & $\begin{array}{c}\text { SPEC } \\
\%\end{array}$ & $\begin{array}{c}\text { SENS } \\
\%\end{array}$ & $\begin{array}{c}\text { SPEC } \\
\%\end{array}$ \\
\hline 6 & 88 & 38 & $4.5[4.2]$ & 94 & 2 & {$[92]$} & [5] \\
\hline 9 & 82 & 55 & 5.6 & 63 & 26 & 62 & $33^{\circ}$ \\
\hline 10 & 82 & 64 & 6.4 & 50 & 43 & 38 & 44 \\
\hline 14 & 65 & 74 & 7.3 & 38 & 60 & 31 & 69 \\
\hline 19 & 53 & 79 & 8.0 & 31 & 77 & 23 & 79 \\
\hline 24 & 53 & 89 & 87 & 19 & 81 & 23 & 87 \\
\hline 27 & 47 & 91 & 9.0 & 19 & 85 & 23 & 95 \\
\hline 28 & 47 & 94 & 10.4 & 13 & 98 & \multicolumn{2}{|c|}{$\begin{array}{l}\text { no values } \\
\text { available }\end{array}$} \\
\hline 31 & 41 & 96 & 11.4 & 0 values & 5 awailable & 8 & 97 \\
\hline 34 & 35 & 98 & 11.8 & 6 & 98 & 0 & 100 \\
\hline
\end{tabular}


Figute 3

ROC curves ilustrating the relation between sensitivity (SENS), specificity (SPEC) and reference values (indicated at the bottom of the figure) of ESR and leveocyte counts, measured by the Technicon H6000 (leuco1) and the Sysmex E-4000 (leuco2), with respect to "pathology" (= inflammatory diseases and malignancies) $(\mathrm{N}=17)$, using "no pathology" and "all other diseases" (N 134) as a reference group.

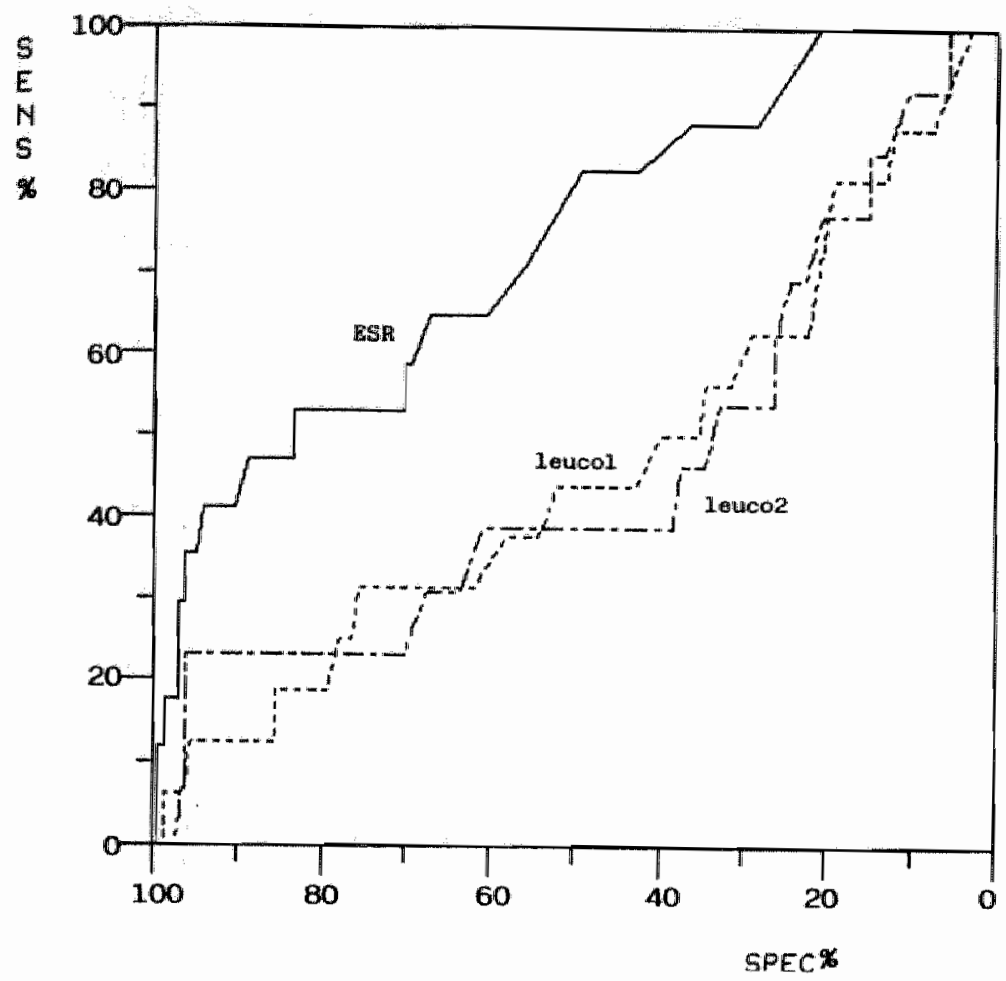

\begin{tabular}{|c|c|c|c|c|c|c|c|}
\hline \multirow{2}{*}{$\begin{array}{l}\text { upper limits of } \\
\text { reference values } \\
\text { (cut-off points) } \\
\text { ESR in mm/1hr }\end{array}$} & \multicolumn{2}{|c|}{ BRS } & \multirow{2}{*}{$\begin{array}{l}\text { upper limits of } \\
\text { reference values } \\
\text { (cut-off points) } \\
\text { leuco in } 10^{9} / 1\end{array}$} & \multicolumn{2}{|c|}{ Jenco 1} & \multicolumn{2}{|c|}{ lenco 2} \\
\hline & $\begin{array}{c}\text { SRNS } \\
\% \%\end{array}$ & $\begin{array}{c}\text { SPEC } \\
\%\end{array}$ & & $\begin{array}{c}\text { SENS } \\
\%\end{array}$ & $\begin{array}{c}\text { SPEC } \\
\%\end{array}$ & $\begin{array}{c}\text { SENS } \\
\%\end{array}$ & $\begin{array}{c}\text { SPEC } \\
\%\end{array}$ \\
\hline 6 & 88 & 28 & $4.5[4,2]$ & 94 & 5 & [92] & {$[6]$} \\
\hline$\dot{9}$ & 82 & 43 & 5.6 & 63 & 22 & 62 & 26 \\
\hline 10 & 82 & 49 & 6.4 & 50 & 35 & 38 & 38 \\
\hline 14 & 65 & 67 & 7.3 & 38 & 58 & 31 & 64 \\
\hline 19 & 53 & 75 & 8.0 & 31 & 74 & 23 & 77 \\
\hline 24 & 53 & 84 & 8.7 & 19 & 79 & 23 & 85 \\
\hline 27 & 47 & 87 & 9.4 & 13 & 85 & 23 & 93 \\
\hline 29 & 47 & 89 & $10.7[9.8]$ & 13 & 94 & [23] & [95] \\
\hline 35 & 35 & 96 & $11.3[10.4]$ & 13 & 95 & {$[23]$} & {$[96]$} \\
\hline 42 & 24 & 97 & 11.8 & 6 & 96 & 0 & 97 \\
\hline
\end{tabular}


and specificity (25). For this theoretically optimal upper limit of reference values, sensitivity, specificity, and their CIs are presented in Table 4. The Odds Ratio, prevalence and predictive values concerned can be read from the same table.

Table 4. Sensitivity (S) and specificity (T) of ESR, with their $95 \%$ confidence intervals (Cr), with regard to "pathology" ( = inflammatory diseases and malignancies), calculated from the ESR curve in Figure 3 at the optimal cut-off point $(C O, 24 \mathrm{~mm} / 1 \mathrm{~h})$. The Odds Ratio (OR) and the sum of sensitivity and specificity $(S+T)$ can be read from the sixth and seventh columns; respectively. Prevalence (P) and the positive $(\mathrm{PV}+)$ and negative predictive values (PV-), with their sum (Psum, see final column), are also listed.

\begin{tabular}{lllllllllllll}
\hline $\begin{array}{l}\mathrm{CO} \\
(\mathrm{mm} / 1 \mathrm{hr}) \%\end{array}$ & $\mathrm{Cl}$ & $\%$ & $\mathrm{~T}$ & $\begin{array}{c}\text { OR } \\
\%\end{array}$ & $\begin{array}{c}\mathrm{S}+\mathrm{T} \\
\%\end{array}$ & $\begin{array}{l}\mathrm{P} \\
\%\end{array}$ & $\begin{array}{l}\mathrm{PV}+ \\
\%\end{array}$ & $\%$ & PV- Psum \\
\hline 24 & 53 & $29-77$ & 84 & $78-90$ & 5.73 & 137 & 11 & 29 & 93 & 122 \\
\hline
\end{tabular}

\section{Discussion}

As far as the indicated population in general practice is concerned, ESR was found to be a better parameter than the two leucocyte count measurements for revealing "pathology", which is in accordance with a recent study on the subject (26). The ROC analysis (Figures 1-3) shows that this conclusion can be regarded as independent of the chosen reference values. Compared to the measured leucocyte counts, ESR values were found to be more frequently elevated in the presence of "pathology" (Table 2). The agreement between the leucocyte counts measured by the Technicon $\mathrm{H} 6000$ and the Sysmex E-4000 was found to be good.

Since leuco 1 could not be measured in four cases, the results may have been biased for the leucol's discriminating ability, as compared to ESR. These four cases concerned three patients who suffered from other diseases than "pathology" or "no pathology", and one patient who suffered from an inflammatory disease and was found to have an ESR of $50 \mathrm{~mm} / 1 \mathrm{~h}$. Only if an extreme leukocytosis had been found in the latter patient would the difference between the leucol and ESR curves have been slightly smaller. In view of the high correlation (96.5\%) and regression coefficients $(0.99)$, and since the leucol and 
leuco2 curves are almost equal, we think that similar conclusions may be drawn with respect to leuco2, despite the fact that 31 leuco 2 values were missing. The loss of these values was probably caused by the fact that the laboratory personnel lacked the necessary routine for double measurements of the leucacyte count. The relation between measured ESR values and the corresponding follow-up diagnoses in these cases can be seen from Table 5 . High ESR values (> $30 \mathrm{~mm} / 1 \mathrm{hr}$ ) were more frequently found in the "pathology" category $(2 / 4,50 \%)$ than in the "no pathology" group $(1 / 8,13 \%)$, which supports the above conclusion.

Table 5. Numerical distribution of the ESR values for which no corresponding leuco2 (Sysmex E-4000) values were available, in relation to the corresponding follow-up diagnoses "pathology" (= inflammatory diseases and malignamcies), "no pathology", and "all other diseases".

\begin{tabular}{lcccc}
\hline $\begin{array}{l}\text { ESR } \\
(\mathrm{mm} / 1 \mathrm{hr})\end{array}$ & $\begin{array}{c}\text { kollow-up diagnoses } \\
\text { "patho" } \\
\text { logy" }\end{array}$ & $\begin{array}{c}\text { no patho- "all other" } \\
\text { logy" }\end{array}$ & totals \\
\hline $0-10$ & 1 & 4 & 6 & 11 \\
$11-20$ & 1 & 2 & 7 & 10 \\
$21-30$ & 0 & 1 & 3 & 4 \\
$31-40$ & 1 & 1 & 0 & 2 \\
$41-50$ & 1 & 0 & 1 & 2 \\
$>50$ & 0 & 0 & 2 & 2 \\
\hline totals & 4 & 8 & 19 & 31 \\
\hline
\end{tabular}

We conclude that the arythmically optimal upper limit of reference values for ESR lies around $24 \mathrm{~mm} / 1 \mathrm{hr}$. Furthermore, at the $24 \mathrm{~mm} / 1 \mathrm{hr}$ cut-off point, specificity $(84 \%)$ was found to be better than sensitivity ( $53 \%$ ), which may be considered useful, given the relatively low prevalence of "pathology" in general practice. Whereas the good specificity enables ESR to rule in "pathology", the relatively high negative predictive value (93\%) makes ESR more useful in ruling out "pathology". In a previous study the same suboptimal cut-off point $(24 \mathrm{~mm} / 1 \mathrm{hr})$ and nearly the same sensitivity $(55 \%)$, specificity $(92 \%)$ and negative predictive value $(91 \%)$ were found (26). However, this study revealed a much better positive predictive value (46\%) than was found in the present study (29\%, see Table 4) (26). 
Since the discriminating ability of both leucocyte count tests was found to be negligible and, with respect to "pathology", considerably different from ESR, we did not investigate the possible modifying effects of age and gender any further (Table 1). Moreover, a previous study had already shown age to be unimportant in the clinical interpretation of ESR with respect to discriminating between "pathology" and "no pathology" (27). In sum, we conclude that the determination of the leucocyte count cannot be regarded as a realistic alternative to ESR in discriminating between "pathology" and "no pathology" in general practice.

\section{References}

1. National Organization for Quality Assurance (in the hospitals) in the Netherlands (CBO), Scientific Council. "Routine"-laboratoriumonderzoek. Is er plaats voor een "routine"-indicatie yan de leukocytendifferentiatie? Utrecht: CBO, 1985 .

2. Dieijen-Visser MP Van, Go PMNYH, Munting JDK, Brombacher PJ. The walue of laboratory investigations in patients suspected of acute appendicitis [abstract]. Ann Biol Clin 1988; 46:

3. Knuth UA, Muehlenstedt D, Schneider HPG. Zur Effectivitaet von Kurzwellenbelastungstests, Blutkoerperchensenkungsgeschwindigkeit und Leukozytenzahl bei der Diagnose der subakuten Adnexitis [summary in english] Geburtshilfe Frauenheilkd 1982; 42: 52-5.

4. Waehlby $L$, Knutsen OH. Leukocyte counts, ESR and fever in the diagnosis of diverticulitis. Acta Chir Scand 1982; 148: 623-4.

5. Wasserman M, Levinistein M, Keller $\mathrm{E}$, Lee $\mathrm{S}$, Yoshikowa $T$. Utility of fever, white blood cells, and differential count in predicting bacterial infections in the elderly. I Am Geriatr Soc 1989" 37: 537-43.

6. Tibblin $\mathrm{G}_{*}$ Willhelmsen $\mathrm{L}$, Werko $\mathrm{L}$. Risk factors for myocardial infarction and death due to ischemic heart disease and other causes. Am $J$ Cardiol 1975; 35: 514-22.

7. Labry LO De, Campion EW, Glynn RJ, Vokonas PS. White blood cell count as a predictor of mortality: results over 18 years from the normative aging study. Gerontology 1990; 43: $153-7$.

8. Friedman $\mathrm{GD}$, Klatsky $\mathrm{AL}$, Siegelaub $\mathrm{AB}$. The lleukocyte count as a predictor of myocardial infarction. NEng J Med 1974; 290: 1275-8.

9. Zalobar JB, Richards JL, Blaude JR. Leukocyte count, smoking and myocardial infarction. $N$ Eng J Med 1981; 394: 465-8.

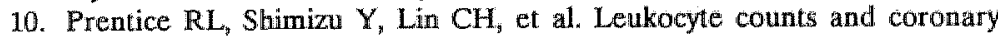
heart disease in a Japanese cohort. Am J Epidemiol 1982: 116: 496-506.

11. Prentice RL, Szatrowski TP, Kato $\mathrm{H}_{3}$ et al Leukocyte counts and cerebrovasculair disease. J Chron Dis 1982; 35: 703-14.

12. Ernst $E$, Hammerschmidt DE, Bagge $U$, et al. Leukocytes and the risk of ischemic diseases. JAMA 1987; 257: 2318-24. 
13. Bender BS, Jagel JE, Adler WH, at All Abolute peripheral blood lympliocyte count and subsequent mortality of elderly men. I. Am Geriatr Soc 1986, 34: 649-54,

14. Grimm RH, Neaton JD, Ludwing W. Prognostic importance of the white blood cell count for coronary cancer, and all-cause mortality. IAMA 1985; 254: 19327.

15. Corberand J, Laharragte P. Fllola G. Blood cell parameters do not change during physiological human ageing. Gerontology 1987, 33: 72-6.

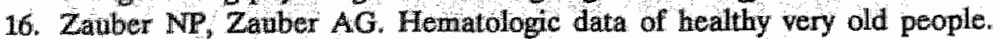
LAMA $1987,257: 21814$.

17. International committe for standardization in hematology. Recommendation for measurement of erythrocyte sedimentation rate of human blood. Am J Chn Pathol 1977; 68: 505-7.

18. Dinant: GJ, Knottnerus JA, Aubel PGJ Van, Wersch JWJ Van. Reliability of the erythrocyte sedimentation rate in general practice. Scand I Prim Health Care 1989; 7: 231-5.

19. Landaas $\$, J u e l l ~ A$. The quality of laboratory analysis in the primary health care. Scand I Prim Health Care 1980; 4: 169-73.

20. Classification Committee of WONCA. ICHPPC-2-defined. Inclusion criteria for the use of the nubrics of the International Classification of Health Problems in Primany Care. Oxford: Oxford University Press, 1983.

21. Meijer JS, Brouwer H, Lamberts H. De ICPC als diagnostische classificatie II [synopsis in English]. Huisarts en Wetenschap 1987; 30:44-8, 60.

22. Sawrey SA. All ather signs, symptoms and ill defined conditions. $N Z$ Fam Physicion 1988; 15: 4-6.

23. Griner PF, Mayewski $\mathrm{RJ}_{\text {, }}$ Mushlin AI, Greenland P. Selection and interpretation of diagnostic tests and procedures. Ann Intem Med 1981; 94: $553-600$.

24. Feinstein AR. Clinical epidemiology. The architecture of clinical research. Philadelphia: WB Saunders Company, 1985.

25. Connell FA, Koepsell TD. Measures of gain in certainty from a diagnostic test. Am J Epidemiol 1985; 121: 744-53.

26. Broek PJ van den, Radder AM, Hermans J. De betekenis van lichaamstemperatuur, bezinking, C-reactief proteine, leukocytenaantal en -differenthatie voor de diagnostiek van infecties op een eerstehulpafdeling voor ixwendige geneeskunde. [summary in English] Ned Tijdsch Geneeskd $1900 ; 134: 253640$.

27. Dinant GJ, Knottherus JA, Wersch JWJ Van. Desktop laboratory in general practice, the discriminating ability of the erythrocyte sedimentation rate. Accepted for publication. 


\section{General discussion}

In the research project reported on in the present thesis, the diagnostic value of the erythrocyte sedimentation rate (ESR) was studied by investigating its reliability in general practice, as well as its ability to discriminate between inflammatory diseases and malignancies ("pathology") and "no pathology". The normal performance of ESR was found to result in a clinically relevant intra- and inter-practice variablity. After an intervention concerning technical aspects of the test performance a significant decrease in the variability resulted. Blood sample transportation by car could not be held responsible for the initial variability. Vibrations within the hospital building could not account for the systematically higher ESR values measured at the reference laboratory.

ESR was found to be a useful parameter in discriminating "pathology" from "no pathology". In these patients reference values were found to be independent of age. The measurement of plasma viscosity was not a reasonable alternative to ESR in discriminating rheumatoid arthritis and ankylosing spondylitis from non-inflammatory complaints and disorders of the locomotor system. In the indicated population in general practice, the discriminating ability of the leucocyte count was far less than that of ESR.

Chapter 5 discusses in more detail several aspects of the methods used, and the implications of the study results for everyday general practice. Furthermore, we concentrate on the significance of our results with respect to previous studies on the subject. Recommendations are made for future studies and the methods to be used in such studies. Finally, we briefly discuss future developments and we list the conclusions.

First we discuss the general practitioners (GP) and laboratory workers" compliance to the study, as well as the interdoctor variability with respect to the data collection (chapter 5.1). 


\subsection{Introduction}

The same group of GPs co-operated in the studies on the reliability and discriminating ability of ESR (Chapters 2.1, 2.2, 3.1 and 3.2) and on the discriminating ability of the leucocyte count as compared to ESR (Chapter 4.2). The 9 GPs were willing to participate, partly because they had had positive experiences with previous studies. The general practice centers (GPC), as well as the De Wever hospital are located in Heerlen (a medium sized city in the south of the Netherlands). The hospital laboratory usually works as the primary care laboratory for the GPCs, but ESR is mostly performed at the GPC's laboratory rather than at the hospital. Of the nine GPs, three were attached to the same GPC, two worked alone, and the remaining four worked in pairs. We found no reasons to assume that the GPs had a working routine and experience much different from those of the "average" GP in the Netherlands. The same conclusion can be postulated for the patient populations studied. On average, the GPs each entered about 40 patients into the studies on the discriminating ability of ESR (Chapters 3.1 and 3.2). However, an important variability was found between the GPs, as can be seen from Table 1. The GPs' assistants confirmed that these figures were normal for their everyday practice.

The considerable contributions of GP1 and GP4 to the data collection can be seen from Table 1 and is also illustrated by the figures in Table 2. The latter table also suggests that the holiday periods, which were in the months of May and June, resulted in an important decline in the number of patients who were entered into the study. In addition, it is possible that the GPs became less motivated for the study after four months of data collection. Furthermore, the first part of the reliability study, as well as the interviews with the GPs (see Appendix II) took place during the same period.

In general, it will always be the investigator's responsibility to guide the doctors who co-operate in a study, to take initiatives when necessary (e.g. the intermediate reporting of study results), to be on call and to search for creative solutions each time a problem crops up, especially during the data collection period. 
Table 1. Frequency distribution of patients entered into the study on ESR discriminating ability, in relation to their GPCs and GPs.

\begin{tabular}{lcrr}
\hline $\begin{array}{l}\text { GPC } \\
\text { code }\end{array}$ & $\begin{array}{c}\text { GP } \\
\text { code }\end{array}$ & N & patients \\
\hline A & 1 & 58 & 16 \\
& 2 & 36 & 10 \\
B & 3 & 33 & 9 \\
& 4 & 75 & 21 \\
C & 5 & 52 & 14 \\
D & 6 & 21 & 6 \\
E & 7 & 19 & 5 \\
\hline unknown & 8 & 45 & 13 \\
totals & 9 & 22 & 6 \\
- & & 1 & 0 \\
\hline
\end{tabular}

Table 2. Frequency distribution of the entering of patients into the study on ESR discriminating ability, in relation to the five successive months in 1987 during which data collection took place.

\begin{tabular}{lrr}
\hline month & \multicolumn{2}{c}{ patients entered } \\
& N & \% \\
\hline February & 85 & 24 \\
March & 88 & 24 \\
April & 88 & 24 \\
May & 52 & 14 \\
June & 46 & 13 \\
\hline unknown & & 1 \\
tolals & 3 & 100 \\
\hline
\end{tabular}

Moreover, this guidance should start in advance of the data collection period and it should not stop until the study ends. In our study we tried to follow these rules and we experienced the special nature of research problems in general practice, such as difficulties in arranging general meetings and a feeling of being a long distance away from the university. A good deal of improvisation was required, e.g. by arranging separate meetings with one or more GPs, anticipating mistakes made in filling in forms and repeatedly discussing the aim of the study and the importance of following the protocol. The enthousiastic co-operation. of the GPs in studying one their most frequently used tools was 
essential. We want to emphasize the importance of repeatedly instructing the doctors preliminar to the data collection, and of obtaining frequent feed-back during this period, if a study is going to be carried out in general practice.

The laboratory presented practical problems too. Several times selected patients were not willing or unable to undergo venepunction, or laboratory workers were found to be unfamiliar with the study protocol. Occasionally, EDTA tubes were out of date, and blood samples proved too small, or were lost due to accidental sample mismanagement. However, an intensive collaboration with the laboratory workers enabled us to find satisfactory solutions for all imperfections. Special support was obtained from one ambulatory laboratory worker. She instructed the GPs' assistants in the methods of taking blood samples by using a vacuum system, she picked up all blood samples, she supplied the GPCs with all the necessary laboratory equipment (including fill-in forms) and she tried to answer all kinds of practical questions raised by the GPs' assistants. Finally, she provided the investigator with feed-back on these subjects.

\subsection{Reliability of the erythrocyte sedimentation rate}

In the Netherlands GP laboratories are not subject to quality control programs. The necessity of such a program is debatable, because of the limited extent of the GP's laboratory activities. However, the results of our study on the reliability of ESR (see Chapter 2.1) do indicate the need for at least a regular verification of the GP's own measurements. This conclusion also holds for more automatized measurements, like the Sicca en Spencer hemoglobine meters, which were initially found to be unreliable after less accurate test performance, as well as the HemoCue meter, which showed disappointing results in test performance by general practice nurses $(1,2)$. More sophisticated and independently working laboratories (including hospital laboratories) in Belgium underwent a quality control test in 1979 and 1988 (3). The 1979 test revealed that quality ought to be improved. However, in 1988, tests on hepatitis B, more classical blood tests and tests on contaminated urine samples still showed an unacceptably low quality in $11 \%, 28 \%$ and $43 \%$ of the laboratories respectively. More recently, cholesterol analyzers have 
made their appearance. Finger-stick methods were found to show a tendency towards false negative results when compared to the laboratory cholesterol values measured after taking a blood sample by venepuncture (4). In a recent study, five compact chemistry analyzers were assayed for total cholesterol measurements (5). Only two of them met the accepted standards for accuracy of the cholesterol measurement. The authors concluded that under controlled conditions chemistry analyzers vary in the reliability of lipid determination and the classification of patients. Finally, five relatively new pregnancy test kits, made for use at home, were tested for their sensitivity, specificity and manageability (6). Only three kits were found to have an acceptable sensitivity, whereas only one out of these three was easily manageable.

These findings should worry every doctor for at least four reasons.

First, developments in laboratory medicine tend towards increasing decentralisation, which implies that, in future, GPs will more frequently perform measurements themselves, instead of having them done at the local (hospital) laboratory. As was already stated in 1985, GPs' laboratory activities invade the clinical market, but the lack of regulations raises reliability concerns (7). So far, physicians receive minimal training in laboratory skills and this aspect should receive more emphasis in the training program of medical students. At present, GPs are generally unfamiliar with reliability aspects, as can also be seen from the results in Chapter $2.3(8,9)$.

Secondly, physicians will be tempted more frequently to buy technically more sophisticated laboratory equipment, enabling them to perform several blood tests within a relatively short period of time, without the necessity of referring the patient to the local (hospital) laboratory. In the case of the Reflotron, these developments have already resulted in a discussion on cost-effectivenes and quality aspects (10-12). The discussion and, more importantly, the research which should precede it, must concentrate on reliability and validity aspects. Such research and discussion should be applied to any new or modified test $(13,14)$. However, many GPs are unfamiliar with the concepts of validity and, hence, hardly able to assess the merits of a new piece of laboratory equipment. Furthermore, computerized communica- 
tion between local laboratories and GPs' offices might be realized in the near future (15). The GP could then face an interesting dilemma: should he buy a Reflotron or a computer?

Thirdly, a wider range of laboratory parameters to be measured in the future GP's laboratory implies that, when a patient must be referred, he or she may have to undergo fewer laboratory tests in the hospital, conditional on a reliable test performance in the GP's laboratory.

Fourth, more and more test kits for use at home will be developed. At present, patients can establish their glucose level or detect pregnancy. Test kits for HIV and cholesterol have already been introduced. The dangers of these developments are clear: GPs will be confronted with false negative and false positive test outcomes, partly due to unreliable test performance by the patient. Moreover, it will be misleading for the patient to obtain false information about the presence or absence of a disease, and it might be dangerous to handle potentially contaminated blood samples (16). Exposure to infectious agents is a dlanger for the laboratory worker too. In the case of ESR, it is highly undesirable to suck the anticoagulant-blood mixture into the sedimentation tube by mouth. Other sources of contamination include breaking or falling sedimentation tubes (17). More advanced ESR equipment, which eliminates these risks, has recently been developed (17). However, its cost is as yet prohibitive for the GP's laboratory.

Quality control is essential for all laboratories, including those in general practice. A regular verification of the GP's own measurements, by performing a test twice on one sample, or by comparing a measurement with the corresponding result from a local laboratory, is easy to perform and should become a habit rather than an incident. More extensive monitoring programs for the GP's office laboratories have been introduced in a few places and deserve greater attention if technically more sophisticated equipment is going to enter the GP's laboratory in future (18-20). Furthermore, GPs should be instructed about the concepts of reliability and validity of laboratory tests, and further research on these aspects should be initiated.

With respect to our studies on the reliability of ESR (Chapter 2.1), it could be questioned whether the inter- and intra-practice variability should not have been compared with an intra-labora- 
tory variability, instead of with one reference value each time. By investigating the possible influence of vibrations on ESR, we did measure an intra-laboratory variability to at least some extent. Whether or not vibrations did exist at the time, the measurements of ESR for the duplicate samples showed a good correlation $(R=99)$. It may therefore be concluded that the inter- and intra-practice variability, especially before our intervention, need to be qualified by referring to any intra-laboratory variability. Instead of using laboratory values as reference values, we could have chosen for a reference such as the mean of each series of measurements performed by the GPs. However, this choice would have meant leaving out valuable information, because GPs are used to measuring ESR at their offices as well as at the local laboratory. They will therefore be interested in the correlation between the values obtained at the GPCs and at the laboratory. Moreover, as was mentioned above, this correlation can be a measure of quality.

The possible effects of vibrations on ESR have been studied before (22). The investigators placed ESR racks on a laboratory bench on which an incorrectly balanced centrifuge was turning. Compared to the duplicate measurements whithout exposure to vibrations, the marked vibrations did not produce any significant changes in the final ESR result. Perhaps the validity of the recommendations on this item should be re-evaluated (23)?

The reliability study after intervention was restricted to ESR values below $60 \mathrm{~mm} / 1 \mathrm{hr}$, this being the more interesting range in general practice. As can be seen from the results in Chapter 3.1, most ESR values were indeed found to be in the lower ranges, which therefore justifies our choice.

In the statistical analysis of the data in Chapter 2.1 we used the coefficient of variation (CV). For the data on the intra-practice variability, a condensed measure such as $\sqrt{\sum d^{2} / n \text { (in which } d}$ stands for the differences between the ESR values measured in each sample pair and $n$ equals the total number of sample pairs) might have been more appropriate, since the CVs were calculated on only two measurements each time. However, the condensed measure does not essentially differ from the standard deviation (SD), which would be equal to $\sqrt{\sum\left(x_{i}-\bar{x}\right)^{2} /(n-1) \text { (in }}$ which $\bar{x}$ is the mean of each pair of measurements and $x_{i}$ stands 
for an individual measurement). Moreover, CV has the advantage of correcting for the mean of each pair of measurements.

In our studies we used the Westergren method to determine ESR. An important advantage of this method is its ability to determine high sedimentation rates (above $40 \mathrm{~mm} / 1$ h) $(24,25$ ). It is therefore useful in monitoring disease, e.g. RA. The Wintrobe method is more sensitive in the lower ESR ranges, needs no dilution with anticoagulant, requires less blood and can be more easily corrected for hematocrit concentrations (24). Hence, it may be questioned whether the Wintrobe method does not deserve more attention, especially in general practice, where lower ESR values are frequently found. However, the ESR values in Figure 1 of Chapter 3.1 show that, had we used the Wintrobe method, an important part of the inflammatory diseases and malignancies would not have been detected by measuring ESR. Moreover, both methods remain dependent on hematocrit concentrations $(26-28)$.

\section{References}

1. Markus HIM, Hoogen HJM van den, Huygen FJA. De betrouwbaarheid van hemoglobinebepalingen in de huisartspraktijk. Huisarts en Wetenschap 1981; 23: 47-51, 71 [summary in English].

2. Neville RG. Evaluation of portable haemoglobinometer in general practice. Br Med J 1987; 294: 1265-6.

3. Test van 54 laboratoria voor klinische biologie. Test-Aankoop Magazine 1988; no.303: 7-14.

4. Natughton $\mathrm{MJ}$, Luepker RV, Strickland D. The accuracy of portable cholesterol analyzers in public screening programs. JAMA 1990; 263: 1213-7.

5. Kaultian HW, McNamara JR, Anderson KM, Wilson PWF, Schaefer EJ. How reliably can compact chemistry analyzers measure lipids? JAMA 1990; 263: 12459 .

6. Roumen FJME, Muyrers JJG. De zwangerschaptest voor thuisgebruik. Huisarts en Wetenschap 1989; 32: 249-51 [abstract in English].

7. Gallivan M. Physician offices invade clunical laboratory market. Hospitals $1985 ;: 84-94$

8. Clinical laboratory tests and standards. Board of Trustees Report. JAMA 1986; $255: 373$.

9. Hilborne LH, Wenger NS, Oye RK. Physician performance of laboratory tests in self-service facilities. JAMA 1990; 264:382-6

10. Bosch W van den, Serrarens A, Loerx M, Sas A van. De Reflotron in de huisartspraktijk. Huisarts en Wetenschap 1989; 32: 96-9 [abstract in English]. 
11. Haan GJH. Reflotron. Huistarts en Wetenschap 1989; 32: 275-7.

12. Post D, Haan GJH. Nogmaals de Reflotron. Huisarts en Wetenschap 1990; 33: $37-8$ [letters].

13. Belsey $R$, Vandenbark $M_{3}$ Goitein RK, Baer DM. Ewalluation of a laboratory system intended for use in physician" offices. JAMA 1987; 258: 357-61.

14. Colle JG Testing time for side room tests. Br Med J 1988; 296: 733 [letter].

15. Damme J van. Informatiseren voor de arts: llabo-uitslagen. Huisarts $\mathrm{Nu}$ 1989; 18: $251-4$.

16. Meijman FJ. Doe-het-zelf-zwangerschapstests. Ned Tijdschr Geneeskd 1989; 133: 2061-3.

17. Koepke JA, Caracappa $P$, Johnson $L$. The evolution of erythrocyte sedimentation rate methodology. Labmedia $1990 ; 468$.

18. Bartola J. Painless office laboratory regulation. Prim Care 1986; 13: 605. 15.

19. Crawley $R$, Belsey $R$, Brock D, Baer DM. Regulation of physicians' office laboratories. JAMA 1986; 255: 374-82.

20. Kenney ML. Quality assurance in changing times: proposals for reform and research in the clinical laboratory field. Clin Chem 1987; 33: 328-36.

21. Buckley EG. Research for all in general practice. Br Med J 1990 ; 301: $357-8$.

22. Hazelion IJ. Erythrocyte sedimentation rate: some observations under adverse conditions. J Med Lab Techn 1968; 25:370-3.

23. International Committee for Standardization in Hematology. Recommendation for the measurement of erythrocyte sedimentation of human blood. Am J Clin Pathol 1977; 68: 505-7.

24. Bull BS, Brecher G. An evaluation of the relative merits of the Wintrobe and Westergren Sedimentation methods, including hematocrit correction. Am J Clin Pathol 1974; 62: 502-10.

25. Galbraith H-JB, Jones KW. Primary atypical pneumonia and high sedimentation rates. Br Med J 1958; 29: 1144-7.

26. Bull BS. Clinical and laboratory implications of present ESR methodology. Clin Lab Haematol 1981; 3: 283-98.

27. Loeliger EA, Souverijn JHM, Helleman PW. Het mechanisme van de bezinkingssnelheid van erythrocyten. Ned Tijdschr Geneeskd 1977; 121: $713-4$.

28. Zijlstra WG. Geldrolworming en bezinkingssnelheid van erythrocyton. Ned Tijdschr Geneeskd 1977; 121: 1917-20. 


\subsection{Discriminating ability of the erythrocyte sedimentation rate}

The diagnostic center for GPS in Maastricht, the Netherlands, receives requests for laboratory investigations from 78 local GPs, who are attached to 57 GPCs. The $78 \mathrm{GPs}$ provide health care for the ca. 150,000 inhabitants of Maastricht. Every third referral from these GPs included a request for the determination of ESR, and between 1983 and 1988, ESR was performed about 1000 times a month (1). Two thirds of the patients concerned were female, which is in agreement with our findings in this respect (see Chapter 3.1) (1). Many requests (10\%) resulted from complaints about fatigue and fatigue-related symptoms, which are very common in general practice $(2,3)$. In $91 \%$ of these cases ESR was requested for, among other tests. For these patients, diagnostic tests were performed in order to exclude pathology (73\%) rather than to confirm the presence of a disease (4\%) (3). These figures illustrate once again the popularity of ESR in generall practice.

The list of references in Chapter 3.1 reveals the long history of studies on the diagnostic value of ESR. As far as specific diseases are concerned, we keep finding older (e.g. on allergy and ESR) as well as more recent reports (e.g. on diverticulitis and on the postpericardiotomy syndrom and ESR) (4-6). Reports on qualitative aspects of ESR were found to be scarce. Few authors emphasize the usefulness of the doctor's reading the ESR himself $(7,8)$. The colors of the sediment and the above standing plasma are indicators for the presence of anemia, icterus, or even hyperlipedemia $(7,8)$. It is in agreement with this limited interest that we received very few answers to the corresponding question (no.9, "prediction of special aspects of ESR") of the questionnaire (see Appendix IV).

The evaluation of the diagnostic validity in terms of sensitivity, specificity, predictive values and likelihood ratios has been studied for over ten years now (9-19). In studying the values of these analytical parameters, an independent final diagnosis ("gold standard") has to be established for each patient. The merits of the follow-up procedure we used for that purpose (in our studies on ESR and the leucocyte count) were evaluated in the Discussion section of Chapter 3.1. Establishing the follow- 
up diagnoses was not always easy. Several patients could not be easily fitted into an ICHPPC-2-defined disease or disease group. They were eventually categorized more or less arbitrarily. Recently it was proposed to label such patients as having "unknown disease" (20). The authors of the latter study developed. a method by which all three disease categories (present, absent and unknown) can be incorporated into the calculation of sensitivity and specificity. These revised sensitivity and specificity figures were then found to drop, compared to the classically calculated figures (20). The variety of diseases we met in our studies, however, makes the suggested method inappropriate.

Similar reasons prevented us from using another alternative, which was to incorporate the outcomes of three highly correlated tests into the establishment of the final diagnosis, one being the test under evaluation $(21,22)$. This method might be interesting for clinicians, who frequently use sophisticated diagnostics which are able to replace the surgical and histological gold standards, or for which in fact no gold standard exists (23).

Using a follow-up procedure entails the risk of recall bias, as was mentioned in Chapter 3.1. Recently; it was advised to distinguish between biased recall and simple inaccuracy (24). Since in our studies the patients were personally interviewed by the investigator, inaccurate recall was largely prevented. Biased recall may have occurred if an inflammatory disorder or malignancy could not be recalled systematically, or if these disorders were misclassified. However, the nature of those disorders makes it unlikely that this bias occurred. Moreover, the information from the interviews was supplemented with various other sources of information in establishing the follow-up diagmoses. Even the relatively poor compliance of the patients to the follow-up revisits (see Appendix III) was thus controlled for. For the reasons mentioned in the Discussion section of Chapter 3.1, we assumed our follow-up procedure to be the most appropriate gold standard in our studies. The therapeutic impact of a diagnostic test will not always be more useful. Patients and doctors might be interested in the prognostic information which can be obtained by merely establishing the diagnosis (25), and sometimes it is just "good to know". 
In the analysis of the study results we used ROC curves, irrespective of clínical utilities of test outcomes (see Chapters 3.1, 4.1 and 4.2). The optimal cut-off points, corresponding with the upper limits of reference values, are therefore rather maximal cut-off points. However, after reflecting upon the clinical meaning of the maximums in the Discussion section of Chapter 3.1, we consider the term optimal (and suboptimal) to be more appropriate.

We received very few answers to question $11 b$ of the questionnaire (see Appendix IV), which concerns the possibility of other findings influencing the establishment of the "diagnosis after" (see Chapter 3.2). We considered this to be an important question, because GPs are frequently interested in ESR in combination with other laboratory test outcomes. It could even be questioned whether the test should not have been evaluated in combination with several other parameters. In the GP's laboratory, however, the other parameters are mostly limited to urine analysis and the determination of glucose or hemoglobin. These parameters usually concentrate on one, or several closely related diseases, rather than on the variety of disorders that correlate to an acute phase response: An evaluation of the discriminating ability of a combination of these tests would therefore be conceptually erroneous.

As far as investigations at the hospital laboratory are concerned, the situation is partly different from that mentioned above. In the Netherlands, GPs request the determination of ESR at the local laboratory only in combination with laboratory parameters which cannot be measured at their office (3). Again, these parameters do not reflect the acute phase reponse, with the exception of plasma viscosity and the leucocyte count. Sometimes GPs even ask for the determination of ESR merely because the patient must be referred to the laboratory anyway.

As we concluded in Chapter 3.1, ESR is found to be a useful parameter in diagnosing patients who are suspected of having an inflammatory disease or malignancy. Because this conclusion could be drawn after a study in a population of patients who presented new complaints, we might add that the test also supports the establishing of the diagnosis at an early stage of disease. It is thus especially interesting for the GP, because the 
early detection of "pathology" can be regarded as an important aspect of the GP's daily work. In everyday practice, GPs may also be confronted with an unexpected high ESR value in an apparently healthy person. The question what to think of this might be answered as follows: 1.Is there any reason to assume that the measurement was performed unreliably? 2.Is the patient known to have an (unexplained) elevated ESR? 3.Are there any reasons to assume the presence of a clinically nonmanifest disease?

In general it will be advisable to repeat the measurement after a short lapse of time, after considering the answers to the questions above.

The special nature of diagnosing in general practice makes it relevant to investigate the discriminating ability of frequently used tests and procedures in this setting, using a follow-up procedure as the gold standard.

\section{References}

1. Pop P, Beusmans GHMI. De B.S.E. als hulpmiddel bij de diagmostiek. The Practitioner [Dutch edition] 1989; 6: 1269-73.

2. Kroenke $\mathrm{K}$, Wood $\mathrm{DR}$, Mangelsdorff $\mathrm{AD}$, Meier NJ, Powell JB. Chrionic fatigue in primary care. JAMA 1988; 260: 929-34.

3. Pop $P$, Beusmans GHMI. Laboratoriumonderzoek bij vage en algemene klachten. The Practitioner [Dutch edition] 1990; 7: 75-81.

4. Parsons DJ. Sedimentation rate - a diagnostic aid in allergy. Ann Allergy 1946; : 220-2.

5. Boer HHM de. Acute diverticulitis. Ned Tijdschr Geneeskd 1989; 133: 1733-6 [abstract in English].

6. Florijn $\mathrm{KW}$, Meeter $\mathrm{K}$. Het postpericardiotomiesyndroom alls oorzaak van recidiverend pleuravocht. Ned Tijdschr Geneeskd 1990; 134: 1183-6 labstract in English].

7. Borst JGG. Noodzakelijk, overbodig en schadelijk gemeeskundig onderzoek. Ned Tijdschr Geneeskd 1961; 105: 2449.5\%.

8. Loeliger EA, Veen AThM van, Souverijn JHM, Helleman PW. De meting en de klinische betekenis van de bezinkingssnelheid der erythrocyten (BSE). Ned Tijdschr Geneeskd 1977; 121: 715 8.

9. Gelldrop WJ. Streptest. Huisarts en Wetenschap 1990; 33: 2045 [1etter].

10. Geldrop WJ. Bosch JSG van den. De keuze van diagnostische tests. Een besliskundige analyse. Huisarts en Wetenschap 1986; 29: 378-381.

11. Geldrop WJ, Pop P. Incidit in scyllam, qui vult vitare charybdim. The Practitioner [Dutch edition] 1990; 7: 65-8.

12. Geldrop WJ, Pop P. Priorkans en testuitslag (2). The Practitioner [Dutch edition] 1990; 7: 797-800. 
13. Hayden GF, Lohr JA, Sturm AW. Wanneer laboratoriumuitslagen niet overeenstemmen met klinische bewindingen. Patient Care [Dutch edition] $1989 ; 16: 13-21$.

14. Heln $H J$ van der, Hische EAH. Gevoeligheid, specificiteit en diagnostische waarde van laboratoriumonderzoekingen. Ned Tijdschr Geneeskd 1979. 123: $1944-51$.

15. Helm HI vain der, Hische EAH. Beoordeling van de diagnostische waarde vam klinisch-chemische onderzoekingen met behulp van het theorema van Bayes. Ned Tifschr Geneeskd 1979; 123: 1983-7.

16. Helm HI van der, Hische EAH. De evaluatie van diagnostische technologien. Een besliskundige benadering. Med Contact 1986; 41: 273-6.

17. Knottnerus JA Interpretatie wan diagnostische gegevens. Maastricht: Rijksumiversiteit Limburg, 1986 [thesis, summary in English].

18. Knottnerus JA. De evaluatie wan diagnostische technieken. In: Habbema JDF, Casparie AF, Mulder JH, et al. Medische technology assessment en gezondheidsbeleid. Alphen aan de Rijn: Sanuson Stafteu, 1989.

19. Pascoe JM. Use of the likelihood ratio in the management of the young child with fever. The Journal of Family Practice $1986 ; 22$ : 349-52.

20. Matchir DB, simel DL, Geweke JF, Feussner JR. A Bayesian method for eviluating medical test operating characteristics when some patients" conditionis fall to be diagnosed by the reference standard. Med Decis Mak 1990; 10: 102 11.

21. Henkelman $\mathbb{R M}_{\text {, Kay }}$, Bronskill MJ. Receiver operating characteristic (ROC) analysis without truth. Med Decis Mak 1990; 10: 24-9.

22. Begg CB, Metz CE. Consensus diagnoses and "gold standards". Med Decis Mak 1990; 10: 29-30.

23. Vandenbroucke JP. De halsstarrigheid van een professie. Ned Tijdschr Geneeskd 1989; 133: 2540-2.

24. Coughlin SS. Recall bias in epidemiologic studies. J Clin Epidemiol 1990; 43: 87-91.

25. Asch DA, Patton JP, Hershey JC. Knowing for the sake of knowing: the value of prognostic information. Med Decis Mak 1990; 10: 47-57. 


\subsection{Discriminating ability of plasma viscosity and leucocyte count}

In 1987 , a study of the population of the USA revealed that arthritic conditions were quite prevalent: $14.6 \%$, while $12.1 \%$ consulted a physician for such conditions (1). The prevalence of theumatoid arthritis (RA) for the Dutch so called "standard" general practice between 1978 and 1982 was calculated as $1.07 \%$ (2). In 1977 the prevalence of joint complaints was estimated at $35 \%$ in a medium sized Dutch town (Zoetermeer) in 1977 (3). Hence, joint complaints and arthritic conditions are common problems in general practice and regular attention is paid to them $(4,5)$. Diagnostic criteria for especially RA are clear $(6,7)$. Neither ESR nor the measurement of plasma viscosity (PV) are included in these criteria. However, ESR, as well as the measurement of C-reactive protein, are still seen as useful parameters in detecting RA and following its disease activity (8-10). PV has received less attention, and at present little is known about its predictive value (11). In a recent report. on blood viscosity in pregnancy problems the authors found blood viscosity to have a minor value in predicting adverse termination of pregnancy (12).

ESR and PV are representative of the joint acute phase protein concentrations (see Chapter 4.1). It is not always clear which protein is most reponsible for each reaction. Moreover, a great intra-individual and inter-disease variability exists in this respect $(13,14)$. We are therefore unable to assess the possibility of different concentrations of one or more acute phase proteins accounting for the greater discriminating ability of ESR compared to PV which we found in our study. The same conclusion probably holds for the greater discriminating ability of ESR for malignancies, than for inflammatory disorders (see Chapter 3.1). Future studies might clear up these questions.

Anemia was found to be unimportant as a covariate in discriminating RA and ankylosing spondylitis (AS) from the control groups (see Chapter 4.1 ). Interestingly, it was recently reported that the relation between hemoglobin concentrations $(\mathrm{Hb})$ and disease activity in RA is disturbed after treatment with sulfasalazine (SASP) (15). Hb was found to be an unsuitable evaluator 
of SASP therapy success in patients suffering from RA, due to hemolysis.

The methods we used in the studies on PV and ESR were retrospective (for RA and AS), as well as prospective (with respect to the control groups). Furthermore, we compared clearly diseased patients with healthy controls, each group coming from another so-called domain (16). In the system proposed by Feinstein (17), our investigations described in Chapter 4.1 may be seen as a combination of a phase II and a phase V study. The studies on ESR and those comparing ESR with the leucocyte count (Chapters $3.1,3.2$ and 4.2) were prospective and included the full spectrum of relevant diseases. Hence, they represent phase $V$ studies. With respect to the data collection, retrospective studies (phases I-IV) are often seen as less vulnerable to e.g. loss of data than are prospective studies. We obtained the same impression from our studies. The fact that the rheumatologists who co-operated in the partly retrospective study had more experience in participating in scientific studies than the GPS who cooperated in the prospective studies, may have contributed to this impression.

At the GPs' diagnostic center in Maastricht (see Chapter 5.4) the determination of the leucocyte count was requested 538 times in October 1988 (18). Fatigue and inflammatory disorders were the most frequent reasons for performing this test. It may be questioned whether in these cases the differential count, including the so-called "left shift", has a better discriminating ability than the "overal]" leucocyte count. With respect to screening asymptomatic members of the general population this was not found to be the case (19). Furthermore, a leucocyte count greater than or equal to $15 \times 10^{\circ} / 1$ (and ESR greater than $30 \mathrm{~mm} / 1 \mathrm{hr})$ were able to identify occult bacterial infections in adults with acute unexplained fever (20). However, leucocytosis proved to be an invaluable guide for decisions about the use of blood cultures in afebrile bacteremia (21). In addition to the poor discriminating ability of the leucocyte count found in our study (see Chapter 4.2 ), the above findings made us consider it less interesting to investigate the value of differential counts in our population of patients. For the same reasons we decided not to perform a serial analysis of ESR and leucocyte count. Theoretically it might be interesting to establish the discrimi- 
nating ability of the leucocyte count in patients with normal ESR values in order to detect false negative results on the latter test.

Halfway through the data collection period for the ESR study (Chapter 3) we started collecting leucocyte counts for these patients. This explains the difference between the total number of patients who co-operated in both studies. Since the data collection used consecutive patients, selection bias is unlikely.

Differential counts are more difficult to measure in the GP's laboratory than leucocyte counts, despite the availability of a more convenient bedside instrument (22). Perhaps the now analyzers, such as the Reflotron, will lower this technical threshold. However, future developments may go much further: monoclonal antibodies have already allowed the classification of leucocyte surface molecules and thus provide information on e.g. malignant disorders $(23,24)$. These developments will replace the time consuming manual leucocyte counting, which is used as soon as the question "pathology" or "no pathology" arises, and which has already been largely replaced by more accurate and advanced instruments, suitable for local (hospital) laboratories $(25,26)$.

\section{References}

1. From the centers for disease control. Prevalence of arthritic conditions United States, 1987. JAMA 1990; 263: 1758-9.

2. Morbidity Figures from General Practice. Data from four general practices 1978-1982. Nijmegen: Nijmeegs Universitair Huisartsen Instituut, 1985.

3. Voorn ThB.Gewrichtsaandoeningen. De huisarts en het bewegingsapparaat, van stilstand tot beweging. The Practitioner [Dutch edition] 1989; 6: 315-6.

4. Hollander JL. Vroege aanwijzingen woor reumatische aandoeningen. Patiemt Care [Dutch edition] 1988; 15: 9-21.

5. Pal B. Spondylitis ankylopoetica. The Practitioner [Dutch edition] 1989; 6: 331-7.

6. Korst JK van der. Artritis op de schaal van Ritchie oftewel: reumatologie als clinimetrie avant la lettre. Ned Tijdschr Geneeskd 1990; 134: 422-3.

7. Leeuwen MA van, Rijswijk MH van. Nieuwe criteria van de American Association voor de classificatie van reumatoide artritis. Ned Tijdschr Geneeskd 1990; 134: 420-2.

8. Amos RS, Constable TJ, Crockson RA, Crockson AP, McConkey $\mathbb{B}$. Rheumatoid arthritis: relation of serum C-reactive protein and erythrocyte sedimentation rates to radiographic changes. Br Med J 1977; 274: 195-7. 
9. Capel HA. Rewmatoide arthritis. De ziekte met wele gezichten. The Practitioner [Dutch edition] 1987; 4: 227-34.

10. Healy $L A$, Sliwinski $A J$, Winkelman JW. Is het bepalen van de BSE een werouderde test? Patient Care [Dutch editition] 1990; 17: 35-8.

11. Ernst $\mathrm{E}$, Matrai $A$, Saradeth $\mathrm{T}$, Resch $\mathrm{KL}$, Koenig $W$. The measurement of plasma and blood viscosity. Tijdschr NVKC 1990; 15:84-8.

12. Zondervan MA. De viscositeil van bloed bij zwangerschapscomplicaties. Ned Tijdschr Geneeskd 1990; 134: 1209-13.

13. Gool I van, Vugt H wan, Bont $\mathrm{E}$ de. Het effect van acute-fase-eiwitten op ontstekingsoedeem ten gevolge van vaccinatie. Ned Tijdschr Geneeskd 1989 ;33: $822-7$.

14. Scherer $\mathrm{R}$, Morarescu $A$, Ruhenstroth-Baner $G$. Die spezifische Wirkung der Plasmaproteine bei der Blutkoerperchensenkwng. Klin Wochenschr 1975; $53: 265-73$ [abstract in English].

15. Wijnands MJH, Nuver Zwart IH, Riel PLCM van, Hof MA van 't, Gribnaw FWJ, Putte LBA van de. Hemolyse geinduceerd door sulfasalazine bij patienten met reumatoide arthritis; Gemoglobinegehalte als ziekte-activiteitskenmerk. Ned Tijdschr Geneeskd 1990; 134: 1477 [abstract].

16. Miettinen OS. Theoretical epidemiology. Principles of oceurrence research in medicine. New York: John Wiley \& Sons, 1985.

17. Feinstein AR. Clinical epidemiology. The architecture of clinical research. Philadelphia: WB Saunders Company, 1985.

18. Beusmans GHMI, Pop P: Leucocyten en de leucocytendifferentiatie. The Practitioner [Dutch edition] 1989; 6: 371-5.

19. Shapiro $M F_{\text {, }}$ Greenfield $\mathrm{S}$. The complete blood count and leukocyte differential count. An approach to their rational application. Ann Intern Med 1987; 106: 65-74.

20. Mellors JW, Horwitz RI, Harvey MR, Horwitz SM. A simple index to identify occult bacterial infection in adults with unexplained fever. Arch Intern Med 1987; 147: 666-71.

21. Gleckman $R$, Hibert $D$. Afebrile bacteremia. A phenomenon in geriatric patients. JAMA 1982; 248: 1478-81.

22. Longmore JM. Bedside haematology: new facility in general practice. $\mathrm{Br}$ Med J 1983; 287: 1849-51.

23. Hansel TT. Leucocyte typing - OKCD? The Lancet 1987 ; i: 1382-3.

24. Ling NR, Johnson GD, MacLennan ICM. Leucocyte typing. The Lancet $1988 ;$ i: $249-50$ [letter].

25. Goldstein $D$, Kang $L$, Castella $A$, strand $C$. Leukocyte indicators of septicemia in 168 patients. Am J Clin Pathol 1986; 86: 404.

26. Nelson $\mathrm{L}$, Charache $\mathrm{S}$, Wingfield S, Keyser $\mathrm{E}$. Laboratory evaluation of differential white blood cell count information from the Coulter S-Plus and Technicon $\mathrm{H}-1$ in patient populations requiring rapid "turaaround" time. Am J Clin Pathol 1988; 89: 563-9. 


\subsection{Future developments and conclusions}

ESR is regarded as a poor reflection of the in-vivo situation with respect to the red-cell aggregration, because the sedimentation proces in a tube does not reflect the continuing process of formation and breaking up of aggregrates which occurs in blood flowing through blood vessels (1). PV is said to be a better parameter for inflammatory conditions, because of its direct measurement of the acute phase reactants, which are the "cement" of the aggregrates. However, it might be more interesting to measure the red-cell aggregration itself, which is perhaps an important phenomenon in all kinds of microvascular problems and related diseases, such as the Raynaud syndrome, peripheral arterial vasculair diseases, complications in diabetes mellitus, or even myocardial infarction (1). This aspect of rheology will be of future interest, and developing a sensitive and accurate measure of red-cell aggregration is becoming a challenge $(2,3)$.

Of comparable interest are the monoclonal antibodies (see also Chapters 1.2, 5.1 and 5.4). Their potential ability to detect distinct malignancies, including HIV and inflammatory disorders like RA are inspiring many investigators (4-8). Desktop equipment using monoclonal antibodies is no longer science fiction and will imply further changes in future diagnostics.

Implicitly, this thesis has already stressed the need for quality assurance programs in the primary health care laboratory, and for educational activities striving towards an improvement of the GP's knowledge of aspects of the diagnostic value of a test (see Chapters 2.1,2.3 and 5.2). Similar recommendations have lately been reported (9-12), and these reports were preceded by studies on factors influencing the doctor's request for laboratory tests (13-16). From these studies it could be concluded that improving the performance of little-ticket tests, like ESR, are likely to increase laboratory costs more than the more expensive tests, because the former are more frequently determined (17).

Subsequently, educational programs on test ordering were introduced and were found to be successful $(18,19)$. These programs should be supported by studies on the discriminating ability of diagnostics, which found their origin in the thirties, but have still scarcely been performed in general practice $(20,21)$. Studies which are properly designed will ultimately reduce the 
GP's diagnostic uncertainty in everyday practice, and thereby the patient's fear of the unknown (22). Hopefully, this thesis will contribute to this development.

\section{Final Conclusions:}

1. In order to prevent unreliable test outcomes in general practice, ESR must be performed accurately, which implies the use of properly cleaned or disposable sedimentation tubes. Neither blood sample transportation by car, nor probably vibrations, influence the reliability.

2. ESR is a useful parameter in detecting inflammatory diseases and malignancies in patients who present with new complaints for which the GP considers the test to be indicated. In these patients the arythmically optimal upper limit of reference values was situated around $12 \mathrm{~mm} / 1 \mathrm{hr}$ in men and $28 \mathrm{~mm} / 1$ hr in women. It needed no correction for age. Using these limits the positive predictive value was $48 \%$ and the negative predictive value $91 \%$.

3. ESR contributes to establishing more appropriate diagnoses in general practice and is a valuable test in reassuring the patient and the doctor when no inflammatory diseases or malignancies are suspected.

4. ESR is a better parameter than PV in discriminating between rheumatoid arthritis and ankylosing spondylitis on the one hand, and non-inflammatory disorders of the locomotor system on the other, independent of the chosen reference values, age, gender and the presence of anemia.

5. The measurement of the leucocyte count is not a clinically interesting alternative to $\mathrm{ESR}$, independent of the chosen reference values.

6. The diagnostic values of laboratory tests which are of interest for GPs need to be investigated in general practice settings. The concepts concerned need further introduction in general. practice.

\section{References}

1. Vermes I, Sluijs Veer $G$ van der, Mellema J, Blom C. Reologische eigenschappen van bloed. Tydschr NVKC 1990; 15: 14-21. 
2. Mellema J, Blom C. Rheology, its basic concept. Tijdschr NVKC 1990; 15: 78-83.

3. Schmid-Schoenbein $\mathrm{H}$, Malotta $\mathrm{H}$, Striesow F. Erythrocyte aggregration: causes, consequences and methods of assessment. Tijdschr NVKC 1990; 15 : 88-97.

4. Banta D. Potentials for home care technology. STG/WHO Commission on Future Health Care Technology, 1987.

5. Cooper ES, Flaum NA, Hart W. De toepassing van monoclonale antistoffen bij het onderzoek van het bloed. Modern Medicine [Dutch edition] 1989; 13: 192-9.

6. Martin L, Fritzler MJ. Immunogenetic markers in rheumatic diseases. Can Fam Physician 1990; 36: 495-9.

7. Re R, Hart W. De diagnostische en therapeutische mogelijkheden van monoklonale antistoffen. Modern Medicine [Dutch edition] 1988; 12: 141-9.

8. Witherspoon $L$, Hart W. Nieuwe toepassingen van immunoassays op het gebied van reumatoide artritis, allergien en maligniteiten. Modern Medicine [Dutch edition] 1990; 14: 77-83.

9. Broughton PMG, Hoerder M, Staehr Johansen $\mathrm{K}$, Nagid E, Laboratory medicine in primary health care: a report of a joint WHO/NORDKEM/ ECCLS workshop. Copenhagen: WHO Regional Office for Europe, 1989.

10. Broughton PMG, Magid E. Laboratory medicine in primary health care. Journal of the International Federation of Clinical Chemists 1990 ; :36-8.

11. Vries T de. Rational and irrational use of ancillary services. 's-Gravenhage: Provinciale Raad voor de Volksgezondtheid in Zuid-Holland, 1988.

12. Vries $\mathrm{T}$ de. Rationeel gebruik van het ziekenhuislaboratorium door artsen. "s-Gravenhage: Provinciale Raad voor de Volksgezondheid in Zuid-Holland, 1988.

13. Beaulieu M-D, Latulipe $L$, Ringuet J, Veilleux J. L'utilisation des tests diagnostigues dans une unite de medecine familiale. Can Med Assoc J 1983; 129: 934-7 [abstract in English].

14. Danzon PM, Manning WG, Marquis MS. Factors affecting laboratory test use and prices. Health Care Financ Rev 1984; 5: 23-32.

15. Epstein AM, McNeil J. Physician characteristics and organizational factors influencing use of ambulatory tests. Med Decis Mak 1985; 5: 401-15.

16. Schmitt BP, Elsteim AS. Laboratory use: attitudes implicit in a mational examination. Med Decis Mak 1988; 8: 81-6.

17. Es JC van. Laboratoriumonderzoek onderzocht. Med Contact 1986; 41: 1571.

18. Kroenke $\mathrm{K}$, Hanley JF, Copley JB, Matthews JI, Davis CE, Foulks CJ, Carpenter $\mathrm{JL}$. Improving house staff ordering of three common laboratory tests. Med Care 1987; 25:928-35.

19. Wong ET, McCarron MM, Shaw ST. Ordering of laboratory tests in a teaching hospital. JAMA 1983; 249: 3076-80.

20. Anderson RE, Hill RB, Key CR. The sensitivity and specificity of clinical diagnostics during five decades. JAMA 1989; 261: 1610-7.

21. Melker RA de. Gebruik diagnostische faciliteiten door de huisarts. Med Contact 1980; 35: 699-705.

22. Crawshaw R. Thoughts about diagnosis. J Clin Epidemiol 1990; 43: 723-5. 



\section{Summary}

The purpose of this thesis is to present a series of coherent studies on the diagnostic value of the erythrocyte sedimentation rate (ESR) in general practice, by which we mean its reliability and discriminating ability. We tried to answer the following questions:

1. a. How reliable is ESR, in terms of intra- and inter-practice variability, when performed in the usual way in general practice and compared with the results from a reference laboratory?

b. How can we explain the variability?

2. To what extent does the answer to the first question change after an intervention concerning technical aspects of the test performance?

3. Which are the indications for determining ESR in general practice?

4. What is the diagnostic impact of ESR before and after its performance?

5. What is the ability of ESR to discriminate "pathology" from "no pathology" in the so-called "indicated population" in general practice?

6. What is the answer to question 5 with respect to alternative tests, viz. the determination of plasma viscosity (PV) and the leucocyte count, in comparison to ESR?

After the general introduction in Chapter 1.1 the scope of our study is described in Chapter 1.2. The concepts of reliability (reproducibility) and discriminating ability (sensitivity, specificity and positive and negative predictive values) are introduced, and their significance for frequently used blood tests in general practice (haemoglobin, ESR and leucocyte count and differentiation) is discussed.

Chapter 2.1 reports on the reliability of ESR before and after intervention (questions 1 and 2). We used centrally prepared blood samples, obtained from the local laboratory, and distrib- 
uted them among the participating general practice centers. Observations and measurements on the performance of ESR were made and a questionnaire was presented to each GPs' assistant(s) (Appendix I). Since we thought that vibrations and the transportation of blood samples might be possible causes of the variability, we investigated these aspects separately by performing additional experiments (Chapters 2.1 and 2.2). The results of the studies in Chapters 2.1 and 2.2 were used in a workshop on the diagnostic value of blood tests in general practice, which provided us with information on the knowledge of GPS about reliability aspects of ESR (Chapter 2.3).

Chapter 3 concentrates on the discriminating ability of ESR (question 5). After a prospective follow-up of 362 patients who were seen by their GP because of a new complaint for which the GP wanted to know ESR (the "indicated population"; question 3), we were able to measure the indices concerned (Chapter 3.1). For that purpose we compared a group of patients with inflammatory diseases or malignancies ("pathology") with a group of patients who had minor complaints or ailments ("no pathology"). The final diagnoses were established after a follow-up period of three months (Appendix III). The study was preceeded by a session in which we questionned 20 GPs about the subject (Appendix II).

In the same study we recorded the diagnoses postulated by the GPs before as well as after the performance of ESR (Appendix IV). A before-after analysis then allowed us to establish the diagnostic impact of ESR (Chapter 3.2, question 4).

In order to compare its discriminating ability with that of ESR, we also determined the leucocyte count among a subsample of the patients described in the Chapters 3.1 and 3.2 (Chapter 4.2; question 6). Two different leucocyte counters were used for this purpose.

Since we considered PV to be a possible alternative to ESR, we studied its discriminating ability as well. We compareed a group of patients suffering from rheumatoid arthritis or ankylosing spondylitis on the one hand, and patients presenting new complaints of the locomotor system which were ultimately diagnosed to be of non-inflammatory origin on the other (Chapter 4.2; question 6). This study was carried out at the outpatient 
rheumatology clinic, the patients who presented new complaints being referred there by their GP.

The general discussion in Chapter 5 reviews our findings and discusses several methods in more detail. In addition, the implications of the study results are summarized, and we try to cast some light on future developments with respect to laboratory testing in primary health care.

The investigations started in November 1986. The data collection ended in April 1989.

Finall conclusions:

1. In order to prevent unreliable test outcomes in general practice, ESR must be performed accurately, which implies the use of properly cleaned or disposable sedimentation tubes. Neither blood sample transportation by car, nor probably vibrations, influence the reliability.

2. ESR is a useful parameter in detecting inflammatory diseases and malignancies in patients who present with new complaints for which the GP considers the test to be indicated. In these patients the arythmically optimal upper limit of reference values was situated around $12 \mathrm{~mm} / \mathrm{hr}$ in men and $28 \mathrm{~mm} / 1 \mathrm{hr}$ in women. It needed no correction for age. Using these limits the positive predictive value was $48 \%$ and the negative predictive value $91 \%$.

3. ESR contributes to establishing more appropriate diagnoses in general practice and is a valuable test in reassuring the patient and the doctor when no inflammatory diseases or malignancies are suspected.

4. ESR is a better parameter than PV in dicriminating between rheumatoid arthritis and ankylosing spondylitis on the one hand, and non-inflammatory disorders of the locomotor system on the other, independent of the chosen reference values, age, gender and the presence of anemia.

5. The measurement of the leucocyte count is not a clinically interesting alternative to ESR, independent of the chosen reference values.

6. The diagnostic values of laboratory tests which are of interest for GPs need to be investigated in general practice settings. The concepts concerned need further introduction in general practice. 


\section{Samenvatting}

Het doel van dit proefschrift is de presentatie van een aantal samenhangende studies naar de diagnostische waarde van de bepaling van de bezinkingssnelheid der erythrocyten (BSE) in de huisartspraktijk, dat wil zeggen de betrouwbaarheid en het onderscheidend vermogen ervan. Getracht is om de volgende vragen te beantwoorden:

1. a. Hoe betrouwbaar is de BSE-bepaling, in termen van intraen interpraktijk variatie, indien de bepaling wordt uitgevoerd op de voor de huisarts gebruikelijke wijze, mede vergeleken met de resultaten van een referentielaboratorium?

b. Hoe kan de gevonden variatie worden verklaard?

2. Wat is het antwoord op de eerste vraag na een interventie die is gericht op technische aspecten van de bepaling?

3. Wat zijn de indicaties voor de BSE-bepaling in de huisartspraktijk?

4. Wat is het effect van de BSE-bepaling op de differentiaal diagnostiek door de huisarts?

5. Wat is het vermogen van de BSE-bepaling om onderscheid te maken tussen "pathologie" en "geen pathologie" in de zogenaamde geïndiceerde populatie in de huisartspraktijk?

6. Wat is het antwoord op de voorgaande vraag met betrekking tot alternatieve tests, namelijk de plasma viscositeitsbepaling (PV) en de leucocytentelling, in vergelijking met de BSEbepaling.

Na de algemene inleiding wordt in hoofdstuk 1.2 het kader waarin de studie plaatsvond beschreven. De begrippen betrouwbaarheid (reproduceerbaarheid) en onderscheidend vermogen (sensitiviteit, specificiteit en positieve en negatieve voorspellende waarde) worden geïntroduceerd, en hun betekenis voor in de huisartspraktijk frequent gebruikt bloedonderzoek (hemoglobinebepaling, BSE en leucocytentelling) wordt beschreven.

Hoofdstuk 2.1 gaat in op de betrouwbaarheid van de BSEbepaling voor en na een interventie die was gericht op tech- 
nische aspecten van de bepaling (vraagstelling 1 en 2). Er werd gebruik gemaakt van uit het locale ziekenhuislaboratorium verkregen bloedmonsters. De monsters werden verspreid onder de deelnemende huisartspraktijken. Observaties en metingen, gericht op de uitvoering van de bepaling, werden in elke praktijk uitgevoerd. Tevens werd een vragenlijst voorgelegd aan de praktijkassistentes (Appendix I). $\mathrm{Na}$ het vermoeden dat trillingen en het bloedmonstertransport per auto mogelijke oorzaken waren van de gevonden variatie, werd de invloed van deze aspecten separaat onderzocht door het uitvoeren van enkele additionele experimenten (hoofdstuk 2.1 en 2.2). De resultaten van de studies in hoofdstuk 2.1 en 2.2 werden gebruikt als illustratie tijdens een workshop die was gericht op de diagnostische waarde van bloedonderzoek in de huisartspraktijk (hoofdstuk 2.3). De workshop informeerde ons tevens over de bekendheid van de huisartsen met het begrip betrouwbaarheid en de betekenis daarvan voor de BSE-bepaling.

Hoofdstuk 3 gaat in op het onderscheidend vermogen van de BSE-bepaling (vraagstelling 5). De betreffende parameters konden worden geschat nadat 362 patiënten die het spreekuur hadden bezocht met een nieuwe diagnostische vraag waarvoor de huisarts na anamnese en lichamelijk onderzoek de BSE-bepaling geïndiceerd achtte (de geïndiceerde populatie; vraagstelling 3) prospectief waren vervolgd. De groep patiënten met inflammatoire aandoeningen of maligniteiten ("pathologie") werd vergeleken met de groep patiënten bij wie self-limiting klachten en symptomen zonder aanwijsbare oorzaak werden gevonden ("geen pathologie"). De follow-up diagnosen werden drie maanden na het eerste consult vastgesteld (Appendix III). De studie werd voorafgegaan door een vragenlijst over het onderwerp die werd voorgelegd aan 20 huisartsen (Appendix II).

Bij dezelfde patiënten werden genoteerd de diagnosen die door de huisarts zowel voor als na het bepalen van de BSE werden vastgesteld (Appendix IV). Zodoende kon een voor-na analyse gericht op diagnostische waarde van de BSE-bepaling worden uitgevoerd (hoofdstuk 3.2; vraagstelling 4).

In een steekproef van de patiënten die deelnamen aan het onderzoek zoals beschreven in de hoofdstukken 3.1 en 3.2 werd het onderscheidend vermogen van de BSE-bepaling vergeleken 
met de leucocytentelling (hoofdstuk 4.2; vraagstelling 6). Daarbij werden tevens twee verschillende geautomatiseerde leucocytentellers met elkaar vergeleken.

De PV-bepaling werd gezien als een mogelijk alternatief voor de BSE-bepaling. Het onderscheidend vermogen van deze bepaling werd door ons onderzocht door het vergelijken van een groep patiënten bekend met reumatoïde arthritis of spondylitis ankylopoëtica enerzijds, versus een groep patiënten met nieuwe klachten van het bewegingsapparaat, uiteindelijk gediagnostiseerd als zijnde niet inflammatoir, anderzijds (hoofdstuk 4.1; vraagstelling 6). De studie werd uitgewoerd in een polikliniek reumatologie. De patiënten met nieuwe klachten waren naar deze polikliniek verwezen door hun huisarts.

In hoofdstuk 5 (Algemene Discussie) worden diverse resultaten opnieuw beschouwd. Tevens worden enkele van de gebruikte methoden meer in detail besproken. Vervolgens worden de implicaties van de studie resultaten samengevat en wordt enig licht geworpen op toekomstige ontwikkelingen op het gebied van laboratoriumonderzoek in de huisartsgeneeskunde.

Het onderzoek startte november 1986. De dataverzameling werd afgerond in april 1989.

De voornaamste conclusies zijn:

1. Ter voorkoming van onbetrouwbare testuitslagen in de huisartspraktijk dient de BSE-bepaling nauwkeurig te worden uitgevoerd, hetgeen vooral inhoudt het gebruik van zorgvuldig gereinigde, of wegwerp bepalingsbuizen. Het bloedmonstertransport per auto, en waarschijnlijk ook trillingen, beinvloeden de betrouwbaarheid niet.

2. De BSE-bepaling is nuttig voor het aantonen van inflammatoire aandoeningen en maligniteiten bij patiënten die nieuwe klachten presenteren warvoor de huisarts de bepaling geîndiceerd acht. Bij deze patiënten ligt de rekenkundig optimale bovengrens van het referentiewaardegebied rond $12 \mathrm{~mm} / 1$ uur bij mannen en $28 \mathrm{~mm} / 1$ uur bij vrouwen. Een correctie voor leeftijd was niet nodig. Bij deze referentiewaarden ligt de positieve voorspellende waarde rond de $48 \%$ en de negatieve voorspellende waarde rond de $91 \%$.

3. De BSE-bepaling draagt bij aan een nauwkeuriger vaststelling van de diagnose in de huisartspraktijk en is een waarde- 
volle test voor het geruststellen van de patiënt en de dokter wanneer geen inflammatoire aandoeningen of maligniteiten worden verwacht.

4. Voor het diagnostisch onderscheid tussen reumatoïde arthritis of spondylitis ankylopoêtica enerzijds en niet-inflammatoire klachten en aandoeningen van het bewegingsapparaat anderzijds is de BSE-bepaling geschikter dan de PV-bepaling. De conclusie geldt ongeacht de gebruikte referentiewaarden, leeftijd en geslacht van de patiënt en de aanwezigheid van anemie.

5. De leucocytentelling is klinisch geen interessant alternatief voor de BSE-bepaling, ongeacht de gebruikte referentiewaarden.

6. De diagnostische waarde van laboratoriumonderzoek dat interessant is voor de huisartsgeneeskunde moet worden onderzocht in de huisartspraktijk. De betreffende begrippen verdienen een verdere introductie bij huisartsen. 


\section{Dankwoord}

Het eerste dankwoord verdienen de patienten die aan het onderzoek deelnamen. $\mathrm{Zij}$ ondergingen gedeeltelijk een extra venapunctie en waren vaak bereid om het controlespreekuur te bezoeken. Tevens toonden vele van hen belangstelling voor de ins en outs van de studie.

Andre Knotterus en Jan van Wersch stonden aan de wieg van het onderzoek en aan de wieg van mijn wetenschappelijke worming. Als trainers en coaches werd door hun inzet het onderzoek volwassen en kwam ikzelf in de groel. Gedurende vele uren binnen en buiten "kantoortij d" doorliepen we alle stadia van het onderzoek. De enorme creativiteit en energie van mijn promotor en co-promotor hebben blijvend veel indruk gemaakt.

Zonder de medewerking van de Heerlense huisartsen Paul van Aubel, Jean Dolhain, Paul Höppener, Math Hundscheid, Henk Logister, Guus Schlösser, Arthur Sijstermans, Ben van der Werf en Felix Zwanikken was de bloedbezinking gebleven wat het was. Hun spreekuren werden belast door een afwijkende routine en het verzoek om een tamelijk uitgebreid formulier herhaaldelijk in te vullen. De praktijkassistentes werden daarbij intensief ingeschakeld en verrichtten vele malen een extra bloedbezinkingsbepaling, gedeeltelijk weer volgens een afwijkende routine. Pia Cuypers was tevens bereid om de experimenten tijdens het NHG-congres 1988 voor haar rekening te nemen. Henk Goei The, Harry Houben en Hille van der Tempel, als reumatologen verbonden aan het De Wever Ziekenhuis te Heerlen, maakten het mogelijk om de plasmaviscositeitsbepaling met de bloedbezinking te vergelijken. De accurate inzet van de assistentes op de polikliniek reumatologie deden dit onderzoek nog gesmeerder verlopen. Paul van Abel, Jean Dolhain en Henk Goei The waren ook nauw betrokken bij de opzet en verslaglegging van de diverse deelstudies. 
In het De Wever Ziekenhuis waren de hoofdlaboranten Wim Hanssen en Sjef Schröder onmisbaar als meedenkers, organisators, en ook als tussempersonen voor de laboranten die vele bloedmonsters verzamelden en bepalingen verrichtten. Elly Vervoerd heeft gedurende vijf maanden dagelijks bloedmonsters bij de deelnemende huisartsen opgehaald en daarin vervolgens de bezinking bepaald. De secretaresses wan het hematologisch laboratorium hebben de verzamelde data zorgwuldig bewaakt, gecontroleerd en doorgebeld. Henk Janssens (Coulter Electronics) voerde alle plasmaviscositeitsbepalingen uit.

De kennis en kunde van Trudie Seegers op informatica gebied speelde een essentiële rol bij de data-analyse en verslaglegging van alle deelstudies. Hubert Schouten, verbonden aan de vadgroep Medische Informatica en Statistiek, maakte van een enkele doodlopende een doorlopende straat. Mijn collega's binnen de vakgroep Huisartsgeneeskunde (de Gang) waren regelmatig bereid om mee te denken en de nodige kritische feed-back te geven.

Zonder Jan Klerkx was dit proefschrift gedeeltelijk verschenen in Dugglish instead of English. Harry Crebolder plaatste nog een enkel puntje op de i. Lutgard Roelen (Infobever) verwerkte vele correcties en maakte middels Wordperfect een spreekwoordelijke lay-out. Jan Leewis (Thesis Publishers) bracht het nodige geduld op alvorens hij het boekje kon uitgeven.

Tot slot was er Gerda die, zonder morren, mij de nodige vrije uren zag besteden aan alweer die bezinking en het onderwerp gelukkig voorzag van een relativerend kader. 


\section{Curriculum vitae}

Geert-Jan Dinant was born on November 29th, 1955 in Eindhoven, the Netherlands. He finished his secondary education ("Atheneum beta") at the Lorentz Lyceum in Eindhoven in 1974. In the same year, he entered medical school at the University of Utrecht, where he graduated in 1983. From 1983 to 1985 he worked at the psychiatric hospital Dennenoord in Zuidlaren and subsequently started his training for general practitioner at the University of Utrecht. From 1986 to 1987 he attended the one year Research Training for General Practitioners at the University of Limburg in Maastricht. Since 1987 he has been working as a general practitioner/investigator at the Department of General Practice of the University of Limburg, where he carried out the study presented here. 


\section{Appendix I \\ Questionnaire, measurements and observations on the reliability of the erytrocyte sedimentation rate (ESR)}

\section{Questions to be answered by the GP's assistant(s) $(\mathrm{N}=5)$}

1. Who usually does the venepunction? Answers given: the GP's assistant: 5

2. How is the venepunction carried out? Answers given: by using a non-vacuum system: 5

3. In what position of the patient is the venepunction carried out? Answers given: the patient usually sits on a chair: 5

4. What is the composition of the anticoagulant-blood mixture? Answers given: $0.4 \mathrm{ml}$ anticoagulant and $1.6 \mathrm{ml}$ venons blood: 5

5. Where do you store the anticoagulant? Answers given: in a dark cupboard: 2

somewhere on a shelf: 3

6. Do you know whether the anticoagulant can be kept for a limited period of time only, and if the answer is yes, do you take notice of this period? Answers given: I do not know and do not take notice: 5

7. How do you bring the anticoagulant-blood mixture into the sedimentation tube?

Answers given: by sucking it from a cup: 2

by using some kind of equipment which makes it unnecessary to suck the mixture by mouth: 3

8. a. How much time elapses after the blood sample bas been taken from the patient, before the ESR measurement takes place?

Answers given: immediately: 4

usually at the end of the surgery hours (=after maximally 4 hours): 1

b. If ESR is not measured immediately, where do you store the mixture in the meantime?

Answers given: on a place not exposed to sunlight or heating apparatus: 1

9. Who usually reads the measurements?

Answers given: the GP"s assistant: 5

10. a. Do you take notice of non-quantitative aspects of the measurements? Answers given: yes: 5

b. If $\mathrm{so}_{3}$ what aspects in particular do you take notice of? (more than one answer is possible)

Answers given: color: 3

other: 4 
11. How long after the timer rings do you read the measurement? Angwers given: immediately: 5

12. How do you clean the sedunentation tubes? Answers given; by using water onlly: 5

13. What is your method of ESR determination called? (see also Appendix II, question II.1)

Answers given: 1 do not know: 3

Westergren: 2

14. Do you sometimes werify your measurements, e.g. by determining ESR also at the local (hospital) laboratory, or by determining. ESR at your office twice, in the same blood sample? (see also Appendix I, question I.3) Aniswers given: I werify occasionally: 4

I do not know: 1

15. Do you (sometimes) speed up ESR determination by using a tube which is placed in a non-vertical position?

Answers given: no: 5

\section{Measurements concerning the determination of ESR in the} participating general practice centers (GPCs) $(\mathbf{N}=5$ )

1. Overall length, scale, external diameter and tube bore of the sedimentation tubes used?

Results: all according to standard": 5

2. Are the tubes placed in a strictly vertical position?

Results: yes: 5

3. Distance between holding device and potentially vibrating equipment which may influence ESR determination?

Results: GPC-A: $0.9 \mathrm{~m}$

GPC-B: $1.0 \mathrm{~m}$

GPC-C: -

GPC-D:-

GPC-E: $2.0 \mathrm{~m}$

\section{Observations concerning the determination of ESR in the} general practice centers $(N=5)$

1. What method is used?

Results: Westergren: 5

2. Are the holding devices exposed to sunlight or heating apparatus during the determination of ESR?

Results: no: 5

* International Committee for standardization in Haemotology. Recommendation for measurement of exythrocyte sedimentation rate of human blood. Am J Clin Pathal 1977; 68: 505-7. 


\section{Appendix II \\ Questionnaire on the diagnostic value of the erytro- cyte sedimentation rate (ESR)}

I. Questions to be answered by 20 general practitioners (GP) (A), preliminary to the clinical study, and by the 9 GPs who participated in the clinical study (B).

1. a. Do you use ESR in discriminating between "pathology" and "no pathology"?

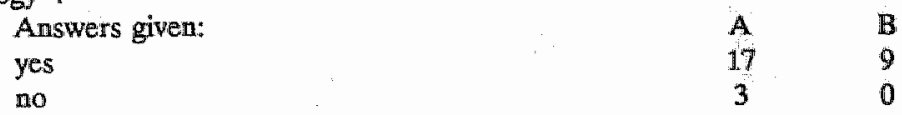

b. If "yes", could you describe its discrimination?

Answers given:

ESR may detect inflammations

ESR may detect inflammations or malignancies

ESR is a global parameter of disease

High ESR walues require further (diagnostic) action

ESR is used to reassure the patient or the doctor

$\begin{array}{cc}\text { A } & \text { B } \\ 1 & 1 \\ 1 & 3 \\ 2 & 3 \\ 4 & \\ 1 & 1 \\ & \\ & \end{array}$

analyses in order to detect "pathology"

9

2. a. Do you use ESR in confirming the presence of a disorder or disease?

Answers given:

yes

no

$\begin{array}{cc}\text { A } & \text { B } \\ 15 & 9 \\ 5 & 0\end{array}$

b. If "yes", which disorders or diseases is it used for?

Answers given:

Inflammations or malignancies

Inflammations

\section{B}

Monitoring disease activity or response to therapy in inflammations or malignancies

No answer given

$\begin{array}{cc}\text { A } & \text { B } \\ 2 & \\ 7 & 6 \\ 5 & 2 \\ 1 & 1\end{array}$

3. a. Which reference values do you use?

Answers given:

$$
\begin{aligned}
& \leq 10 \\
& \leq 15 \\
& \leq 20 \\
& \leq 30 \\
& \text { higher } \\
& \text { no answer given }
\end{aligned}
$$

b. Do the reference values depend on special aspects?

Answers given: 
c. If "yes" (question 3b), which aspects?

Answers given:"

$\begin{array}{rr}\text { A } & \text { B } \\ 11 & 5 \\ 8 & 6 \\ 3 & 1 \\ 1 & 1 \\ 1 & 1 \\ 3 & 2 \\ 2 & 1\end{array}$

4. How frequently do you determine ESR together with other blood measurements at the local (hospital) laboratory?

Answers given:

Mostly at the GP's office

A $\quad$ B

At the $\mathrm{GP}^{\prime}$ s office and the local laboratory

4

16

Mostly at the local laboratory

II. Questions to be answered by the GPs who participated in the clinical study $(\mathrm{N}=9)$

1. How is your method of ESR determination called? (see Appendix $I$, question 1.13)

Answers given: I do not know:

3

Westergren:

6

2. How much time passes between asking (during your morning surgery) for ESR determination in your office and receiving the measured value?

Answers given: approximately one hour:

2

maximum two hours: 3

less than a day:

5

3. Do you (sometimes) verify your measurements, e.g. by also determining ESR also at the local (hospital) laboratory or by determining ESR at your

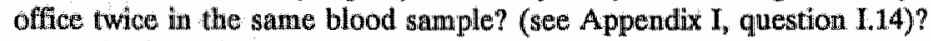

Answers given: never:

rarelly:

3

approximately once a year:

* Several GPs gave more than one answer. 


\section{Appendix III}

Discriminating ability of the erythrocyte sedimentation rate. Procedures followed in establishing the follow-up diagnoses for the 361 coobperating patients, identified by 9 general practitioners (GP).

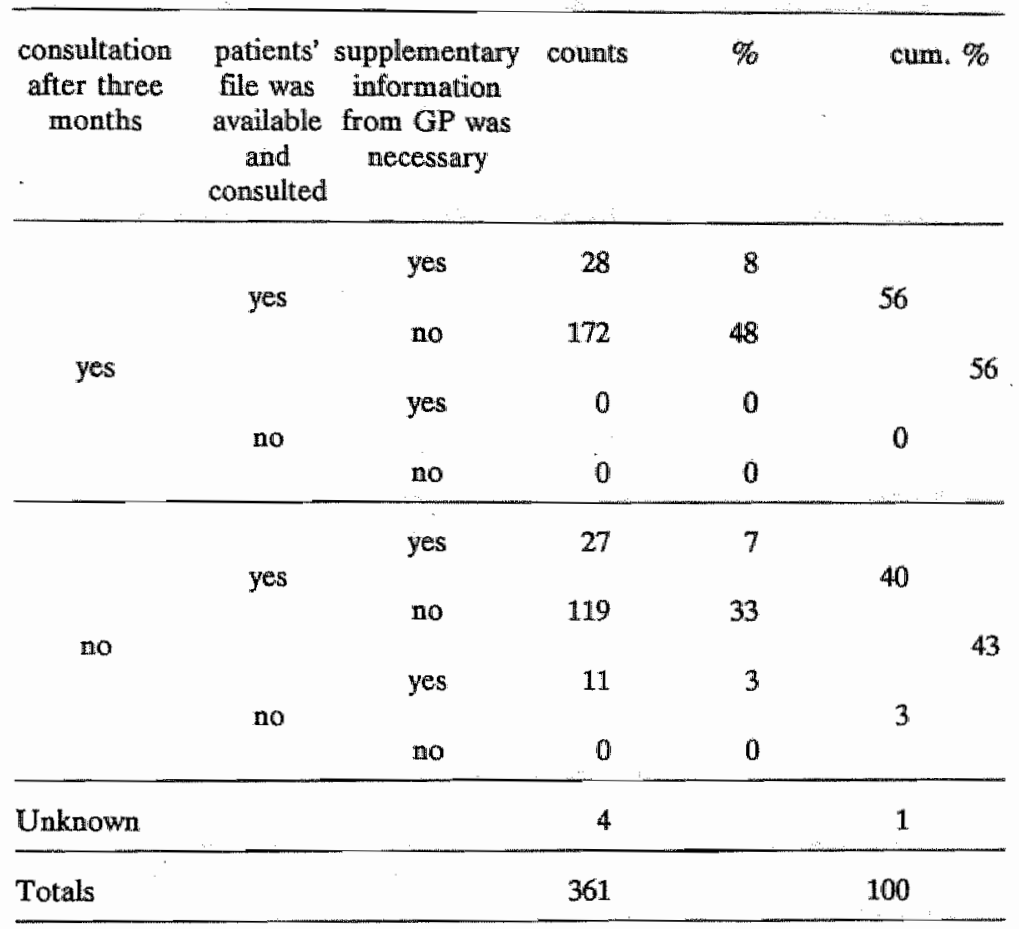





\section{Appendix IV}

Discriminating ability of the erythrocyte sedimentation rate (ESR), Owestionnaire used by the cooperating general practitioners (GPs). After the GPs filled in the form, parts $A+D$ were separated from parts $B+C$. During the follow-up consultations the investigator could only consult the upper half (parts $A+D)$ of the form.

\section{Part A: general data}

01 GP's name:

02 Patient"s name:

03 Year of birth:

04 Gender: 1, male

2. female

05 Date of tirst consultation: day: $\ldots \ldots \ldots \ldots \ldots \ldots$ month:

06 Important pre-existing pathology (optional):

upper half

lower half

\section{Part B: conclusions at the end of the first consultation}

07 Possible diagnoses, the most likelly one first, and clinical judgements in terms of "pathology" and "no pathology":

first diagnosis: . . . . . . . . . . . . . . 1. "pathology"

2. "mo pathology"

second diagnosis:

1. "pathology"

2. "no pathology"

third diagnosis:

1. "pathology"

2. "no pathology"

fourth diagnosis:

1. "pathology"

08. Prediction of ESR:

2. "no pathology"

1. very high

2. high

3. normal

4. low

09 Prediction of special aspects of ESR (optional): . . 


\section{Part D: follow-up conclusion and procedure}

13 Date of follow-up consultation: day:

month:

14 Follow-up diagnosis:

15 Hospital letters were used: 1. yes:

2. no:

16 Supplementary information from the GP was necessary:

1. yes

2. no

upper half

\section{Part C: conclusions after determination of ESR}

lower half

10 Possible diagnoses, the most likely one first, and clinical judgements in terms of "pathology" and "no pathology":

lirst diagnosis:

1. "pathology"

2. "no pathology"

second diagnosis:

1. "pathology"

2. "no pathology"

third diagmosis:

1. "pathology"

2. "no pathology"

fourth diagnosis:

1. "pathology"

2. "no pathology"

11 Diagnoses were influenced by:
a. the measured ESR value:
1. yes
b. other findings (optional):
2. no
1. yes
2. no
12. ESR was determined twice:
1. yes
2. no 